Aus der Abteilung Neuropathologie

(Prof. Dr. med. W. Brück)

im Zentrum Pathologie und Rechtsmedizin

der Medizinischen Fakultät der Universität Göttingen

\title{
Axonpathologie in Immunsubtypen von Multiple-Sklerose-Läsionen
}

\author{
INAUGURAL-DISSERTATION \\ zur Erlangung des Doktorgrades \\ der Medizinischen Fakultät \\ der Georg-August-Universität zu Göttingen
}

vorgelegt von

Janosch Haußmann

aus Filderstadt

Göttingen 2012 
Dekan: Prof. Dr. rer. nat. H. K. Kroemer

I. Berichterstatter: Prof. Dr. med. W. Brück

II: Berichterstatter/in: Priv.-Doz. Dr. med. Kitze

III: Berichterstatter/in: Prof. Dr. med. Oppermann

Tag der mündlichen Prüfung: 26.10.2013 


\section{Inhaltsverzeichnis}

Seite

1 EINLEITUNG

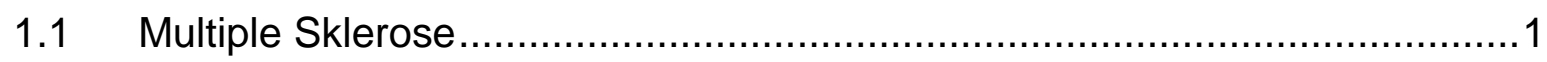

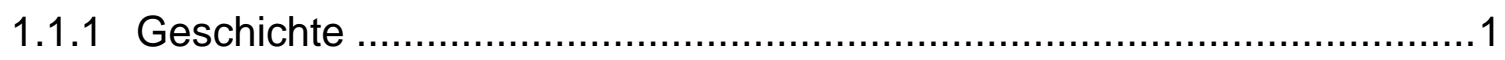

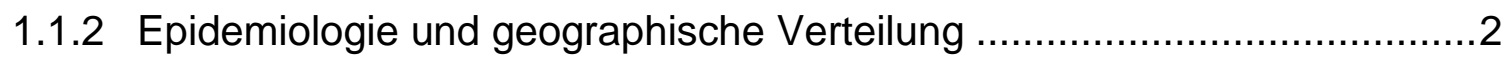

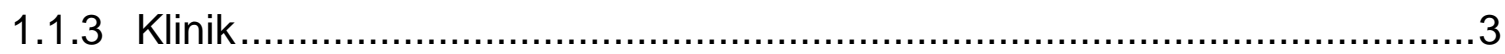

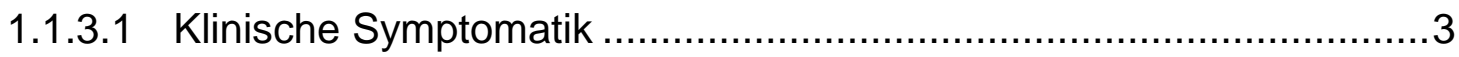

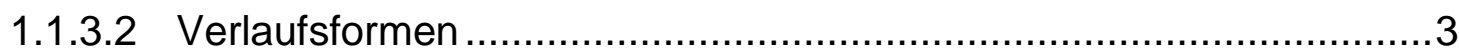

1.1.4 Ätiologie und Pathogenese der Multiplen Sklerose ..................................4

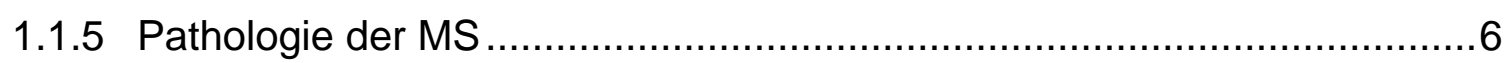

1.1.5.1 Demyelinisierende Läsionsaktivitäten ...........................................

1.1.5.2 Immunsubtypen der Multiplen Sklerose ........................................

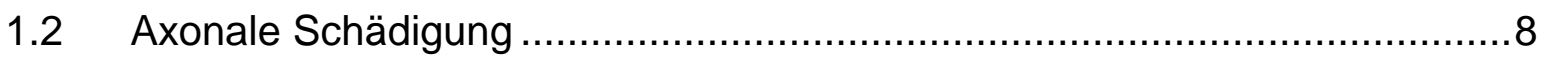

1.2.1 Histologische Nachweismethoden der axonalen Schädigung …...............9

1.2.1.1 Versilberung nach Bielschowsky ................................................

1.2.1.2 Immunhistochemische Färbung des Amyloid-Precursor-Proteins

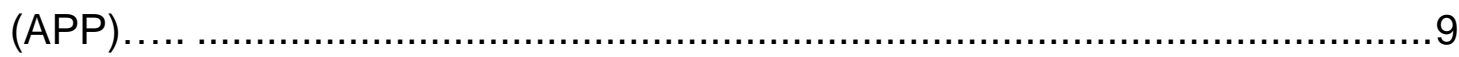

1.2.2 Ausmaß und zeitlicher Verlauf der axonalen Schädigung …....................

1.2.3 Nachweis der axonalen Schädigung mittels Bildgebung ........................11

1.2.4 Pathogenese der axonalen Schädigung ...........................................12

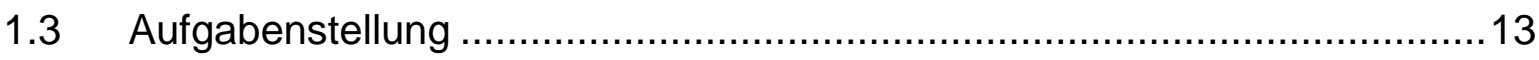

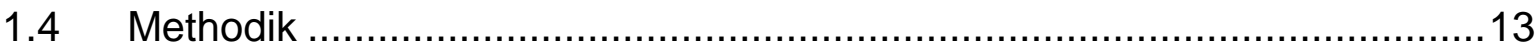

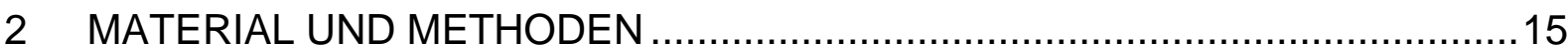

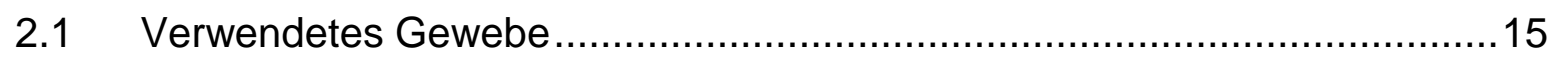

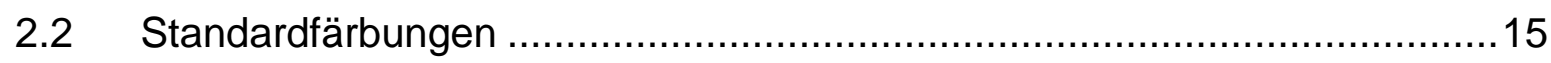

$2.3 \quad$ Versilberung nach Bielschowsky ..........................................................

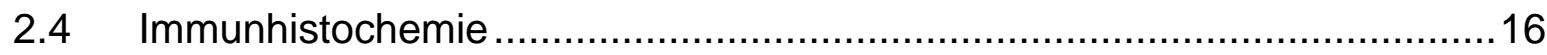

2.4.1 ABC (Avidin-Biotin-Komplex) -Methode ……..................................16

2.4.2 Substratumsetzung der Peroxidase.................................................18

2.4.2.1 Klassifikation der Läsionen anhand ihrer demyelinisierenden Aktivität

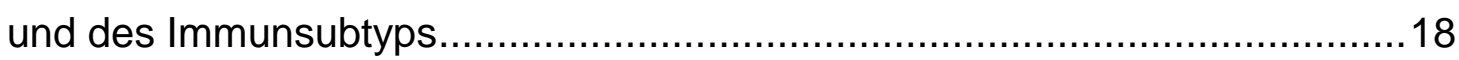

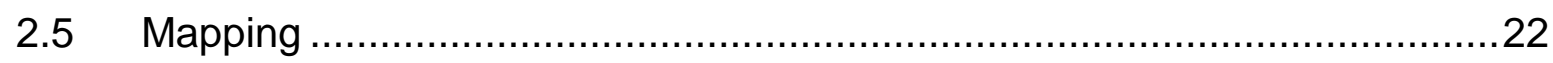




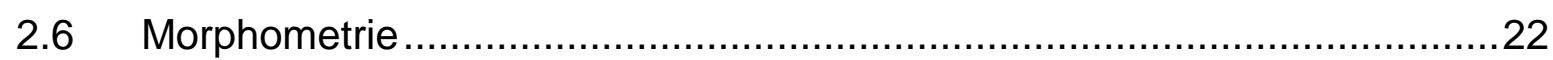

2.6.1 Akute axonale Schädigung (APP-Immunhistochemie) ..........................22

2.6.2 Axonale Dichte (Versilberung nach Bielschowsky) ................................22

2.7 Korrelation der Axonparameter mit T-Zellen und Makrophagen .................23

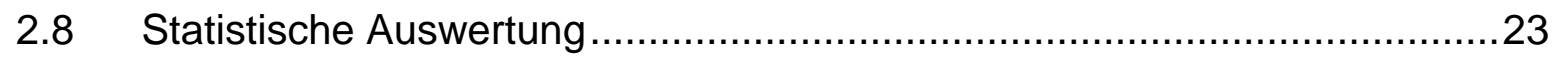

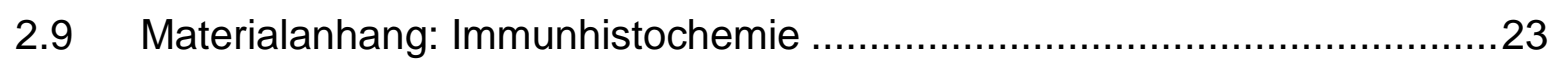

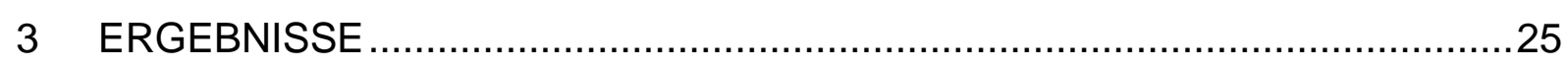

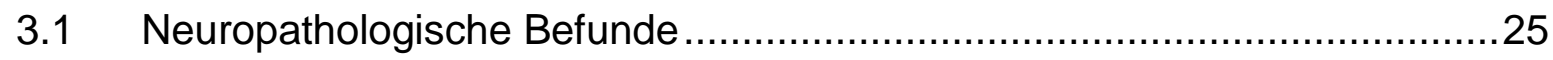

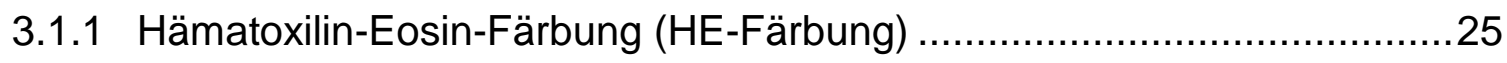

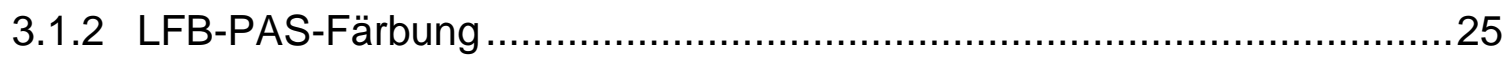

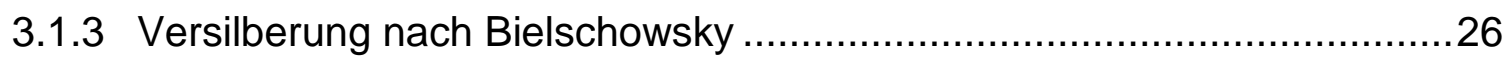

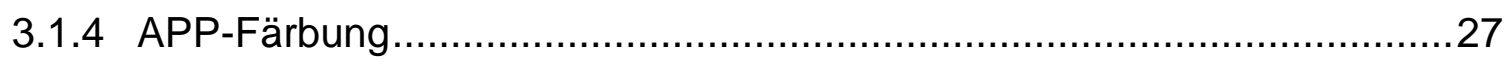

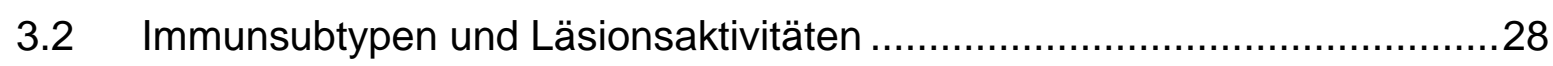

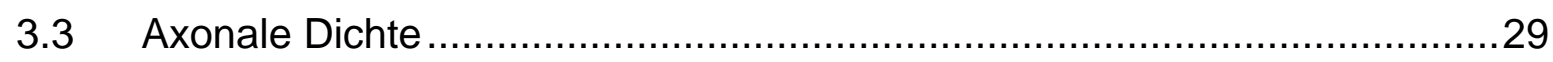

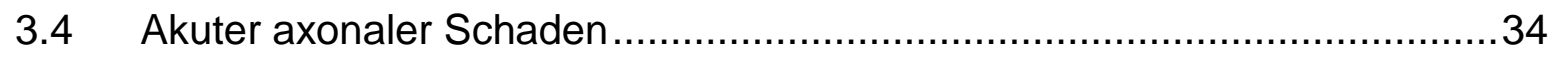

3.5 Korrelationen von axonaler Dichte und akuter axonaler Schädigung...........38

3.6 Korrelationen der Axonpathologie mit den Entzündungszellen ...................38

3.6.1 Korrelationen der axonalen Dichte mit den Entzündungszellen ..............39

3.6.1.1 Gemeinsame Auswertung aller Immunsubtypen sowie

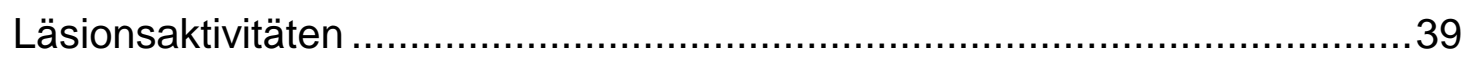

3.6.1.2 Auswertung der früh aktiven Läsionsareale sowie getrennt der NAWM (unabhängig vom Immunsubtyp) .................................................39

3.6.1.3 Auswertung der früh aktiven Läsionen in Abhängigkeit des

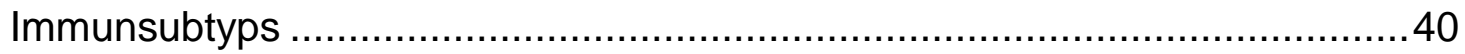

3.6.1.4 Auswertung der NAWM in Abhängigkeit des Immunsubtyps ...........40

3.6.2 Korrelationen des akuten axonalen Schadens mit den

Entzündungszellen .................................................................. 40

3.6.2.1 Gemeinsame Auswertung aller Immunsubtypen sowie

Läsionsaktivitäten

3.6.2.2 Auswertung der früh aktiven Läsionsareale sowie getrennt der NAWM (unabhängig vom Immunsubtyp).

3.6.2.3 Auswertung der früh aktiven Läsionen in Abhängigkeit des

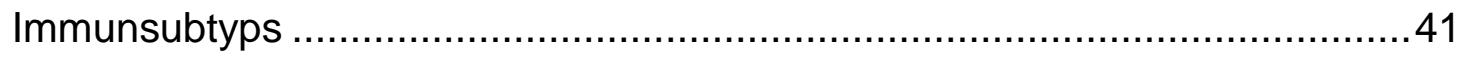

3.6.2.4 Auswertung der NAWM in Abhängigkeit des Immunsubtyps 
3.7 Korrelation der Axonparameter mit epidemiologischen Daten ...................42

3.7.1 Mediane Krankheitsdauer vor Biopsieentnahme .................................42

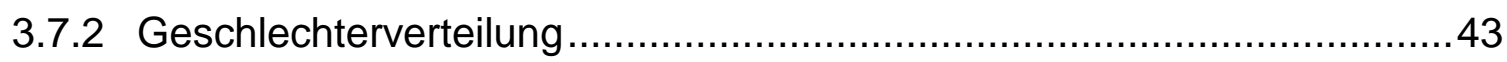

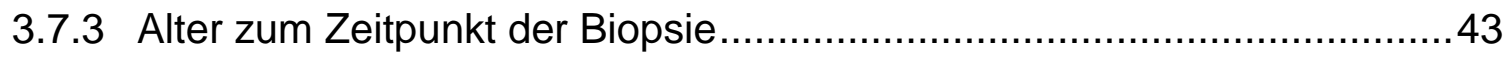

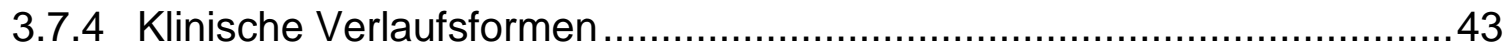

3.7.5 Vorangehende Hochdosis-Kortison-Therapie.....................................44

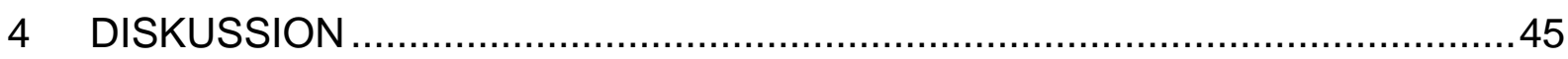

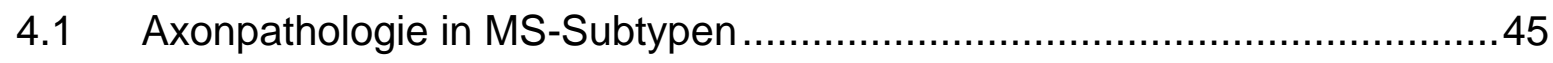

4.2 Axonale Schädigung der normal erscheinenden weißen Substanz …........46

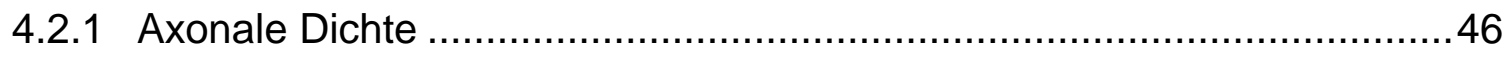

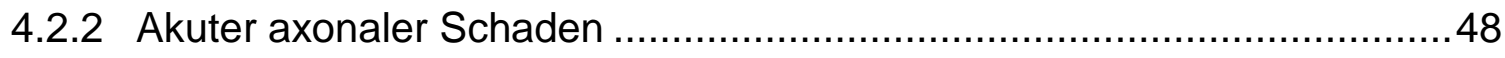

4.3 Axonale Schädigung innerhalb der Läsionen ..........................................50

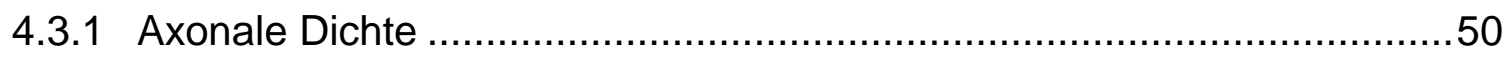

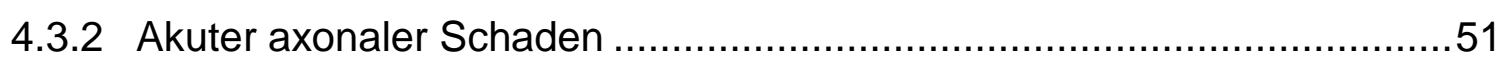

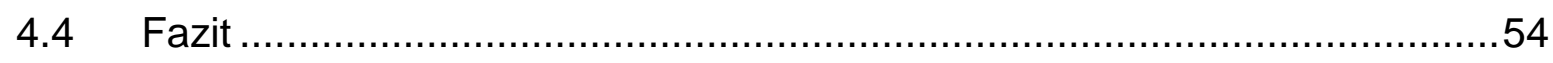

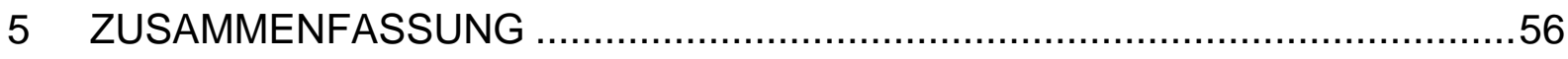

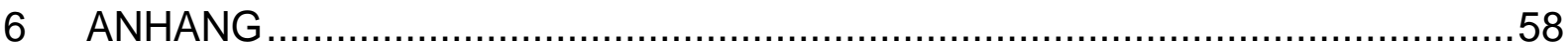

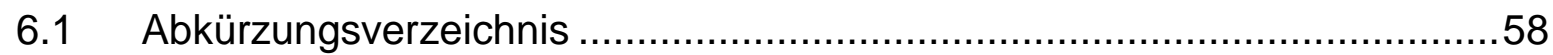

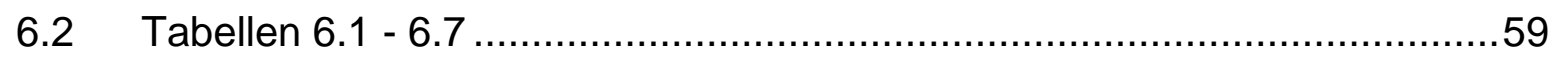

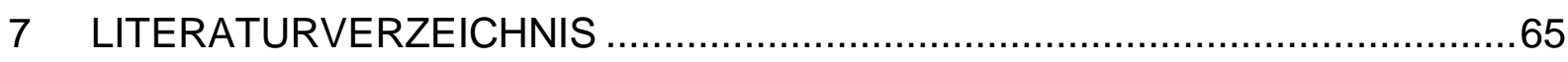




\section{EINLEITUNG}

\section{$1.1 \quad$ Multiple Sklerose}

Die Multiple Sklerose (MS) ist eine entzündliche, demyelinisierende Erkrankung des zentralen Nervensystems (ZNS).

\subsubsection{Geschichte}

Schon sehr früh wurden erste Fälle beschrieben, die mit den typischen Symptomen einer MS einhergingen.

In der Island Saga von St. Thorlakr wurde über die Wikingerfrau „Hala“ berichtet, dass sie vorübergehend in den Jahren zwischen 1293 und 1323 mehrfach erblindete und Sprachstörungen entwickelte (Schmidt 2006). Beide Symptome bildeten sich nach wenigen Tagen zurück.

Genauere Beschreibungen der klinischen Symptomatik finden sich in dem Tagebuch des Cousins von Queen Victoria, Augustus Frederick d'Este (1794-1848) (Firth 1941 und Landtblom et al. 2010): Mit 28 Jahren traten bei ihm erstmals - sich anschließend vollständig zurückbildende - Sehstörungen auf. Fünf Jahre später entwickelten sich Lähmungen der Beine sowie in den folgenden Jahren immer wieder Sensibilitätsstörungen im Bereich des Unterbauches. Nach 13 Jahren war Augustus Frederick d'Este rollstuhlpflichtig.

Die neuropathologischen Veränderungen der MS wurden erstmals 1868 von dem französischen Arzt Charcot in der Pariser Nervenklinik Salpêtrière beschrieben. Charcot entdeckte eine disseminierte, perivaskulär lokalisierte Ansammlung von Entzündungszellen in Gehirn und Rückenmark von Patienten mit intermittierenden Episoden von neurologischen Ausfällen (Charcot 1868).

Zunächst wurde die MS noch als eine "Geisteskrankheit" angesehen. Erst 1950 wurde sie auf einem New Yorker Symposium als organische Erkrankung eingestuft. Wegweisend für die Diagnostik der MS waren in den 1960er und 1970er Jahren entwickelte Möglichkeiten der Liquordiagnostik mit dem Nachweis von oligoklonalen Banden. Das CT fand Einzug und dank Young ist es seit 1981 möglich, mittels Kernspintomographie (MRT) MS-Herde nachzuweisen und in ihrem Verlauf zu beschreiben (Young et al. 1981). Eine 1972 von Halliday entwickelte Methode zur Messung visuell evozierter Potentiale (VEP) dient noch heute der Diagnostik (Halliday et al. 1973). 
1993 konnte ein großer Fortschritt in der Therapie der MS erreicht werden. Mit BetaInterferon wurde das erste Medikament zur Therapie der MS mit modifizierender Wirkung auf den Krankheitsverlauf in den USA zugelassen. Zwei Jahre später folgte die Zulassung auch in Deutschland. Zahlreiche weitere Medikamente kamen bis heute hinzu.

Immer wieder gab es Versuche, Kriterien zur Diagnosestellung der MS zu erstellen. 1945 wurden die Allison-Millar-Kriterien veröffentlicht. 1961 folgten die Schumacherkriterien. Nach den McAlpine-Kriterien 1972 wurden im Jahr 1983 weitere Kriterien von Poser veröffentlicht (Poser CM und Brinar 2001). Voraussetzung für die Diagnose einer MS ist die örtliche und zeitliche Dissemination von Läsionen. Die Poser-Kriterien stützen sich auf die klinische Symptomatik und berücksichtigen zudem Laboruntersuchungen.

2001 veröffentlichte McDonald diagnostische Kriterien (McDonald et al. 2001), welche in den 2005 und 2011 revidierten Fassungen heute Gültigkeit besitzen. Diese beziehen ergänzend die MRT-Bildgebung mit ein und ermöglichen daher eine frühe Diagnosestellung bereits nach dem ersten Schubereignis.

\subsubsection{Epidemiologie und geographische Verteilung}

Die Multiple Sklerose ist eine der häufigsten neurologischen Erkrankungen junger Erwachsener. In Deutschland sind ca. 122.000 Menschen an einer MS erkrankt (Hein und Hopfenmüller 2000). Die Prävalenz beträgt 30-60 pro 100.000 Einwohner (Delank und Gehlen 2001) und zeigt eine ansteigende Tendenz (Poser $S$ et al. 1989). Die Krankheit manifestiert sich meist im jungen Erwachsenenalter. Frauen erkranken doppelt so häufig wie Männer. Das Prädilektionsalter liegt zwischen dem 20. und 40. Lebensjahr.

MS-Erkrankungen finden sich insbesondere in den gemäßigten Klimazonen (Martyn und Gale 1997). In den Tropen tritt die Erkrankung so gut wie nicht in Erscheinung. Die höchsten Erkrankungsraten findet man in Nordeuropa, Kanada und den USA, wobei jeweils für den Norden dieser Gebiete höhere Erkrankungszahlen vorliegen als für den Süden. Auf der Südhalbkugel verhält sich dies spiegelbildlich, wobei jeweils mit zunehmender Entfernung vom Äquator die Erkrankungsraten zunehmen. 


\subsubsection{Klinik}

\subsubsection{Klinische Symptomatik}

An MS erkrankte Personen können sehr unterschiedliche neurologische und psychiatrische Symptome entwickeln.

Abhängig von der Lokalisation der entzündlichen Läsionen kann es sowohl zu motorischen, sensiblen, ataktischen oder auch vegetativen Symptomen kommen.

Typisch für die MS sind einseitige Sehstörungen, die durch eine Optikusneuritis verursacht sind. Motorisch können spastische Paresen auftreten. Es kann zu einer Gangsteifigkeit sowie Para-, Tetra- oder Hemiparesen kommen. Bei der neurologischen Untersuchung finden sich gesteigerte Muskeleigenreflexe sowie positive Pyramidenbahnzeichen. Ein Erlöschen der Bauchhautreflexe ist ebenfalls typisch. Sensibilitätsstörungen mit zentraler Verteilung treten auf. Diese folgen nicht den Dermatomen. Zerebelläre Störungen können sich mit einer Ataxie oder einer skandierenden Sprache äußern. Häufig finden sich ebenfalls vegetative Symptome wie beispielsweise eine neurogene Blasenentleerungsstörung (Urge-Inkontinenz oder eine Entleerungsstörung mit Restharnbildung). Psychische Störungen sind dysphorische Störungen, eine Fatigue (Ermüdung) oder Störungen des Gedächtnisses bis hin zur Demenz.

Die Charcot-Trias beschreibt einen typischerweise bei der MS auftretenden Symptomenkomplex bestehend aus Nystagmus, Intentionstremor und skandierender Sprache. Allerdings können zusätzlich auch andere neurologische Symptome auftreten (Gleixner et al. 2004, Delank und Gehlen 2001).

\subsubsection{Verlaufsformen}

Unterschiedliche Verlaufsformen der MS werden beobachtet. Die MS kann zum einen schubförmig verlaufen (85-90\% der Fälle, relapsing remitting MS, RRMS), wobei ein Schub als ein neu auftretender neurologischer Ausfall, der länger als 24 Stunden persistiert, definiert ist (Poser CM und Brinar 2001). Die Krankheitsschübe entwickeln sich über Stunden bis Tage und können sich im Verlauf teilweise oder komplett zurückbilden (Remission).

Zum anderen können sich die Symptome von Anfang an schleichend entwickeln, wobei man von einer primär chronisch progredienten MS spricht (primary progressive MS, PPMS). Beim sekundär chronisch progredienten Verlauf (secondary progressive 
MS, SPMS) kommt es nach einem zunächst schubförmigen Verlauf sekundär zu einer schleichenden Verschlechterung des klinischen Krankheitsbildes, teils mit weiteren, sich überlagernden Schüben (siehe Abbildung 1.1).

Schweregrad der
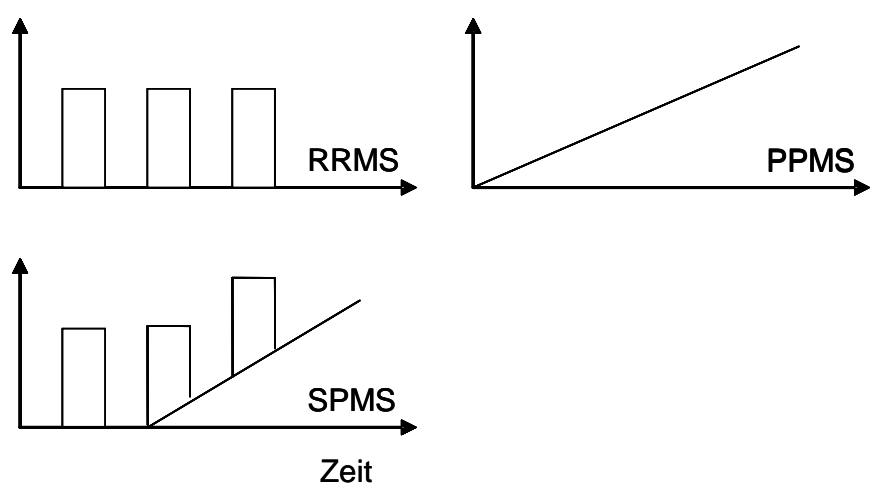

\section{Abbildung 1.1: Verlaufsformen der Multiplen Sklerose (MS)}

$R R M S=$ relapsing remitting $M S, P P M S=$ primary progressive $M S$ und $S P M S=$ secondary progressive MS

Weiterhin wird ein sog. klinisch isoliertes Syndrom (clinically isolated syndrom, CIS) unterschieden. Bei einem CIS handelt es sich um einen einzelnen Schub; eine zeitliche Dissemination liegt nicht vor. Die McDonald Kriterien (McDonald et al. 2001) zur Diagnose einer MS sind somit nicht erfüllt.

Selten findet sich die so genannte akute MS (Marburg-Variante), bei der es zu einem sehr aggressiven, schnell fortschreitenden Verlauf kommt, der rasch zu einer schwerwiegenden Behinderung oder zum Tode führt.

\subsection{4 Ätiologie und Pathogenese der Multiplen Sklerose}

Die Ätiologie der MS ist nicht vollständig geklärt. Zur Entstehung gibt es zahlreiche Theorien.

Studien belegen, dass genetische, ethnische und sozioökonomische sowie Umweltfaktoren die Krankheitsentstehung beeinflussen können.

Ein Argument für die Bedeutung von Umwelteinflüssen ist das epidemische Auftreten von MS-Fällen z.B. auf den Färöer Inseln (Kurtzke et al. 1993). Ferner wurde in Migrationsstudien gezeigt, dass Einwanderer, die jünger als 15 Jahre waren, mit 
einer Häufigkeit an MS erkrankten, die dem Einwanderungsland entsprach. Einwanderer über 15 Jahren entwickelten eine MS mit einer Häufigkeit entsprechend ihrem Ursprungsland (Martyn und Gale 1997).

Die Multiple Sklerose ist jedoch auch eine genetisch mitbedingte Krankheit, die mit unterschiedlichen HLA-Typen (Humanes Leukozyten Antigen) assoziiert ist. Hafler zeigte 2007 weitere Genorte wie IL2RA und IL7RA, die mit einem erhöhten Risiko, an einer MS zu erkranken, einhergehen (Hafler et al. 2007). Ziel ist es, die unterschiedlichen Genkombinationen mit der Bedeutung von Umweltfaktoren in Zusammenhang zu bringen (Hafler 2004).

Eine weitere Theorie besagt, dass die Reaktion auf einen infektiösen Erreger zu einer autoimmunen Kreuzreaktivität führen kann. Dies wird als so genanntes molekulares Mimikry bezeichnet. In der Folge könnte es zu einer Schädigung von Proteinbestandteilen des Myelins kommen. Aloisi und Serafini (Serafini et al., 2007) veröffentlichten 2007 eine Studie, die einen Zusammenhang zwischen einer Infektion mit dem Epstein-Barr-Virus (EBV) und der MS nahe legt. So fanden sie in nahezu allen untersuchten Fällen von an einer MS erkrankten, verstorbenen Patienten eine stattgefundene Infektion mit dem Epstein-Barr-Virus. Die Durchseuchung der erwachsenen, nicht an MS erkrankten Bevölkerung liegt jedoch bereits bei über $90 \%$, so dass die Studienergebnisse relativiert werden. Bei anderen entzündlichen neurologischen Krankheiten des zentralen Nervensystems wurden hingegen keine erhöhten Zahlen von EBV-Infektionen gefunden (Serafini et al., 2007).

Nach dem heutigen Stand der Forschung wird davon ausgegangen, dass es bei der MS zu einer Aktivierung von autoreaktiven T-Zellen in der Peripherie kommt. Diese autoreaktiven Zellen sind möglicherweise gegen Komponenten des zentralen Myelins gerichtet (Buddeberg et al. 2003). Aktivierte T-Zellen führen zur Öffnung der BlutHirn-Schranke und durchschreiten diese. Dies hat zur Folge, dass weitere T-Zellen, B-Zellen, Makrophagen und Antikörper-bildende Plasmazellen ins ZNS einwandern (Buddeberg et al. 2003, Medana et al. 2001). Es kommt schließlich zu einer entzündlichen Entmarkung der Axone im ZNS. Ein potentieller Pathomechanismus ist die Demyelinisierung durch Antikörperbindung an das Myelin, verbunden mit einer Aktivierung des Komplementsystems und nachfolgender Myelinschädigung (Archelos und Hartung 2000). 


\subsubsection{Pathologie der MS}

Die MS-Läsionen stellen sich makroskopisch als multiple graue Herde in der weißen Substanz dar. Auch finden sich Läsionen der grauen Substanz. Diese so genannten Plaques sind typischerweise an Prädilektionsstellen wie periventrikulären Arealen lokalisiert. Weitere Prädilektionsstellen sind juxtakortikal, der Hirnstamm, das Kleinhirn und das Rückenmark.

Mikroskopisch finden sich ein entzündliches Infiltrat, eine Demyelinisierung, eine axonale Schädigung bei relativem axonalen Erhalt und eine reaktive Astrozytose.

Entzündungszellen wie CD4+-T-Helfer-Zellen, $\mathrm{CD}^{+}{ }^{+}$-zytotoxische T-Zellen und teils auch B-Zellen sowie Plasmazellen infiltrieren das Gewebe perivaskulär, sind jedoch auch diffus in der Läsion lokalisiert. In der normal erscheinenden weißen Substanz (NAWM) können sich ebenfalls einzelne T-Lymphozyten finden. Makrophagen sind insbesondere in frühen Demyelinisierungsstadien in hoher Anzahl zu finden und können Myelinabbauprodukte enthalten. In späteren Stadien findet eine vermehrte Mikrogliaaktivierung statt.

Die Demyelinisierung ist bei der MS flächig und häufig um kleine Gefäße lokalisiert. Es kann eine Remyelinisierung stattfinden. Diese weist dünne, in Myelinfärbungen schwächer anfärbbare, neu gebildete Myelinscheiden auf.

Die Axone zeigen sich in MS-Läsionen rarefiziert und durch das entzündliche Infiltrat distendiert. Es findet sich jedoch ein Erhalt eines Teiles der Axone. Dies wird als relativer axonaler Erhalt bezeichnet.

In den Läsionen kommt es ferner zu einer reaktiven Astrogliose. Zunächst erscheinen die Astrozyten mit einem geblähten, eosinophilen Zytoplasmabauch, einer sog. gemistozytären Astrogliose entsprechend. Im Verlauf bilden die Astrozyten ein dichtes Netz aus Fortsätzen. Dies wird als fibrilläre Gliose bezeichnet.

\subsubsection{Demyelinisierende Läsionsaktivitäten}

Die Läsionen der MS können anhand ihrer demyelinisierenden Aktivität in unterschiedliche Stadien eingeteilt werden (Bitsch et al. 2000, Lucchinetti et al. 1996). Die Unterteilung erfolgt dabei anhand der Myelinabbauprodukte in Makrophagen und dem Nachweis einer Remyelinisierung mittels der LFB-PASFärbung sowie der immunhistochemischen Anfärbung von Myelinproteinen (siehe 2.5, Seite 22). 


\subsubsection{Immunsubtypen der Multiplen Sklerose}

Die früh aktiv entmarkenden Läsionen können anhand ihrer unterschiedlichen neuropathologischen Charakteristika in verschiedene Subtypen eingeteilt werden. Lucchinetti et al. untersuchten MS-Biopsien von Patienten mit einer früh aktiven Entmarkungsaktivität und konnten die unten genannten vier verschiedenen "Muster" der Demyelinisierung beobachten, die möglicherweise unterschiedlichen pathogenetischen Entstehungsmechanismen entsprechen (Lucchinetti et al. 2000).

Die vier verschiedenen Subtypen zeigen Unterschiede hinsichtlich des Entzündungsinfiltrates, des Vorkommens von spezifischen Immunglobulin- und Komplementablagerungen, der Oligodendrozytenpathologie teils mit selektivem Verlust von Myelinproteinen sowie der Läsionsbegrenzungen (diffuse Abgrenzung gegenüber unscharfer Abgrenzung) (Lucchinetti et al. 2000).

Bisherige Untersuchungen lassen erkennen, dass die Immunsubtypen bei unterschiedlichen Patienten verschieden sind (interindividuelle Heterogenität). Verschiedene Läsionen eines Patienten sind jedoch immer dem gleichen Subtyp zuzuordnen (intraindividuelle Homogenität).

$$
\begin{aligned}
& \text { Subtyp I } \longrightarrow \text { T-Zell- und Makrophagen-mediierte DM } \\
& \text { Subtyp II } \longrightarrow \text { Antikörper- und Komplement-mediierte DM } \\
& \text { Subtyp III } \longrightarrow \text { Oligodendrogliopathie und Apoptose } \\
& \text { Subtyp IV } \longrightarrow \text { Primäre Oligodendrozytendegeneration }
\end{aligned}
$$

\section{Abbildung 1.2.: Einteilung der Immunsubtypen}

$\mathrm{DM}=$ Demyelinisierung

Immunsubtyp I und II zeigen eine Makrophagen- und T-Zell-dominierte Entzündung (vgl. Abbildung 1.2). In Subtyp I scheinen toxische Stoffe der aktivierten Makrophagen wie beispielsweise TNF- $\alpha$ oder reaktive Sauerstoffradikale hauptsächlich für die Demyelinisierung verantwortlich zu sein (Lassmann et al. 2001). Subtyp II zeigt eine zelluläre und humorale Autoimmunität. Zusätzlich zu einer von TZellen und Makrophagen vermittelten Demyelinisierung wird eine durch Antikörper (hauptsächlich $\lg G$ ) und Komplement (C9neo) vermittelte Demyelinisierung angenommen. 
Die Demyelinisierung ist in beiden Subtypen typischerweise um kleine Venen zentriert und zeigt scharfe Läsionsgrenzen.

Subtyp III und IV sind hauptsächlich durch einen Oligodendrozytenuntergang charakterisiert, der mehr virus- oder toxisch induzierten Demyelinisierungen ähnelt als Autoimmunprozessen (Lucchinetti et al. 2000).

Im Subtyp III findet sich eine Oligodendrozytendystrophie mit einer Fehlregulation der Myelinproteine (sog. MAG-Verlust), d.h., das Myelinprotein MAG, welches distal im Bereich der Myelinscheide lokalisiert ist (am nächsten zum Axon gelegen), geht als erstes verloren. Andere Myelinproteine sind jedoch weiterhin präsent (z.B. MOG). Es zeigt sich ebenfalls ein entzündliches Infiltrat, insbesondere bestehend aus Makrophagen, aktivierter Mikroglia und T-Lymphozyten. Die Läsionen erscheinen insgesamt jedoch zellärmer. Die Grenzen der Entzündungsläsionen sind unscharf. Es ist keine Konzentrierung um kleine Venen zu erkennen

Subtyp IV zeigt ebenfalls eine Makrophagen- und T-Lymphozyten-dominierte Entzündung. Die Demyelinisierung ist jedoch durch ein Absterben von Oligodendrozyten in der angrenzenden weißen Substanz gekennzeichnet, bei der eine Fragmentierung der Oligodendrozyten-DNA stattfindet. Morphologische Merkmale einer Apoptose fehlen.

\subsection{Axonale Schädigung}

Der axonale Schaden bei der MS wurde seit den 1990er Jahren verstärkt untersucht, nachdem zahlreiche bildgebende Studien einen Zusammenhang zwischen dem axonalen Schaden und der klinischen Behinderung der MS zeigten (vgl. 1.2.3). Auch korreliert das Ausmaß des akuten axonalen Schadens, nachgewiesen durch die Konzentration an Neurofilamenten im Liquor, mit der klinischen Behinderung, gemessen durch den EDSS (Kurtzkes Expanded Disability Status Scale) (Lim et al. 2005). Zahlreiche histologische Studien untersuchten das Ausmaß der axonalen Schädigung bei der MS (vgl. 1.2.2) 


\subsubsection{Histologische Nachweismethoden der axonalen Schädigung}

\subsubsection{Versilberung nach Bielschowsky}

Die Reduktion der axonalen Dichte kann mit Hilfe der Versilberung nach Bielschowsky (Bielschowsky 1903) bestimmt werden. Die Silberimprägnation färbt die axonalen Strukturen an. Sie ermöglicht jedoch keine direkte Unterscheidung zwischen geschädigten und intakten Axonen. Es können aber sog. axonale Sphäroide (axonale Auftreibungen) als Zeichen einer axonalen Schädigung erkannt werden. Durch die Bestimmung der axonalen Dichte und Nachweis einer Reduktion dieser können ebenfalls Hinweise auf axonale Schäden erhalten werden. Hinweise über den Zeitpunkt der axonalen Schädigung (akut versus chronisch) werden nicht gewonnen.

\subsubsection{Immunhistochemische Färbung des Amyloid-Precursor-Proteins (APP)}

APP ist ein Transmembran-Glykoprotein, das im Soma der Neurone produziert wird. Es hat neuroprotektive und neurotrophe Einflüsse auf die Nervenzellen (Mattson et al. 1993). Durch schnellen axonalen Transport wird es in Richtung Synapse transportiert.

Ist ein Axon geschädigt, wie es bei MS-Patienten der Fall ist, so akkumuliert APP in axonalen Sphäroiden. Es ist noch ungeklärt, ob sich APP ausschließlich in irreversibel oder auch in reversibel geschädigten Axonen zeigt (Bitsch et al. 2000). APP ist immunohistochemisch in gesunden axonalen Strukturen nicht nachweisbar. Der Nachweis von APP ist bis circa 30 Tage nach axonaler Schädigung möglich (Bramlett et al. 1997, Li et al. 1995, Pesini et al. 1999, Yam et al. 1997). Die APPFärbung dient somit der Bestimmung des akuten axonalen Schadens.

\subsubsection{Ausmaß und zeitlicher Verlauf der axonalen Schädigung}

In fast allen MS-Läsionen kann histologisch eine Reduktion der Axone beobachtet werden. Das Ausmaß der axonalen Reduktion variiert dabei zwischen den einzelnen MS-Verlaufsformen und den unterschiedlichen Läsionsstadien.

Bei der akuten MS vom Typ Marburg kann es innerhalb weniger Monate zum Tode oder zu einer schweren Behinderung kommen (Marburg 1906). Der axonale Verlust beträgt bei der akuten MS bis zu $80 \%$ (Lassmann 2003b). Bei Untersuchungen von 
frühen MS-Stadien (Biopsiematerial) mit unterschiedlichen Läsionsaktivitäten zeigt sich im Median ein axonaler Verlust von 37,5\% (in früh aktiv entmarkenden Läsionen, EA) bis 60\% (in spät aktiv entmarkenden Läsionen, LA) (Bitsch et al. 2000). Bei Patienten mit einer sekundär chronisch progredienten MS konnte bei Untersuchung von Autopsiegewebe ein axonaler Verlust von 65\% im Rückenmark nachgewiesen werden (Lovas et al. 2000). Klinisch stumme MS-Läsionen, welche als Zufallsbefund bei der Autopsie diagnostiziert werden und späten Stadien der MS entsprechen, zeigen eine durchschnittliche axonale Reduktion von 64\%. In remyelinisierten Läsionen zeigt sich eine Reduktion von durchschnittlich 59\% (Mews et al. 1998).

Das Ausmaß der axonalen Schädigung ist zwischen den einzelnen MS-Patienten unterschiedlich, aber auch innerhalb eines einzigen Patienten sind starke Schwankungen zwischen den einzelnen MS-Plaques möglich (Bitsch et al. 2000).

Ferner weisen zahlreiche neuropathologische Studien eine akute axonale Schädigung in MS-Läsionen nach. Der Nachweis einer akuten axonalen Schädigung kann mittels des Markers Amyloid-Precursor-Protein (APP) erfolgen (vgl. 1.2.1.2., Seite 9). Die höchste Anzahl von APP-positiven Sphäroiden findet sich in Läsionen mit früh- und spät-aktiver Demyelinisierung (Kornek et al. 2000). Ferguson et al. konnten ebenfalls zeigen, dass eine akute axonale Schädigung insbesondere in akuten Läsionen - definiert als Läsionen mit LFB-PAS-positiven Makrophagen und einer hohen Anzahl von T-Zellen und Makrophagen - sowie im Randbereich von chronisch aktiven Läsionen nachzuweisen ist (Ferguson et al. 1997). Chronisch aktive Läsionen sind definiert als Läsionen mit einem Randwall von Entzündungszellen (insbes. Makrophagen) (Ferguson et al. 1997). Diese Ergebnisse bestätigte Trapp mit einer Studie, in der immunhistochemisch SMI-32 positive axonale Sphäroide in MS-Läsionen untersucht wurden (Trapp et al. 1998). Die Färbung mittels SMI-32 weist dephosphorylierte, geschädigte Axone nach. Auch Trapp et al. fanden die höchsten Zahlen geschädigter Axone in aktiven Läsionen sowie im Randbereich chronisch aktiver Läsionen (Trapp et al. 1998).

Kuhlmann et al. wiesen nach, dass der axonale Schaden mit dem Ausmaß der Entzündung korreliert und bereits in frühen Krankheitsstadien beginnt (Kuhlmann et al. 2002). 
Klassischerweise wird die MS als eine entzündliche demyelinisierende Krankheit beschrieben, die durch Plaques innerhalb der weißen Substanz charakterisiert ist. Allerdings ist die Pathologie der MS weitaus komplexer: Es kann ebenfalls ein axonaler Schaden in der normal erscheinenden weißen und grauen Substanz nachgewiesen werden. In der weißen Substanz wurde dies in histologischen Studien von Ganter 1999 und Bjartmar 2001 beschrieben (Bjartmar et al. 2001; Ganter et al. 1999). In der grauen Substanz wurde dies von Peterson 2001 ebenfalls in einer histologischen Studie beschrieben (Peterson et al. 2001).

\subsubsection{Nachweis der axonalen Schädigung mittels Bildgebung}

MRT (Magnetresonanztomographie)-Studien belegen eine Korrelation der axonalen Schädigung mit der klinischen Behinderung:

Mittels einer MRT Studie wiesen Losseff et al. eine enge Korrelation zwischen der Atrophie des Rückenmarkes (als Ausdruck des axonalen Verlustes) und der klinischen Behinderung, gemessen mittels EDSS, nach (Losseff et al. 1996). Der EDSS (Expanded Disability Status Scale) nach Kurtzke ist eine Skala zur Bewertung des Grades der neurologischen Behinderung und reicht von 0 (= keine Behinderung) bis zu 10 (= Tod durch MS). Die mit Hilfe der Magnetresonanzspektroskopie erfolgte Bestimmung von NAA (N-Acetyl-Aspartat) im Hirngewebe stell eine weitere Möglichkeit dar, den axonalen Schaden zu messen. NAA ist ein spezifischer Marker für Neurone und deren Fortsätze. Eine Verminderung des NAA-Spiegels korreliert mit dem histologisch nachgewiesenen axonalen Verlust in Rückenmarksläsionen von MS-Patienten (Bjartmar et al. 2000). Auch eine Verminderung des NAA-Spiegels korreliert mit der klinischen Behinderung (De Stefano et al. 1998).

Bjartmar untersuchte den axonalen Schaden mittels NAAMagnetresonanzspektroskopie in akuten und chronischen MS-Stadien (Bjartmar et al. 2001). Hierbei fand sich nach initialer Verminderung des NAAs in der MS-Läsion, einhergehend mit einer Besserung der klinischen Symptomatik, ein Anstieg der NAAKonzentration (Bjartmar et al. 2001), hinweisend auf eine reversible axonale Schädigung. In chronischen Stadien der MS zeigte sich hingegen eine Korrelation von einem verminderten NAA-Spiegel und einem irreversiblen klinischen Defizit (Bjartmar et al. 2000). Auch in der normal erscheinenden weißen Substanz konnte mit dieser Methodik ein axonaler Schaden nachgewiesen werden (Bjartmar et al. 2001). 


\subsubsection{Pathogenese der axonalen Schädigung}

Es gibt unterschiedliche mögliche Pathomechanismen der Axonschädigung. Obwohl der axonale Schaden in den verschiedenen Subtypen der Entmarkung unterschiedliche Pathomechanismen aufweisen kann, ist es möglich, dass er in einer gemeinsamen Endstrecke mündet (Lassmann et al. 2001), die bei allen axonalen Schädigungen unterschiedlichster Genese gleich verläuft (Lopachin und Lehning 1997).

Sowohl in frühen, entzündlichen Krankheitsstadien als auch in chronischen Läsionen findet eine Axonschädigung statt. Während Phasen akuter Entzündung werden zahlreiche Axone durch entzündungsbedingte Mediatoren geschädigt (Lassmann 2003a). Hinzu kommt eine langsame (,slow burning“), axonale Schädigung in inaktiven Läsionen ohne wesentliches Entzündungsinfiltrat (Lassmann 2003a).

Zytotoxische $\left(\mathrm{CD}^{+}\right)$T-Zellen können eine Rolle bei der Axonschädigung spielen (Neumann et al. 2002). In einer Neuronenkultur kommt es nach Antigenstimulation zu einer Peptidpräsentation durch MHC-I. Bei Hinzugabe von spezifischen zytotoxischen T-Zellen erfolgt eine Axonschädigung mit Membranschädigung und Sphäroidformation (Medana et al. 2001). Histologisch findet sich bei der Untersuchung von MS-Biopsien eine Korrelation von zytotoxischen T-Zellen und der akuten axonalen Schädigung (Bitsch et al. 2000).

Der axonale Schaden korreliert ferner mit der Anzahl an Makrophagen, welche insbesondere in frühen Stadien in hoher Anzahl in MS-Läsionen zu finden sind. Makrophagen produzieren toxische Mediatoren, die zu einer Axonschädigung führen können (Lassmann et al. 2001, Lassmann 2003a). Einige dieser Mediatoren, wie beispielsweise NO (Stickstoffmonoxid) oder Proteasen, wurden in MS-Läsionen beschrieben (Kapoor et al. 1999, Anthony et al. 1998). Je nach Konzentration führt NO zunächst zu einer funktionellen und schließlich irreversiblen Schädigung der Axone (Smith und Lassmann 2002, Redford et al. 1997). Dies erfolgt teilweise über eine Blockade der mitochondrialen Funktionen und somit der Energieversorgung der Axone (Bolanos et al. 1997). Mahad et al. zeigten ebenfalls einen Zusammenhang zwischen der axonalen Schädigung und einer mitochondrialen Schädigung im Komplex IV der mitochondrialen Atmungskette (Mahad et al. 2009).

Ferner können spezifische Antikörper zu einer Axonschädigung führen. Mathey et al. zeigten, dass Antikörper gegen Neurofascin, welches an Ranvierschen Schnürringen lokalisiert ist, zu einer axonalen Schädigung bei der MS führen. Es fand sich eine 
Axonschädigung ohne Entmarkung (Mathey et al. 2007). Antikörper gegen MOG wurden nachgewiesen und eine Studie von Zhou et al. weist einen Zusammenhang zwischen anti-MOG Antikörpern sowie einer Demyelinisierung in der EAE (experimentelle autoimmune Enzephalomyelitis) nach (Zhou et al. 2006).

Letztendlich dient die Myelinscheide u.a. der trophischen Unterstützung des Axons. Durch die Entmarkung kommt es zu einem sog. „loss of trophic support". Die Remyelinisierung ist insbesondere in chronischen MS-Stadien limitiert (Bjartmar et al. 2003; Compston 2004). Die Folge ist eine Axondegeneration.

\subsection{Aufgabenstellung}

Bisher gibt es weitreichende Untersuchungen hinsichtlich der akuten axonalen Schädigung sowie der Reduktion der axonalen Dichte bei der MS. Allerdings gibt es keine Studien, die den akuten axonalen Schaden und die axonale Reduktion zwischen den einzelnen Immunsubtypen untersuchen und vergleichen. Eine solche Studie kann weitere Hinweise auf unterschiedliche pathogenetische Mechanismen liefern. Die vorliegende Studie hat somit folgende Ziele:

1. Untersuchung der axonalen Reduktion in den einzelnen Läsionen der unterschiedlichen Immunsubtypen mit vergleichender Auswertung

2. Untersuchung des akuten axonalen Schadens in den einzelnen Läsionen der unterschiedlichen Immunsubtypen mit vergleichender Auswertung

3. Korrelation der Ergebnisse mit Entzündungszellen sowie epidemiologischen Daten.

\subsection{Methodik}

In der vorliegenden Studie wurden die axonale Dichte sowie der akute axonale Schaden in verschiedenen Immunsubtypen der Entmarkung bestimmt.

Hierbei erfolgte zunächst die Klassifizierung bzgl. der Läsionsaktivität und des immunpathogenetischen Subtyps anhand immunhistochemischer Färbungen.

Im zweiten Schritt wurde die axonale Dichte bestimmt. Hierzu wurden Präparate, die nach der Methode von Bielschowsky mit einer Silbernitratlösung angefärbt waren, ausgewertet. Ferner wurde der akute axonale Schaden mittels einer 
immunhistochemischen Färbung (APP $=$ Amyloid-Precursor-Protein) bestimmt (vgl. 2.4, Seite 16). Es erfolgte eine Auswertung sowohl der früh aktiven Läsionsareale, als auch der angrenzenden normal erscheinenden weißen Substanz. 


\section{MATERIAL UND METHODEN}

\subsection{Verwendetes Gewebe}

Insgesamt wurden 55 Biopsien mit einer entzündlichen Entmarkung ausgewertet. 40 dieser Biopsien wurden zwischen 1997 und 2004 in unterschiedlichen neurochirurgischen Zentren in Deutschland entnommen. Die Probenentnahme erfolgte aus diagnostischen Gründen. Sie diente beispielsweise dazu, einen Tumor oder eine Infektionserkrankung auszuschließen. Anschließend wurden die Biopsien zu einer weiteren konsiliarischen Beurteilung an Herrn Prof. Brück geschickt. Histologisch konnte die Diagnose einer chronisch entzündlichen ZNS-Erkrankung gesichert werden. Zusätzlich wurden 15 Präparate aus der Mayo Klinik der USA (Kooperationspartnerin Fr. Dr. Lucchinetti) zur Auswertung hinzugezogen.

Nach neuropathologischer Standardmethode wurden die Präparate in Formalin fixiert und in Paraffin eingebettet.

\subsection{Standardfärbungen}

Zur Beurteilung der Zellmorphologie und des Entmarkungszustandes erfolgten die Färbungen mittels Hämatoxilin-Eosin (HE) und Luxol-Fast-Blue-Period-Schiffsäure (LFB-PAS) (Brück und Stadelmann 2003). Die Versilberung nach Bielschowsky wurde zur Bestimmung der axonalen Dichte durchgeführt. Die Färbungen wurden routinemäßig nach Standardprotokollen im histologischen Labor der Abteilung Neuropathologie/Göttingen angefertigt.

\subsection{Versilberung nach Bielschowsky}

Die Silberimprägnation nach Bielschowsky färbt Axone dunkelbraun bis schwarz (Bielschowsky 1903). So können Axone mikroskopisch sichtbar gemacht und ihre Dichte bestimmt werden.

Zur Färbung der histologischen Präparate wurden 6-8 $\mu \mathrm{m}$ dicke Schnitte entparaffiniert und die Präparate anschließend 20 Minuten in $20 \%$ ige Silbernitratlösung $\left(\mathrm{AgNO}_{3}\right)$ gegeben. Dadurch färbten sich die Markscheiden braun an. $\mathrm{Zu}$ der 20\%igen $\mathrm{AgNO}_{3}$-Lösung wurde tropfenweise 25\%iges Ammoniak zugegeben und gut geschüttelt, bis der entstandene Niederschlag verschwand. Hierdurch erfolgte eine Umwandlung des Silbernitrates in Silberdiammoniumnitrat, 
was dann eine Gelbfärbung der Axone bewirkte. Zwei weitere Tropfen Ammoniak wurden zugefügt und die Schnitte 15 Minuten im Dunkeln inkubiert. Im nächsten Schritt wurden drei Tropfen Ammoniak zugegeben und die Schnitte in dieser Lösung geschwenkt. Anschließend wurden zehn Tropfen Entwickler zugefügt und gut geschüttelt. Der Entwickler bestand aus $20 \mathrm{ml}$ Formalin (37\% säurefrei), $100 \mathrm{ml}$ Aqua bidest. 0,5 g Zitronensäure und einem Tropfen konzentrierter Salpetersäure. Die Schnitte wurden darin belassen, bis die Nervenfasern schwarz und der Hintergrund braun gefärbt waren (mikroskopische Kontrolle). Nach dem erneuten Waschen wurden die Schnitte in $2 \%$ ige $\mathrm{Na}$-Thiosulfatlösung gegeben. Anschließend erfolgte erneut ein Waschvorgang und die Schnitte wurden in eine aufsteigende Alkoholreihe (Xylol) gegeben und mit Depex eingedeckelt.

\subsection{Immunhistochemie}

Um die Läsionen anhand ihrer unterschiedlichen Aktivität zu klassifizieren, wurden die $4 \mu \mathrm{m}$ dicken Präparate immunhistochemisch mit der Biotin-Avidin- oder AlkalinePhosphatase-/ Anti-Alkaline-Phosphatase-Methode gefärbt. Als Primärantikörper wurden verwendet: Anti-Myelin-Basisches Protein (anti-MBP, Boehringer Mannheim, Mannheim, Deutschland), anti-Myelin-assoziiertes Glykoprotein (anti-MAG, Prof. Schwab, Universität Zürich, Schweiz), anti-2',3'-zyklische Nukleotid-3'Phosphodiesterase (anti-CNPase, Sternberger Monoclonals Inc., Baltimore, MD, USA), anti-proteo-lipid protein (anti-PLP, Biozol, Eching, Deutschland), anti-MyelinOligodendrozyten-Glykoprotein (anti-MOG, Prof. Linington, Universität Aberdeen, UK), anti-KiM1P (Makrophagen, Prof. Radzun, Universität Göttingen, Deutschland), anti-CD3 (T-Zellen, Serotec, Oxford, UK), anti CD8 (T-Zellen, Dako, Glostrup, Dänemark), anti-lgG (Plasmazellen, Dako, Glostrup, Dänemark) und anti-APP (Boehringer Mannheim, Mannheim, Deutschland).

\subsubsection{ABC (Avidin-Biotin-Komplex) -Methode}

Um den akuten axonalen Schaden nachzuweisen, wurde das Amyloid-PrecursorProtein (APP) immunhistochemisch gefärbt.

Hierbei erfolgte die Färbung mittels der Avidin-Biotin-Komplex- Methode (Boenisch 2003, Hsu et al. 1982), die in der Abbildung 2.1 dargestellt ist. 
Bei diesem indirekten Nachweis des Proteins werden monoklonale Antikörper aus Mäusen als Primärantikörper verwendet. Sie werden auf die Probe gegeben und binden an das APP. Anschließend werden diese durch einen biotinylierten Sekundärantikörper erkannt. Über dieses Biotin wird das APP-Protein mit einem Avidin-Peroxidase (biotinyliertes Enzym)-Komplex verbunden und über eine Farbreaktion sichtbar gemacht.

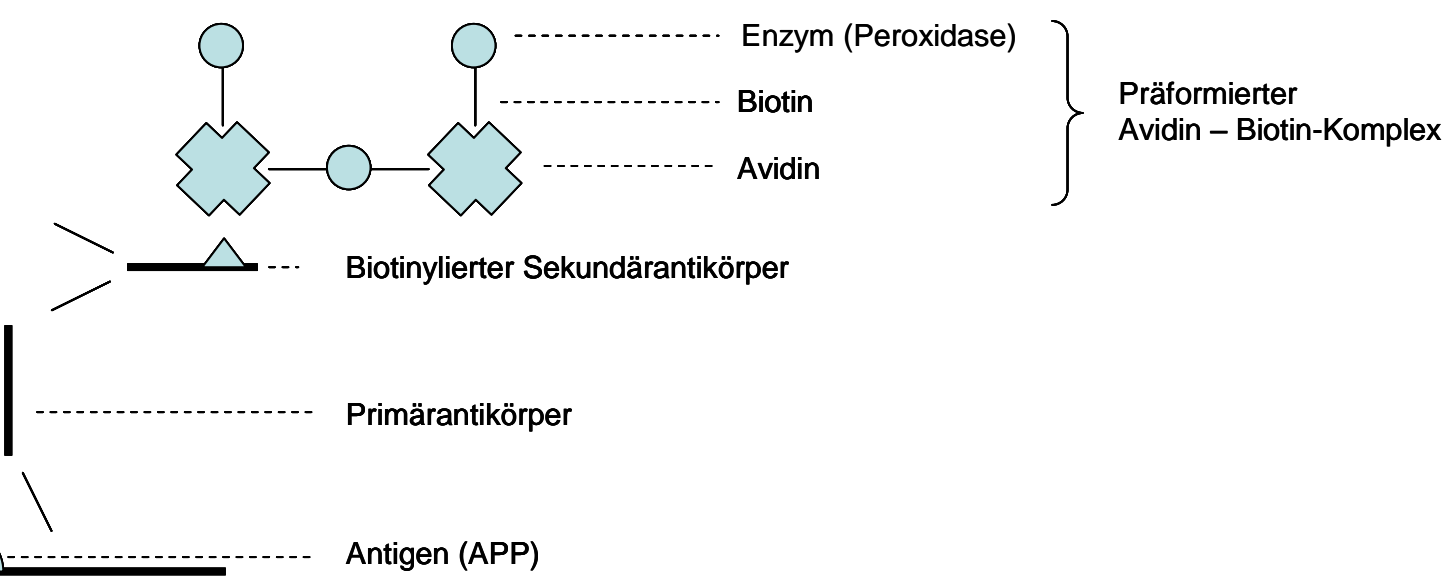

Abbildung 2.1: ABC-Methode

Durchführung:

Die Schnitte wurden in Xylol entparaffiniert und in einer absteigenden Alkoholreihe rehydriert. Die Verweildauer betrug in Xylol zehn Minuten und in den Alkoholen und in Aqua dest. je fünf Minuten. Anschließend wurde mit entionisiertem Wasser gespült und eine Vorbehandlung in der Mikrowelle mit Citratpuffer (10 mM und $\mathrm{pH}$ 6) durchgeführt. Die Schnitte wurden $5 \times 3$ Minuten gekocht und die Küvette dazwischen abwechselnd mit Aqua dest. und Citratpuffer aufgefüllt. Sie wurden dann mit entionisiertem Wasser gespült und für zehn Minuten in eine Küvette mit PBSPuffer gestellt. Das Stehen in $3 \% \mathrm{H}_{2} \mathrm{O}_{2} /$ PBS bewirkte eine Blockierung der endogenen Peroxidase und führte somit zu einer Reduktion der unspezifischen Hintergrundfärbung. Es wurde erneut mit PBS gespült. Anschließend wurden die histologischen Schnitte in ein Coverplate-System eingebracht und wieder mit PBS gespült. Folgend wurden vorhandene unspezifische Proteinbindungen durch Auftragen von 10 \% FCS (fetal calf serum)/PBS (120 $\mu \mathrm{l}$ ) blockiert. Danach wurde der Primärantikörper (APP mouse monoclonal antibody 1:3000) eingebracht und bei $4{ }^{\circ} \mathrm{C}$ über Nacht inkubiert. Erneut wurden die Schnitte mit PBS gespült und dann der 
biotinylierte Sekundärantikörper (anti mouse) (Amersham, 1:200) eingebracht. Die Schnitte wurden daraufhin 60 Minuten bei Raumtemperatur inkubiert. Dem folgte ein erneutes zweimaliges gründliches Spülen mit PBS. Der Avidin-Biotin Komplex mit gebundener Peroxidase (Sigma, 1:1000) wurde eingebracht und erneut bei Raumtemperatur für 45 Minuten inkubiert. Die zugesetzten Peroxidase-konjugierten Avidin-Biotin-Komplexe binden dabei mit noch vorhandenen freien Biotinbindungsstellen am Sekundärantikörper. Dem folgte zum Abschluss ein erneutes Spülen mit PBS.

\subsubsection{Substratumsetzung der Peroxidase}

Die an Biotin gekoppelte Peroxidase überträgt Wasserstoffionen. 3,3'Diaminobenzidin (50 ml PBS je Küvette mit 1ml DAB Stammlösung und $20 \mu \mathrm{l} 30 \%$ $\mathrm{H}_{2} \mathrm{O}_{2}$ ) diente als Substrat zur Farbentwicklung und wurde in einen braunen Farbstoff umgesetzt. Die Reaktion wurde durch Spülen in PBS gestoppt. Es erfolgte eine Gegenfärbung mit Hämalaun (60 Sek.). Die histologischen Schnitte wurden kurz mit Aqua dest. gespült und nach kurzem Eintauchen in $\mathrm{HCl}$-Alkohol und Spülen in Leitungswasser für 7 Minuten in eine aufsteigende Alkoholreihe (Aqua dest. $\rightarrow$ Xylol; je fünf Minuten) gegeben. Zum Abschluss wurden die Objektträger mit den Präparaten mit Eukitt/Depex eingedeckelt.

\subsubsection{Klassifikation der Läsionen anhand ihrer demyelinisierenden}

\section{Aktivität und des Immunsubtyps}

Alle ausgewerteten Läsionen zeigten die typischen Charakteristika von MS-Läsionen mit Demyelinisierung, relativem axonalen Erhalt der weißen Substanz und einem entzündlichen Infiltrat (siehe Bild 2.1, Seite 20), bestehend aus Lymphozyten (siehe Bild 2.5 und 2.6, Seite 21), Makrophagen (siehe Bild 2.7, 2.8 und 2.9, Seite 21) und Mikrogliazellen. Anhand ihrer demyelinisierenden Aktivität wurden sie folgendermaßen klassifiziert (Brück et al. 1995) (siehe auch 1.1.5.2, Seite 7):

1. In früh aktiven Läsionen zeigen sich Makrophagen, die LFB-positive Myelinabbauprodukte (siehe Bild 2.2, Seite 20) enthalten und für alle Myelinproteine, einschließlich MOG, MAG und CNP (siehe Bild 2.3 und 2.4, Seite 20), immunoreaktiv sind. Die Makrophagen exprimieren typischerweise den 
frühen Aktivierungsmarker MRP14. In den früh aktiven Läsionen können bereits remyelinisierte Axone enthalten sein.

2. In spät aktiven Läsionen ist der Myelinabbau weiter fortgeschritten, womit ein Verlust der Immunoreaktivität für MOG, MAG und CNP in Makrophagen einhergeht. Andere Myelinabbauprodukte (PLP, MBP) sind aber weiterhin in Makrophagen enthalten.

3. Früh remyelinisierende Läsionen werden durch Cluster dünn myelinisierter ungerichteter Axone erkannt. Eine Entzündung ist vorhanden, aber eine aktive Demyelinisierung lässt sich nicht nachweisen.

4. In spät remyelinisierten Läsionen ist die Entzündungsreaktion reduziert. Die Remyelinisierung ist weiter fortgeschritten. Im Vergleich zur normalen weißen Substanz sind die Myelinscheiden ungerichteter und dünner. Dies zeigt sich durch eine schwächere Anfärbbarkeit.

5. In inaktiv demyelinisierten Läsionen enthalten die Makrophagen keine immunhistochemisch anfärbbaren Myelinproteine. Stattdessen zeigen sich leere Vakuolen oder PAS-positive Granula im Zytoplasma. Die Läsionen zeigen eine vollständige Demyelinisierung.

6. Normal erscheinende weiße Substanz wird als weitere Aktivitätsstufe hinzugefügt. Damit ist jene weiße Substanz gemeint, die scheinbar noch nicht betroffen ist und keine Zeichen der Demyelinisierung aufweist. Allerdings können sich hier z.B. bereits entzündliche Infiltrate oder Zeichen der axonalen Schädigung zeigen.

Es erfolgte die Einteilung der Läsionen hinsichtlich ihrer demyelinisierenden Aktivität. Die früh aktiv entmarkenden Läsionen wurden anschließend hinsichtlich ihres Immunsubtyps weiter klassifiziert (siehe 1.1.5.1, Seite 6).

Im Folgenden zeigen Grafiken histologische Färbungen einer früh aktiven Läsion und normal erscheinender weißer Substanz (siehe auch Bilder vom gleichen Fall in Kapitel 3 „Ergebnisse“, Seite 25 bis Seite 26 und Seite 32 bis Seite 33 ). 


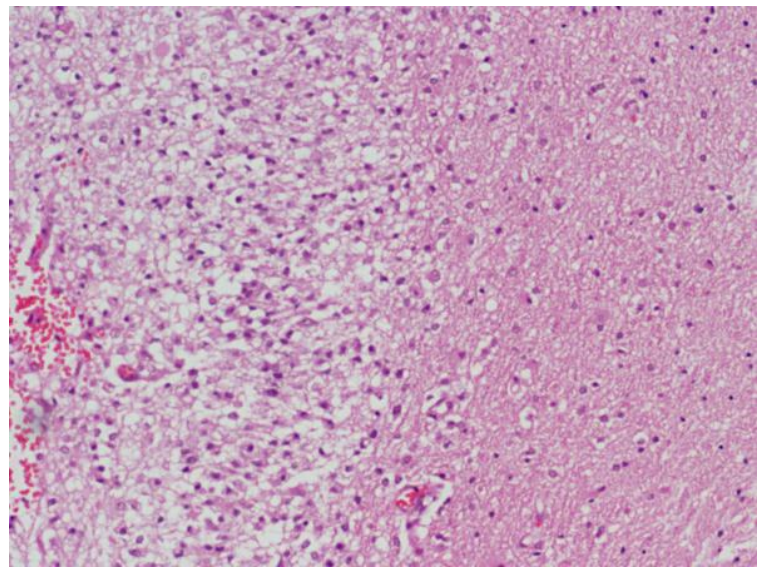

Bild 2.1: Die HE-Färbung lässt eine zellreiche Läsion (links) mit scharfem Übergang zur angrenzenden normal erscheinenden weißen Substanz erkennen (rechts) (HE-Färbung; x10; Fall 3598).

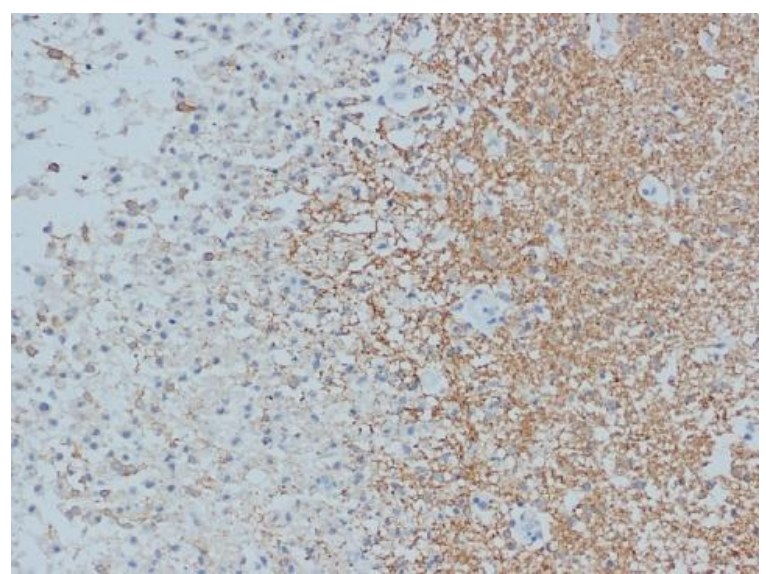

Bild 2.3: Bei Färbung des Myelinproteins CNP zeigt sich ebenfalls die flächige Entmarkung (links) mit relativ scharfem Übergang zur angrenzenden normal erscheinenden weißen Substanz (rechts) (Anti-CNPase; x10; Fall 3598)

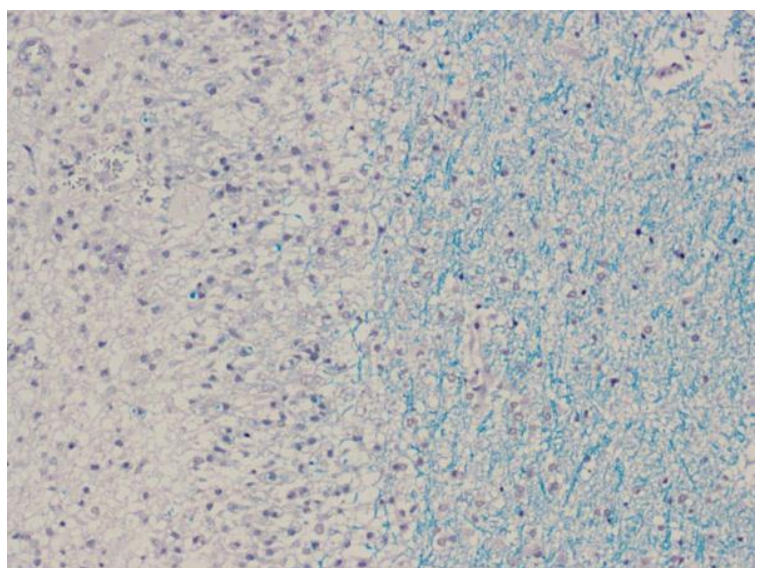

Bild 2.2: Die Läsion zeigt sich flächig entmarkt (links); in der normal erscheinenden weißen Substanz ist das Myelin erhalten (rechts) (LFB-PASFärbung; x10; Fall 3598).

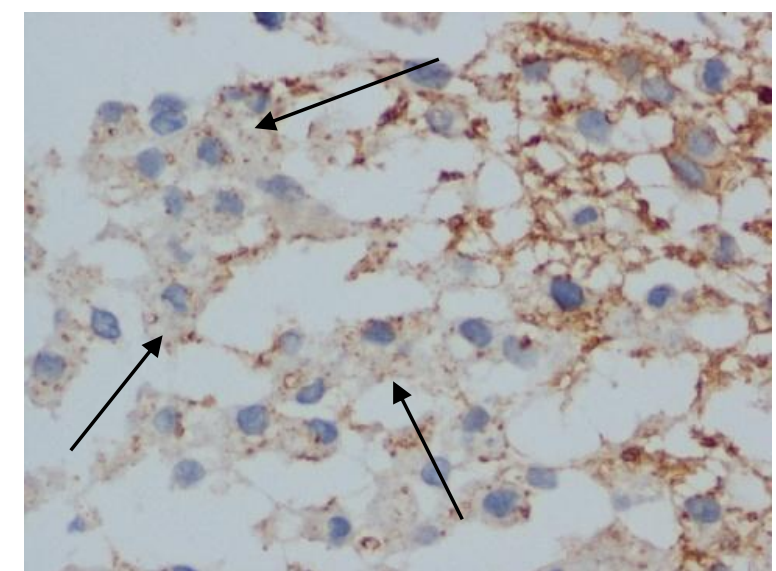

Bild 2.4: In dem Übergangsbereich lassen sich CNP-positive Abbauprodukte innerhalb von Makrophagen erkennen, einer früh aktiven Entmarkungsaktivität entsprechend (Anti-CNPase; x40; Fall 3598) 


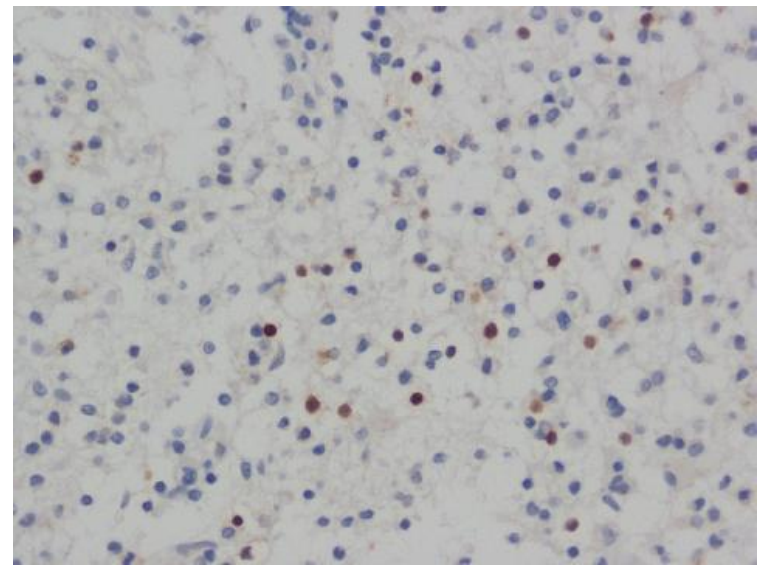

Bild 2.5: In der früh aktiven Läsion stellen sich diffus verteilte $\mathrm{CD}^{+}-\mathrm{T}$-Zellen dar (Anti-CD3; x20; Fall 3598).

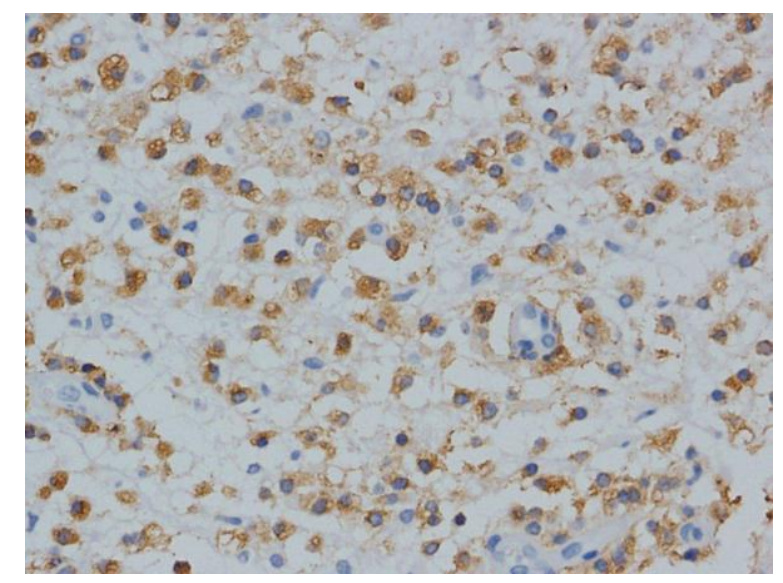

Bild 2.7: Zahlreiche Makrophagen kommen in der Läsion zur Darstellung (Anti- KiM1P; x20; Fall 3598).

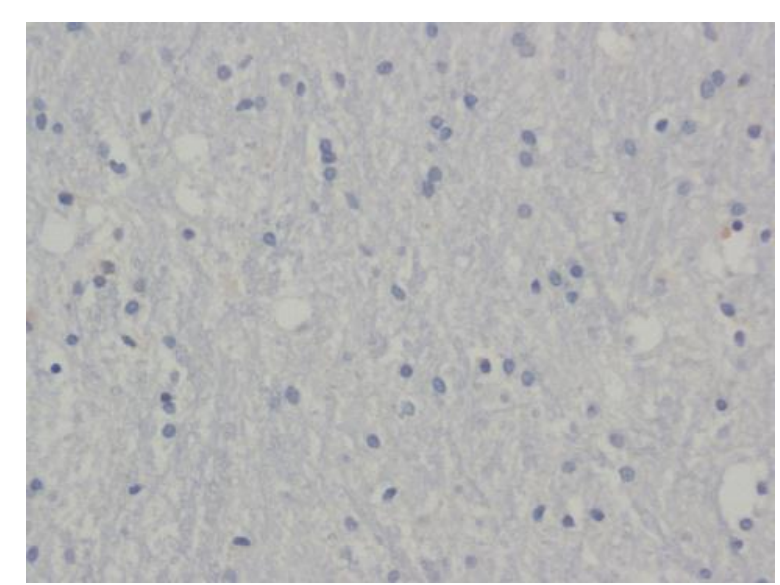

Bild 2.6: Hingegen finden sich keine $\mathrm{CD}^{+}{ }^{-}$-T-Zellen in der normal erscheinenden weißen Substanz (AntiCD3; x20; Fall 3598).

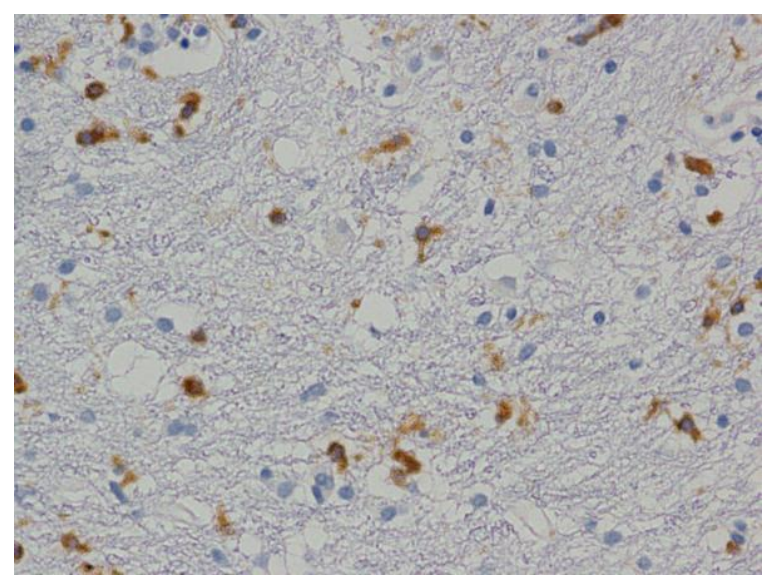

Bild 2.8: In der normal erscheinenden weißen Substanz zeigt sich eine Mikrogliaaktivierung (Anti- KiM1P; x20; Fall 3598).

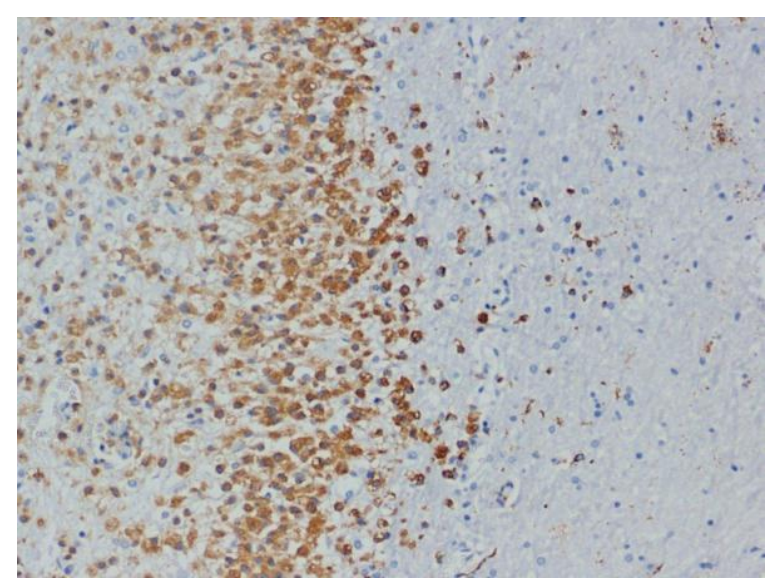

Bild 2.9: Eine Akkumulation von Makrophagen ist im Bereich des Läsionsrandes zu erkennen (Anti- KiM1P; x10; Fall 3598) 


\subsection{Mapping}

Da die meisten MS-Biopsien mehrere Stadien der demyelinisierenden Aktivität aufwiesen (vgl. 2.4, Seite 16), wurde von jedem histologischen Schnitt eine Karte angefertigt, in die die unterschiedlichen Läsionsaktivitäten der MS-Plaques eingezeichnet wurden. Dieses Vorgehen gewährleistet eine einheitliche und reproduzierbare Auswertung. Bei jeder Biopsie war mindestens ein früh aktives Areal vorhanden, so dass eine Bestimmung des Immunsubtyps möglich war. Jedes Areal wurde einzeln nach seiner entsprechenden demyelinisierenden Aktivität ausgewertet.

\subsection{Morphometrie}

Die Biopsieschnitte wurden lichtmikroskopisch unter einem Zeiss ${ }^{\circledR}$ Mikroskop ausgewertet.

\subsubsection{Akute axonale Schädigung (APP-Immunhistochemie)}

Die Auswertung erfolgte unter 1000-facher Vergrößerung (Okular 10 x, Objektiv 100 $x)$. Die Zahl der APP-positiven Sphäroide wurde mit Hilfe eines Zählgitters quantitativ bestimmt. Je Läsionsaktivität wurden 20 Gesichtsfelder ausgewertet. Um die Werte für die Fläche von $1 \mathrm{~mm}^{2}$ zu erhalten, musste der Mittelwert der Zählfelder mit 100 multipliziert werden.

\subsubsection{Axonale Dichte (Versilberung nach Bielschowsky)}

Die Auswertung erfolgte unter 800-facher Vergrößerung (Okular 8 x, Objektiv 100)

Die relative axonale Dichte wurde mit Hilfe eines 25-Punkte-Zählgitters der Firma Zeiss ${ }^{\circledR}$ bestimmt (Brück 1997). Das Zählgitter enthielt 25 Kreuzungen, deren Schnittmenge mit den axonalen Strukturen bestimmt wurde. Je Schnitt wurden in der Regel zwanzig Gesichtsfelder ausgewertet, mindestens jedoch zehn Gesichtsfelder je Läsionsareal. Zunächst wurden die Mittelwerte für die einzelnen Patienten ermittelt. Waren von einem Patienten mehrere Läsionsareale mit gleicher Läsionsaktivität vorhanden, wurde ein gemeinsamer Mittelwert gebildet.

Mithilfe dieser Werte wurden die Medianwerte der unterschiedlichen Immunsubtypen sowohl für die Läsionen, als auch die normal erscheinende weiße Substanz (NAWM) gebildet. Die Medianwerte der Bielschowsky-gefärbten Axone in der NAWM unterschieden sich nicht signifikant bezüglich der einzelnen Immunsubtypen. Sie 
konnten daher zusammengefasst werden. Der so ermittelte Wert wurde mit $100 \%$ axonaler Dichte gleichgesetzt und als Referenzwert verwendet.

Die axonale Dichte in den Läsionen wurde in Bezug auf diesen Referenzwert in Prozent angegeben. So konnte die relative axonale Dichte in den Läsionen beschrieben werden.

\subsection{Korrelation der Axonparameter mit T-Zellen und Makrophagen}

Weiterhin wurden die Ergebnisse der Untersuchung der axonalen Dichte und des akuten axonalen Schadens mit der Anzahl der Entzündungszellen verglichen. Folgende Entzündungszellen wurden von Fischer aus derselben Arbeitsgruppe ausgewertet: $\mathrm{CD}^{+}{ }^{-}$und CD8+-T-Zellen, KiM1P- und MRP14-positive Zellen. Das Gesamtkollektiv ist dasselbe und es wurden die identischen Fälle ausgewertet, jedoch teilweise in anderen Läsionsgebieten. Die Läsionsaktivitäten waren stets identisch.

\subsection{Statistische Auswertung}

Die statistische Auswertung wurde mit der GraphPad PRISM® Software durchgeführt. Es wurden der Kruskal-Wallis-Test und der Mann-Whitney-U-Test verwendet. Alle Tests wurden bei einem $\mathrm{p}$-Wert unter 0,05 als statistisch signifikant gewertet. Für die schriftliche Ausarbeitung wurden Microsoft® Word, Excel und PowerPoint verwendet.

\subsection{Materialanhang: Immunhistochemie}

PBS (Phosphat Buffered Solution):

9,55 g PBS wurden auf 1 I Aqua bidest. gelöst.

Citratpuffer:

2,1 g Citrat wurden auf 1 I Aqua dest. gelöst und auf einen pH-Wert von 2,0 eingestellt.

DAB (3,3'-Diaminobenzidin)-Färbelösung:

$1 \mathrm{ml} \mathrm{DAB}$ wurde in $50 \mathrm{ml}$ PBS gelöst und anschließend gefiltert. Kurz vor Gebrauch wurden $16 \mu \mathrm{l} 30 \% \mathrm{H}_{2} \mathrm{O}_{2}$ hinzugefügt. 
Material und Methoden

Die für die Immunhistochemie verwendeten Substanzen wurden bei Boehringer Mannheim, Sigma, Seromed, Merck, Aldrich und Biochrom bestellt. 


\section{ERGEBNISSE}

\subsection{Neuropathologische Befunde}

Alle Biopsien erfüllen die neuropathologischen Kriterien einer entzündlichen demyelinisierenden ZNS-Erkrankung.

\subsubsection{Hämatoxilin-Eosin-Färbung (HE-Färbung)}

In der HE-Färbung (Bild 3.1 und 3.2) stellen sich Läsionen mit einer vermehrten Zelldichte dar (Bild 3.1). Diese ist Ausdruck eines entzündlichen Infiltrates, welches hauptsächlich aus Makrophagen und Lymphozyten besteht. Das Infiltrat ist diffus im Gewebe verteilt, bei einigen Läsionen jedoch auch perivaskulär betont lokalisiert (vgl. 1.1.5, Seite 6). Ferner zeigen sich reaktive Astrozyten mit eosinophilem Zytoplasma. Der Gewebegrund erscheint aufgelockert. Die Läsionen sind in der HE-Färbung meist scharf begrenzt.

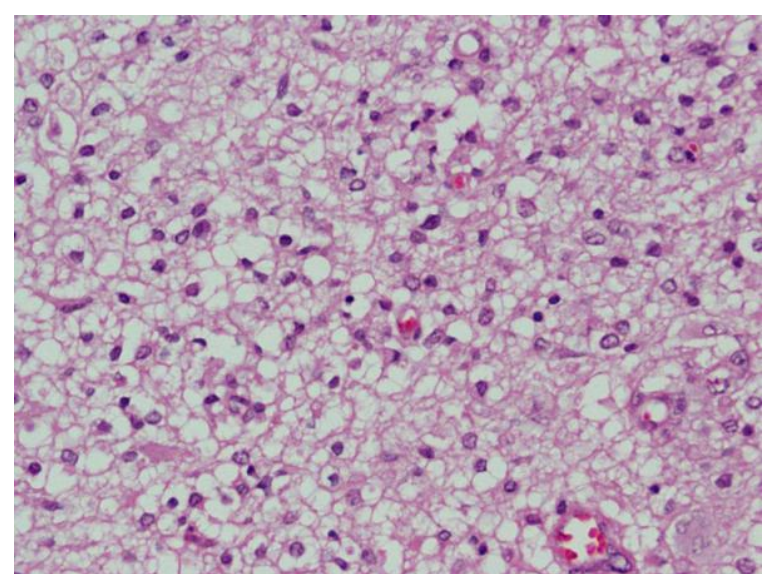

Bild 3.1: In der früh aktiven Läsion stellt sich eine erhöhte Zelldichte und Auflockerung des Gewebegrundes dar Zelldichte (HE-Färbung; x20; Fall 3598). (HE-Färbung; x20; Fall 3598).

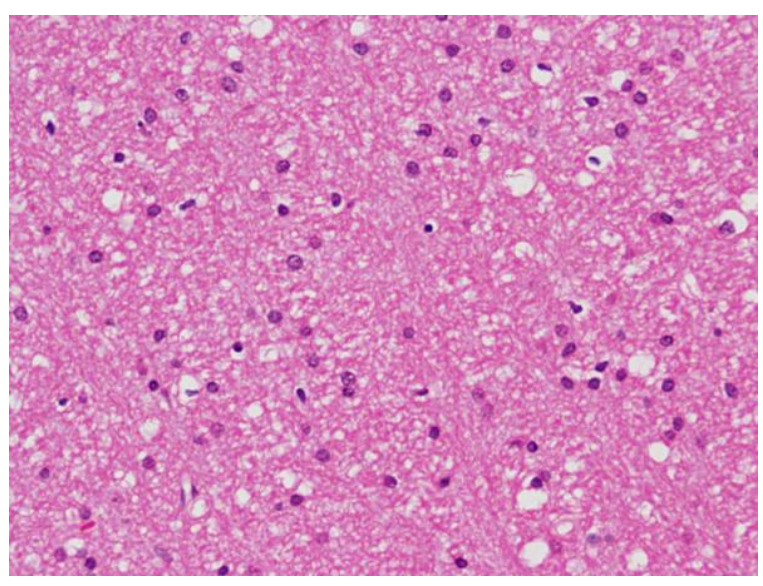

Bild 3.2 Die normal erscheinende weiße Substanz zeigt hingegen eine reguläre

\subsubsection{LFB-PAS-Färbung}

Mit der LFB-PAS-Färbung werden Myelinscheiden blau dargestellt (Bild 3.3 und 3.4). Es finden sich sowohl komplett demyelinisierte Plaques als auch remyelinisierte Areale mit neu gebildeten, dünnen Markscheiden, die sich in der LFB-PAS-Färbung zartblau darstellen. Makrophagen enthalten Myelinabbauprodukte, die sich in frühen 
Stadien der Demyelinisierung als blaue und in späteren Stadien als rosa Granula innerhalb des Zytoplasmas erkennen lassen.

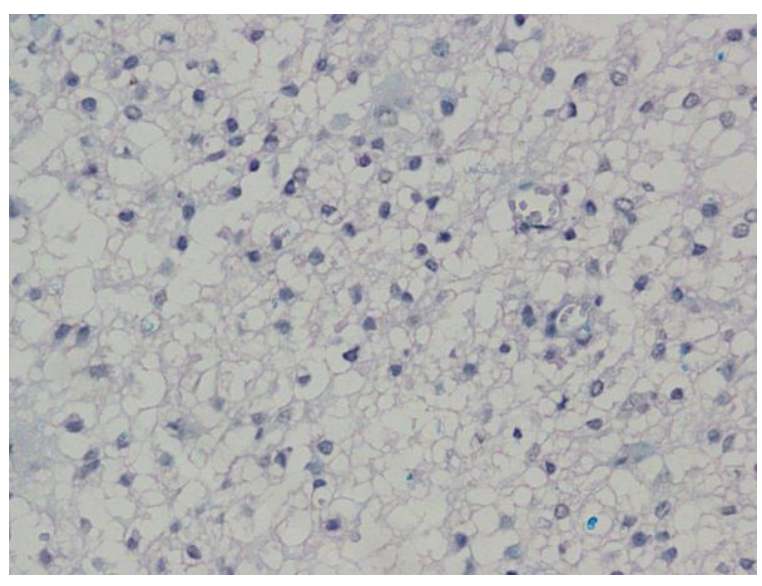

Bild 3.3: Flächig entmarkte Läsion (LFBPAS-Färbung; x20; Fall 3598).

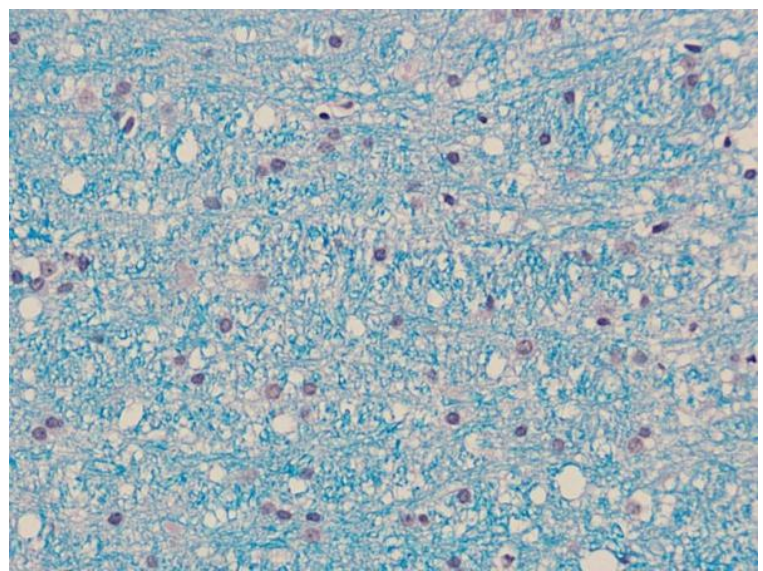

Bild 3.4: Myelinscheiden in der normal erscheinenden weißen Substanz stellen sich blau gefärbt da (LFB-PAS-Färbung; x20; Fall 3598).

\subsubsection{Versilberung nach Bielschowsky}

Die Versilberung nach Bielschowsky zeigt eine verminderte axonale Dichte innerhalb der Läsionen (Bild 3.5) gegenüber der normal erscheinenden weißen Substanz (Bild 3.6). Die axonale Dichte variiert von einem fast vollständigen Verlust der Axone bis zu einem nahezu kompletten Axonerhalt. 


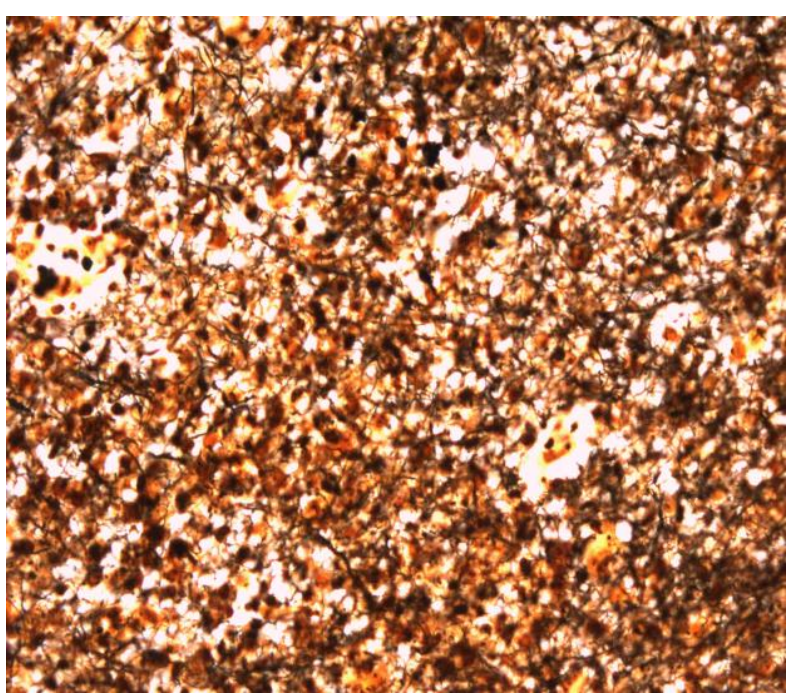

Bild 3.5: In der früh aktiven Läsion zeigt sich eine deutliche Axonreduktion (Versilberung nach Bielschowsky; x400; Fall 3584).

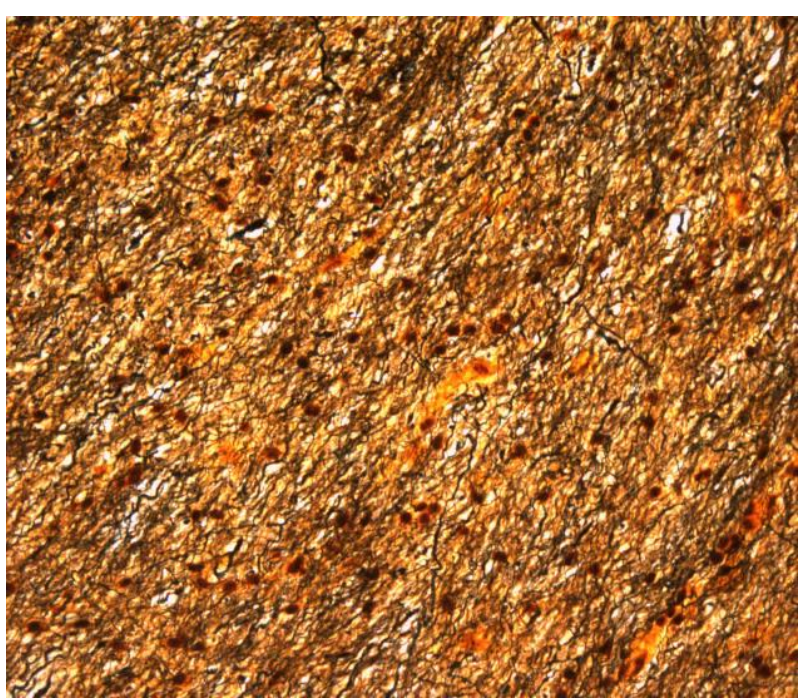

Bild 3.6: Demgegenüber zeigt sich in der normal erscheinenden weißen Substanz ein dichtes axonales Gerüst (Versilberung nach Bielschowsky; x400; Fall 3584).

\subsubsection{APP-Färbung}

Die immunhistochemische Färbung mit Antikörpern gegen das Amyloid-PrecursorProtein (APP) stellt akut geschädigte Axone dar, in denen das APP akkumuliert. Je nach verwendetem Farbsubstrat stellen sich die APP-positiven Sphäroide rot oder braun dar (Bild 3.7). In den Läsionen zeigt sich eine hohe Anzahl APP-positiver Sphäroide als Zeichen der akuten axonalen Schädigung. In einem weit geringeren Maß wurden jedoch auch in der NAWM APP-positive Sphäroide gefunden (Bild 3.8).

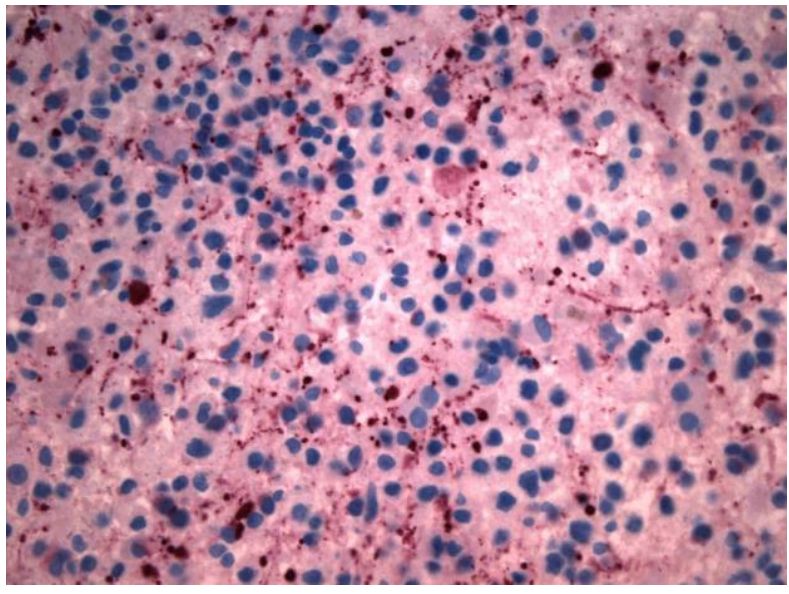

Bild 3.7: Zahlreiche akut geschädigte Axone (braune Strukturen) finden sich in dieser früh aktiven Läsion (APP; x400; Fall 3553).

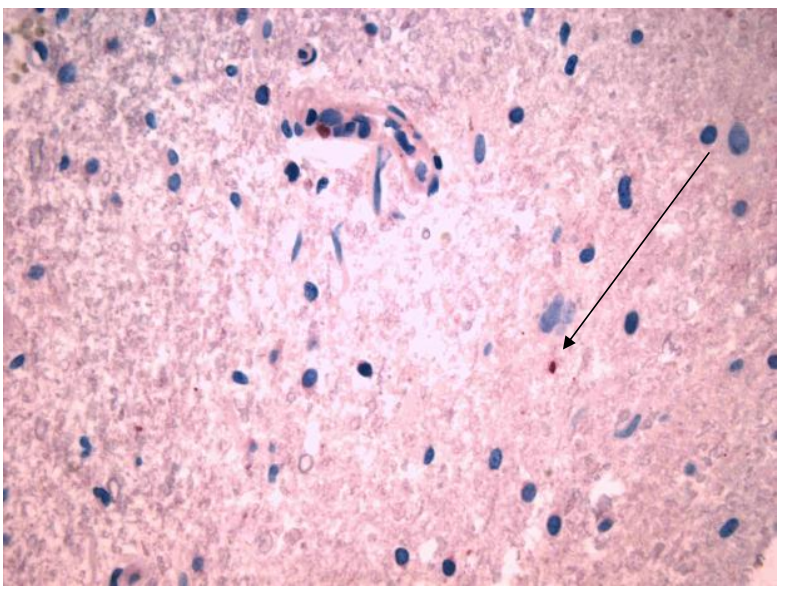

Bild 3.8: Demgegenüber zeigen sich in der normal erscheinenden weißen Substanz nur vereinzelt akut geschädigte Axone (Pfeil) (APP; x400; Fall 3553). 


\subsection{Immunsubtypen und Läsionsaktivitäten}

Eine Unterteilung in vier unterschiedliche immunpathogenetische Typen der aktiven Demyelinisierung (sog. Immunsubtypen) (vgl. 1.1.5.2, Seite 7) wurde bei der Auswertung der in der Studie verwendeten MS-Fälle durchgeführt (Lucchinetti et al. 2000, Bitsch und Brück 2002) (siehe Abb. 1.2, Seite 7).

Von den einzelnen Immunsubtypen und Färbungen wurden unterschiedliche Fallzahlen ausgewertet (Tabelle 3.1).

Mittels der Bielschowsky-Versilberung wurden früh aktive Läsionen von 13 Fällen (25\%) des Subtyps I, von 27 Fällen (52\%) des Subtyps II und von 12 Fällen (23\%) des Subtyps III untersucht.

Zudem wurden anhand der APP-Färbung früh aktive Läsionen von 11 Fällen des Subtyps I (27\%), von 19 Fällen des Subtyps II (46\%) und von 11 Fällen des Subtyps III (27\%) untersucht.

Die Anzahl der ausgewerteten Fälle der Bielschowky- und APP-Färbung für die normal erscheinende weiße Substanz können der Tabelle 3.1 entnommen werden.

Unterschiedliche Fallzahlen ergeben sich für die APP- und Bielschowsky-Färbungen, da einige Fälle ausgeschlossen werden mussten. Dies lag z.B. begründet in zu kleinen Gewebeproben oder einer zu schlechten Qualität der Färbungen und der fehlenden Möglichkeit der Nachfärbung.

In Kollektiven von biopsierten MS-Patienten finden sich zum Vergleich der Subtyp I mit einer Häufigkeit von 19\%, Subtyp II von 53\%, Subtyp III von $26 \%$ und Subtyp IV von $2 \%$ (Lucchinetti et al. 2000).

Ausgewertet wurden folgende Fälle: 


\begin{tabular}{|c|c|c|c|c|}
\hline Färbung & Läsionsareal & Subtyp I & Subtyp II & Subtyp III \\
\hline Bielschowsky & EA & $13(25 \%)$ & $27(52 \%)$ & $12(23 \%)$ \\
\hline Bielschowsky & NAWM & $6(23 \%)$ & $10(39 \%)$ & $10(39 \%)$ \\
\hline APP & EA & $11(27 \%)$ & $19(46 \%)$ & $11(27 \%)$ \\
\hline APP & NAWM & $5(21 \%)$ & $10(42 \%)$ & $9(38 \%)$ \\
\hline $\begin{array}{c}\text { MS- } \\
\text { Normalkollektiv }\end{array}$ & & $19 \%$ & $53 \%$ & $26 \%$ \\
\hline
\end{tabular}

Tabelle 3.1: Anzahl der ausgewerteten Fälle unterteilt nach Immunsubtypen sowie die Verteilung der Immunsubtypen im Kollektiv biopsierter Patienten (Lucchinetti et al. 2000) zum Vergleich (gerundet auf gerade Zahlen);

$A P P=$ Amyloid-Precursor-Protein; $E A=$ early active (früh aktiv); NAWM = Normal appearing white matter (normal erscheinende weiße Substanz)

\subsection{Axonale Dichte}

Die axonale Dichte wurde durch die Auswertung der mit der Versilberung nach Bielschowsky angefärbten Schnitte bestimmt. Es wurden die Axonwerte der Läsionen und der NAWM ermittelt. Der ermittelte Wert der Läsionen wurde in Bezug zur normalen weißen Substanz gesetzt. Ein Referenzwert wurde durch Mittelung der Werte der NAWM gebildet (vgl. 2.6.2, Seite 22) und die axonale Dichte in den Läsionen als relativer Prozentsatz dieses Referenzwertes angegeben.

Bei Untersuchung der normal erscheinenden weißen Substanz ließ sich kein signifikanter Unterschied hinsichtlich der axonalen Dichte zwischen den einzelnen Immunsubtypen nachweisen. Dennoch findet sich beim Immunsubtyp II mit einem Median von 89\% eine geringere axonale Dichte als in Immunsubtyp I und III (101 bzw. 111\%, vgl. auch Abbildung 3.1). Die Werte über 100\% ergeben sich rechnerisch aufgrund der Verwendung des gemeinsamen Referenzwertes. Subtyp I weist eine Spannweite von $87 \%$ bis $121 \%$ auf. Subtyp II zeigt eine Spannweite von $45 \%$ bis $123 \%$ und Subtyp III weist die größte Spannweite von $31 \%$ bis $128 \%$ auf. Die 
Standardabweichung in Subtyp I ist mit einem Wert von 13\% am geringsten. Subtyp II weist mit 23\% einen ähnlichen Wert auf wie Subtyp III mit 26\%.

Zusammenfassend finden sich stark variierende Axonwerte in der NAWM. Die Spannweite der ausgewerteten Daten sowie die minimalen und maximalen Werte können Tabelle 3.2 entnommen werden.

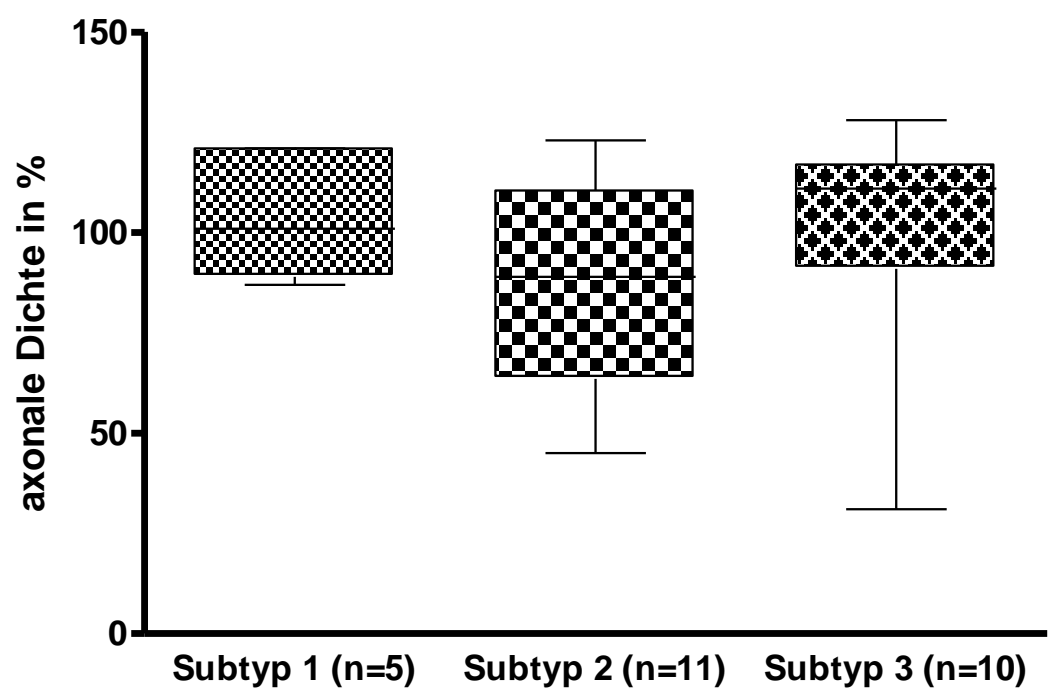

Abbildung 3.1 - axonale Dichte der normal erscheinenden weißen Substanz (NAWM) in den einzelnen Immunsubtypen; grafisch dargestellt sind: Mittelwert, Minimum, Maximum sowie die Perzentilen 25 und 75

In den früh aktiven Läsionen ist die Axondichte im Median auf ca. die Hälfte reduziert: Es zeigt sich mit einem Median von $51,5 \%$ eine statistisch signifikante Reduktion der axonalen Dichte gegenüber der NAWM (Median per definitionem $100 \%)(P<0,0001)$. Dies ist in Abbildung 3.2 dargestellt. 


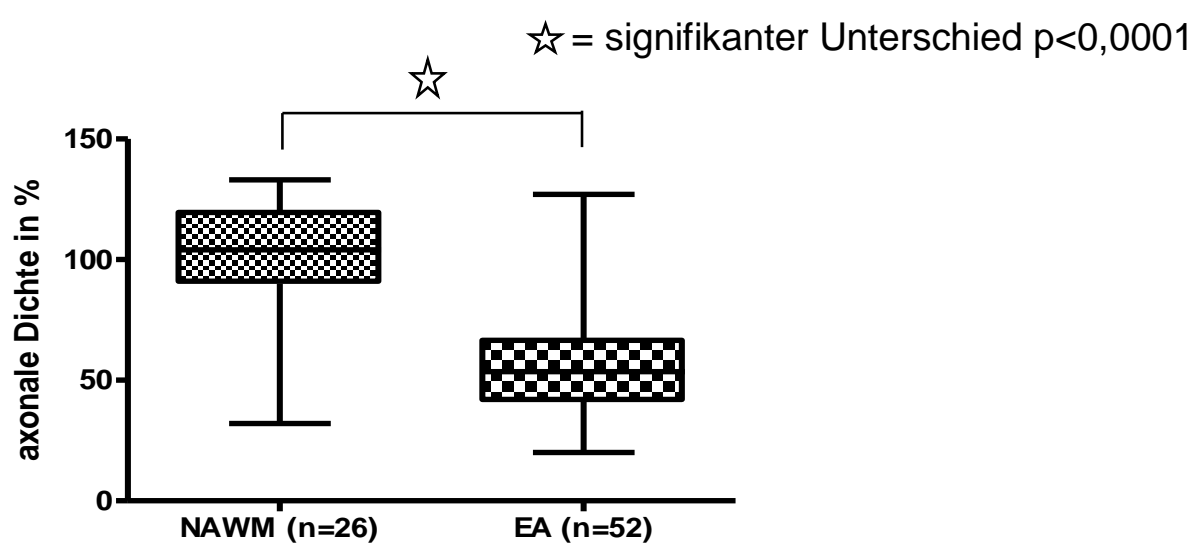

\begin{abstract}
Abbildung 3.2 - Axonale Dichte der normal erscheinenden weißen Substanz (NAWM) im Vergleich zu frühaktiven Läsionen (EA); grafisch dargestellt sind: Mittelwert, Minimum, Maximum sowie die Perzentilen 25 und 75
\end{abstract}

Es zeigt sich beim Vergleich der Läsionen eine große Variabilität der axonalen Dichte, von einer massiven Reduktion der Axone bis hin zu einem kompletten Erhalt reichend. In Subtyp II findet sich mit einem Median von 49\% eine geringere axonale Dichte als in Subtyp I (Median 54\%) und in Subtyp III (Median 54\%). Ein signifikanter Unterschied zwischen den Immunsubtypen lässt sich jedoch nicht nachweisen (vgl. Abbildung 3.3). Innerhalb der einzelnen Immunsubtypen zeigt sich eine deutliche Schwankungsbreite. Die Spannweite beim Subtyp I ist mit Werten von 33\% bis $123 \%$ am größten. Subtyp II zeigt eine Spannweite von 19\% bis 102\% und Subtyp III von $37 \%$ bis $93 \%$.

Zusammenfassend finden sich keine signifikanten Unterschiede zwischen den verschiedenen Subtypen der Entmarkung bei dem Vergleich der axonalen Dichte. 


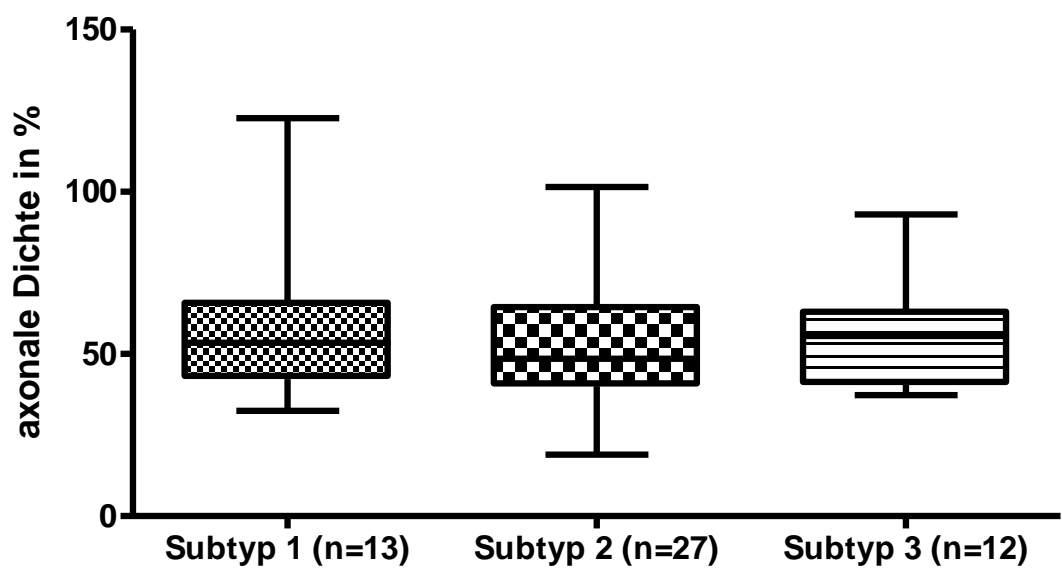

\section{Abbildung 3.3 - Vergleich der axonalen Dichte zwischen den einzelnen Immunsubtypen in den früh aktiven Läsionarealen}

Im Folgenden finden sich Bilder aus früh aktiven Läsionen mit unterschiedlichen axonalen Dichten (Bild 3.9 bis 3.13).

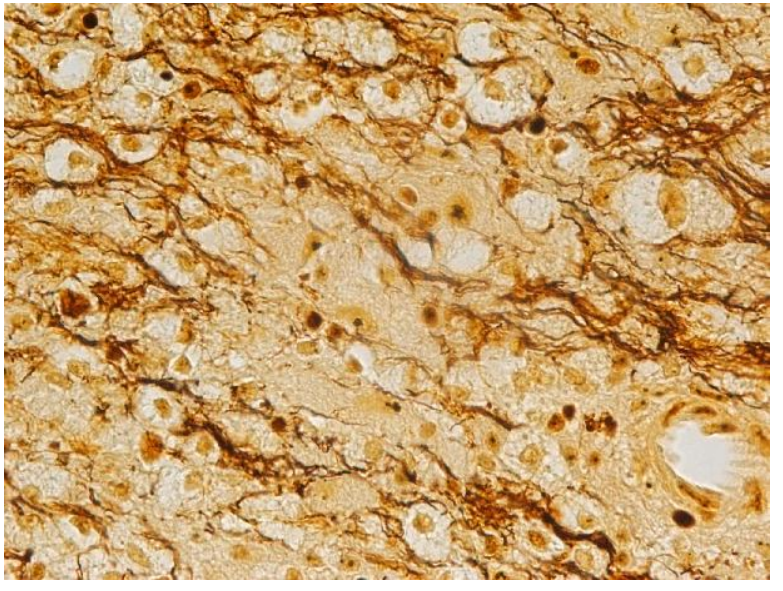

Bild 3.9: Axonale Dichte in der früh aktiven Läsion von ca. $40 \%$ (Versilberung nach Bielschowsky; x400)

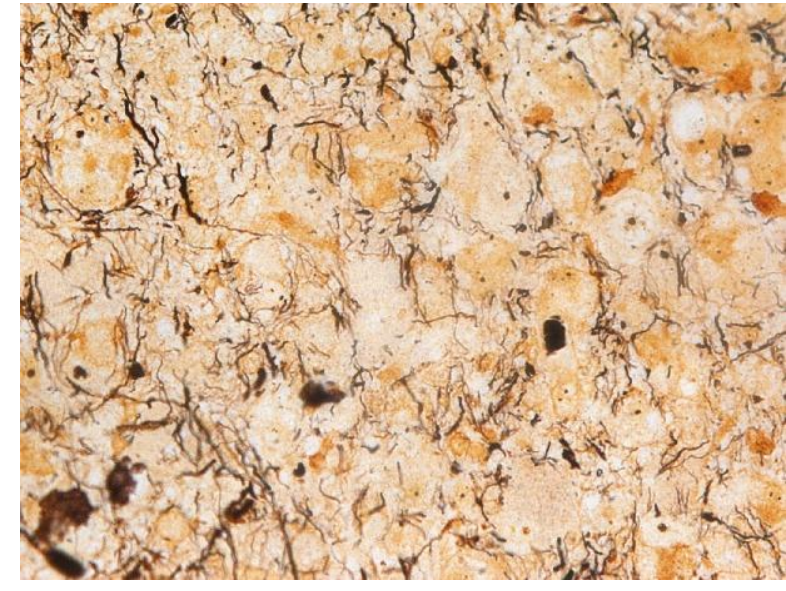

Bild 3.10: Axonale Dichte in der früh aktiven Läsion von ca. $45 \%$ (Versilberung nach Bielschowsky; $x 400$ ) 


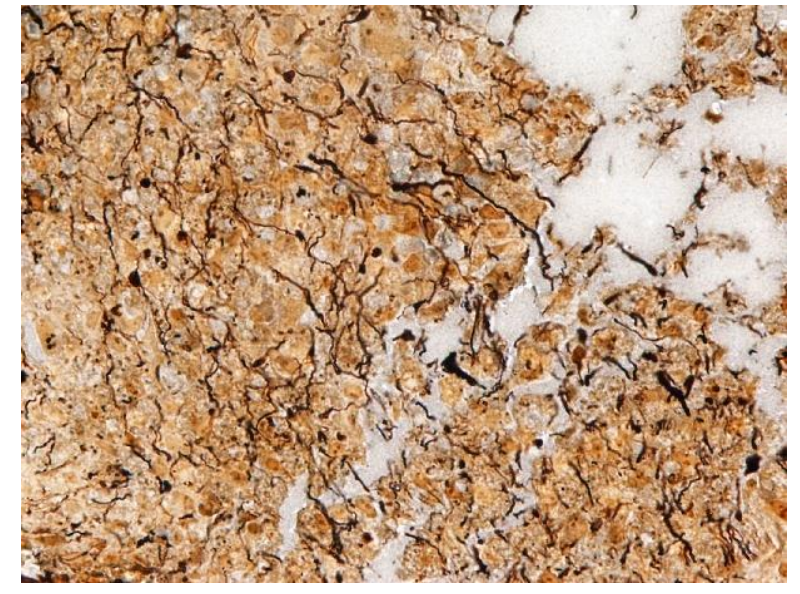

Bild 3.11: Axonale Dichte in der früh aktiven Läsion von ca. $60 \%$ (Versilberung nach Bielschowsky; $x 400$ )

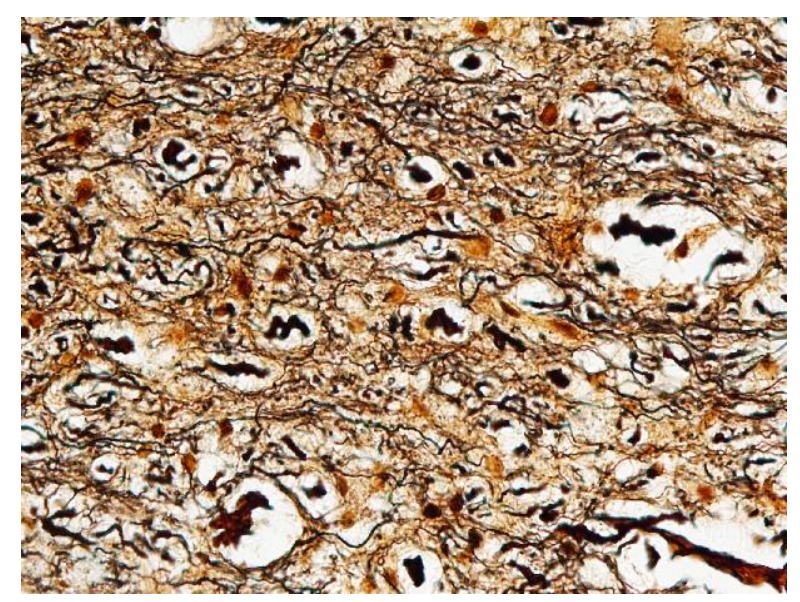

Bild 3.13: Axonale Dichte in der früh aktiven Läsion von ca. $123 \%$ (Versilberung nach Bielschowsky; $x 400$ )

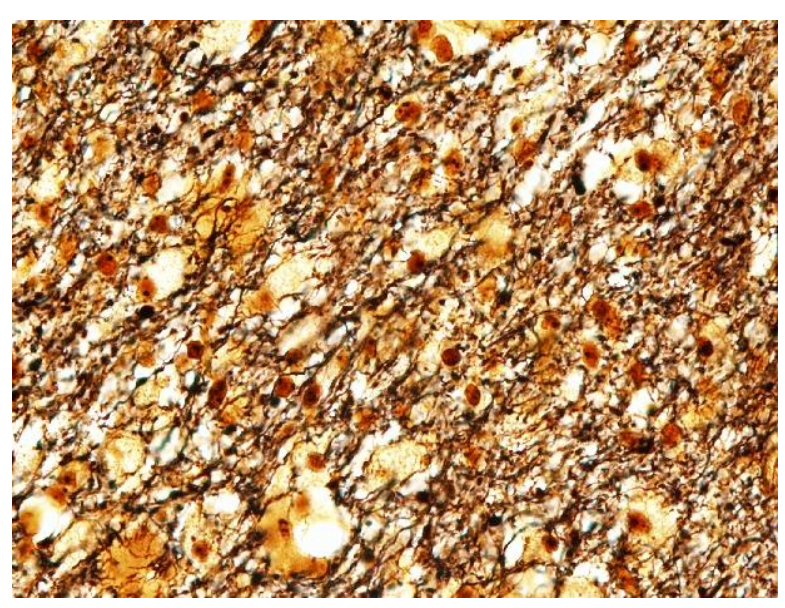

Bild 3.12: Axonale Dichte in der früh aktiven Läsion von ca. $86 \%$ (Versilberung nach Bielschowsky; $x 400$ )

Die einzelnen Medianwerte sowie die minimalen und maximalen axonalen Dichtewerte für die einzelnen Immunsubtypen der früh aktiven Läsionen und der NAWM sind in Tabelle 3.2 wiedergegeben. 


\begin{tabular}{|c|c|c|c|}
\hline $\begin{array}{c}\text { Median } \pm \\
\text { STABWN in \% } \\
\text { (Min-Max) }\end{array}$ & Subtyp I & Subtyp II & Subtyp III \\
\hline NAWM & $101 \pm 13 \%$ & $89 \pm 23 \%$ & $111 \pm 26 \%$ \\
& $(87-121 \%)$ & $(45-123 \%)$ & $(31-128 \%)$ \\
\hline EA & $54 \pm 23 \%$ & $49 \pm 18 \%$ & $54 \pm 15 \%$ \\
& $(33-123 \%)$ & $(19-102 \%)$ & $(37-93 \%)$ \\
\hline
\end{tabular}

Tabelle 3.2: Axonale Dichte der NAWM und der früh aktiven Läsionen (EA) bei Vergleich der Immunsubtypen

\subsection{Akuter axonaler Schaden}

Durch die Auswertung der mit Antikörpern gegen das APP gefärbten Biopsieschnitte konnte der akute axonale Schaden in den unterschiedlichen Immunsubtypen in der NAWM und in den Läsionen erfasst werden.

In der normal erscheinenden weißen Substanz lassen sich akut geschädigte Axone in geringer Anzahl nachweisen. In Subtyp III zeigen sich mit im Median 360 APP-positiven Sphäroiden $/ \mathrm{mm}^{2}$ mehr akut geschädigte Axone als in Subtyp II (Median 341 Sphäroide $/ \mathrm{mm}^{2}$ ) und Subtyp I (Median 200 Sphäroide $/ \mathrm{mm}^{2}$ ) (vgl. Abbildung 3.4). Diese Unterschiede sind statistisch jedoch nicht signifikant.

Subtyp III zeigt mit 994 Sphäroiden $/ \mathrm{mm}^{2}$ eine sehr hohe Standardabweichung, welche durch die Abweichung eines einzelnen Falles (3350 Sphäroide/ $\mathrm{mm}^{2}$ ) zu erklären ist.

Die Spannweite ist in der normal erscheinenden weißen Substanz groß und zeigt damit eine ausgeprägte Variabilität zwischen den einzelnen Fällen auf. Subtyp I weist eine Spannweite von 10 bis 300 Sphäroiden $/ \mathrm{mm}^{2}$ auf. Subtyp II zeigt eine Spannweite von 0 bis 830 Sphäroiden $/ \mathrm{mm}^{2}$ und Subtyp III von 20 bis 3350 Sphäroiden $/ \mathrm{mm}^{2}$ (siehe Tabelle 3.3). 


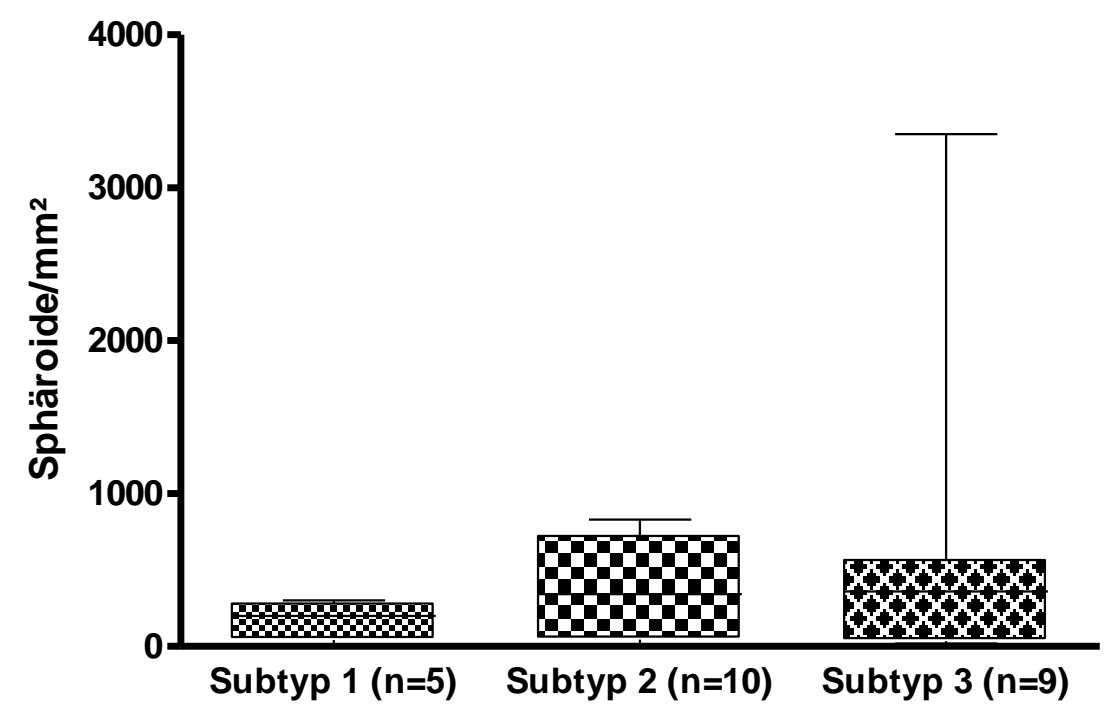

Abbildung 3.4 - APP-positive Sphäroide innerhalb der normal erscheinenden weißen Substanz (NAWM) bei Vergleich der Immunsubtypen

Es zeigen sich in den früh aktiven Läsionen (alle Immunsubtypen zusammengefasst) signifikant mehr akut geschädigte Axone als in der NAWM $(P<0,0001)$. Der Median in den früh aktiven Läsionen ist ca. 26-mal höher als in der normal erscheinenden weißen Substanz (6560 APP-positive Sphäroide pro $\mathrm{mm}^{2} \mathrm{im}$ Vergleich zu 256 Sphäroiden pro $\mathrm{mm}^{2}$ ) (vgl. Abbildung 3.5).

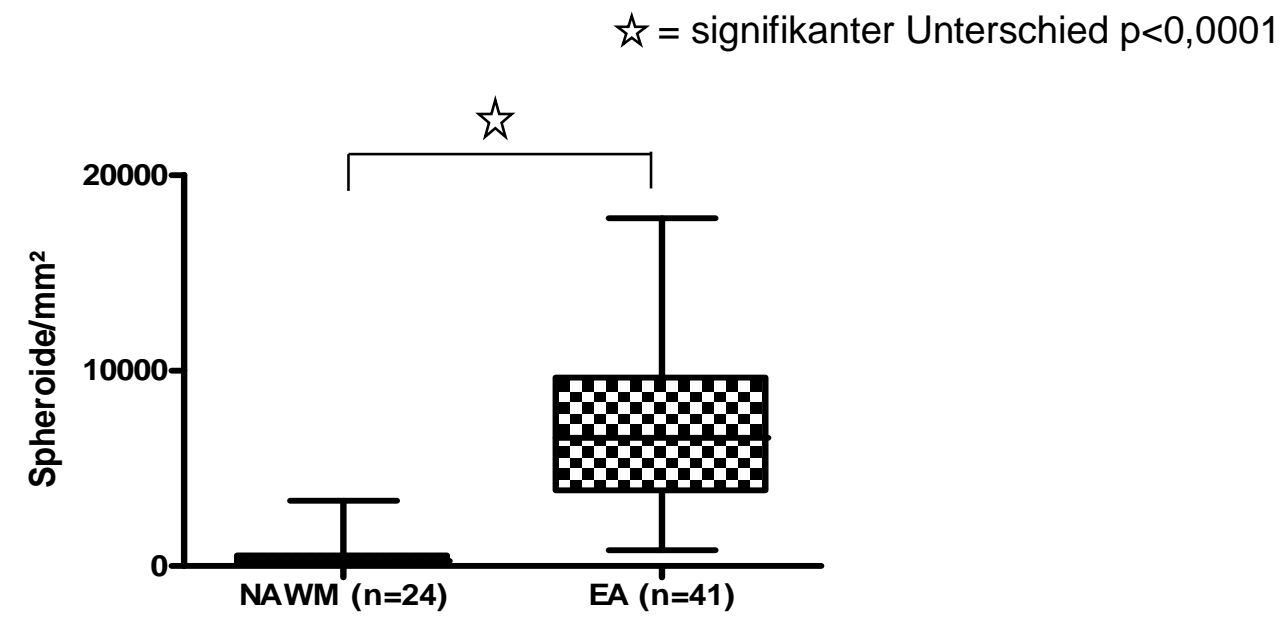

Abbildung 3.5 - Akuter axonaler Schaden der früh aktiven Läsionen (EA) im Vergleich zur normal erscheinenden weißen Substanz (NAWM); grafisch dargestellt sind: Mittelwert, Minimum, Maximum sowie die Perzentilen 25 und 75

Vergleicht man die akute axonale Schädigung in den Läsionen zwischen den einzelnen Immunsubtypen, so finden sich beim Immunsubtyp I mit im Median 9060 
Sphäroiden $/ \mathrm{mm}^{2}$ signifikant mehr akut geschädigte Axone als beim Immunsubtyp II (Median 4500 Sphäroide/mm²) (Mann-Whitney-U-Test $p<0,003$ ). Subtyp III zeigt mit im Median 7000 Sphäroiden $/ \mathrm{mm}^{2}$ ebenfalls hohe Zahlen akut geschädigter Axone, ohne jedoch im Vergleich zu den anderen Immunsubtypen einen signifikanten Unterschied aufzuweisen (vgl. Abbildung 3.6).

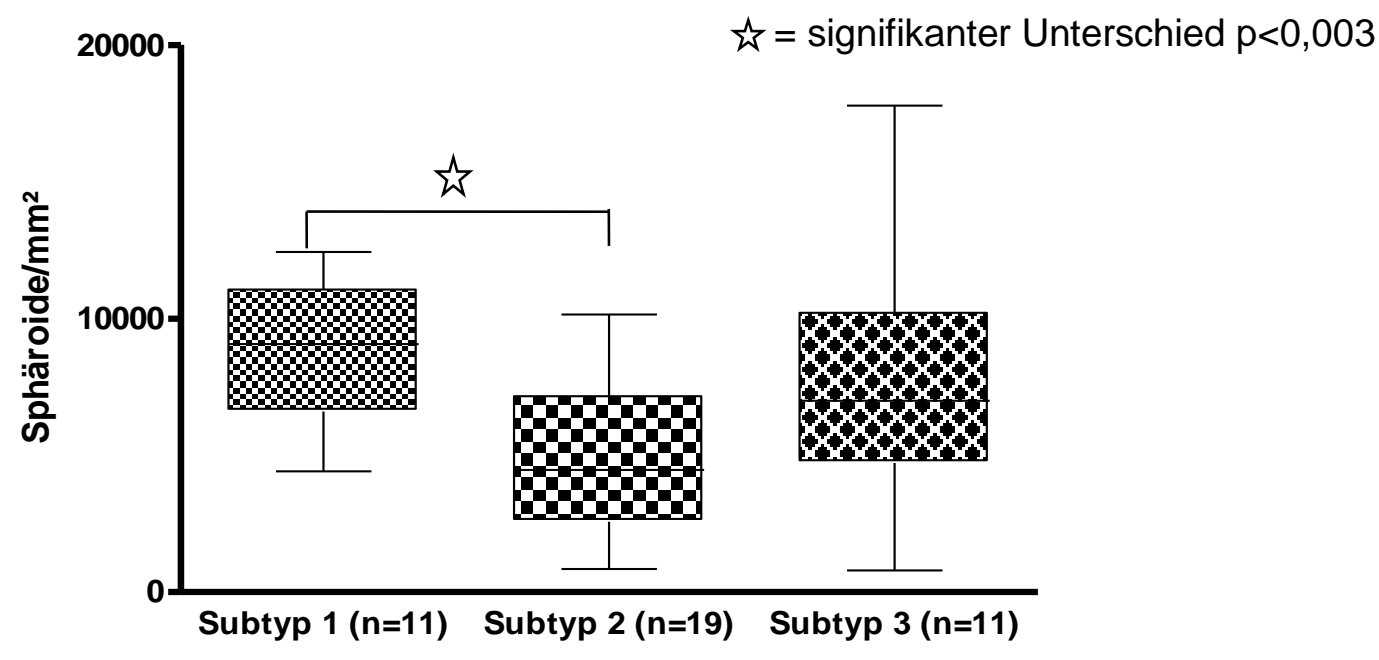

\section{Abbildung 3.6 - Akuter axonaler Schaden der früh aktiven Läsionen (EA) bei Vergleich der einzelnen Subtypen; grafisch dargestellt sind: Mittelwert, Minimum, Maximum sowie die Perzentilen 25 und 75}

Der niedrigste Wert von akut geschädigten Axonen liegt beim Subtyp I bei 4415 Sphäroiden $/ \mathrm{mm}^{2}$ innerhalb der Läsionen. Kein Wert liegt darunter. Beim Immunsubtyp II liegen hingegen $42 \%$ der Fälle unter diesem Wert und verdeutlichen somit die geringere akute axonale Schädigung.

Die Spannweite reicht beim Subtyp I von 4415 Sphäroiden $/ \mathrm{mm}^{2}$ bis zu 12430 Sphäroiden $/ \mathrm{mm}^{2}$. Subtyp II weist Werte von 840 Sphäroiden $/ \mathrm{mm}^{2}$ bis zu 10140 Sphäroiden $/ \mathrm{mm}^{2}$ auf und Subtyp III von 800 Sphäroiden $/ \mathrm{mm}^{2}$ bis zu 17785 Sphäroiden $/ \mathrm{mm}^{2}$.

Die einzelnen Medianwerte sowie die minimalen und maximalen Werte der akuten axonalen Schädigung für die einzelnen Immunsubtypen der früh aktiven Läsionen und NAWM sind in Tabelle 3.3 wiedergegeben. 


\begin{tabular}{|c|c|c|c|}
\hline $\begin{array}{c}\text { Median } \pm \\
\text { STABWN } \\
(\text { Min-Max })\end{array}$ & Subtyp I & Subtyp II & Subtyp III \\
\hline NAWM & $200 \pm 110$ & $341 \pm 302$ & $360 \pm 994$ \\
& $(10-300)$ & $(0-830)$ & $(20-3350)$ \\
\hline EA & $9060 \pm 2611$ & $4500 \pm 2715$ & $7000 \pm 4766$ \\
& $(4415-12430)$ & $(840-10140)$ & $(800-17785)$ \\
\hline
\end{tabular}

Tabelle 3.3: Akuter axonaler Schaden: APP-positive Sphäroide in der normal erscheinenden weißen Substanz (NAWM) und in den früh aktiven Läsionen (EA) pro $m m^{2}$

Im Folgenden finden sich Bilder von APP-positiven Sphäroiden in den unterschiedlichen Immunsubtypen früh aktiver Läsionen (Bilder 3.14-3.19).

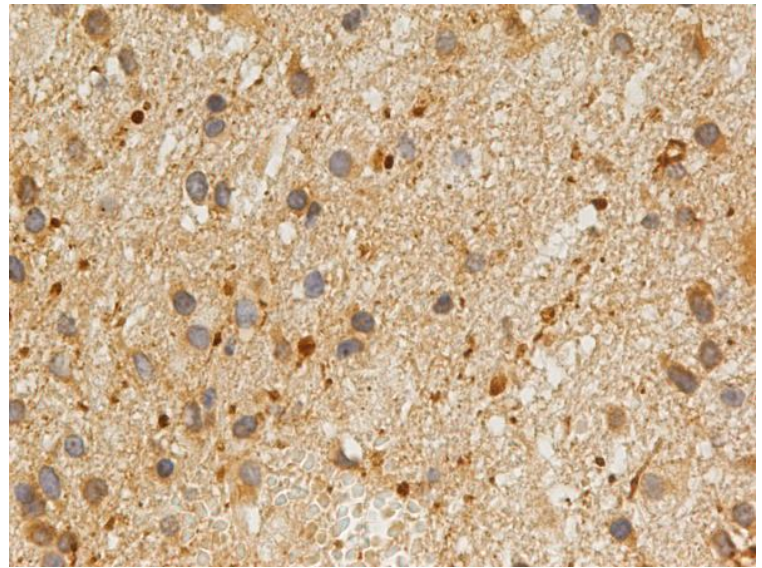

Bild 3.14: Akut geschädigte Axone (braune Strukturen) in früh aktiver Läsion des Subtypen I (APP; x400).

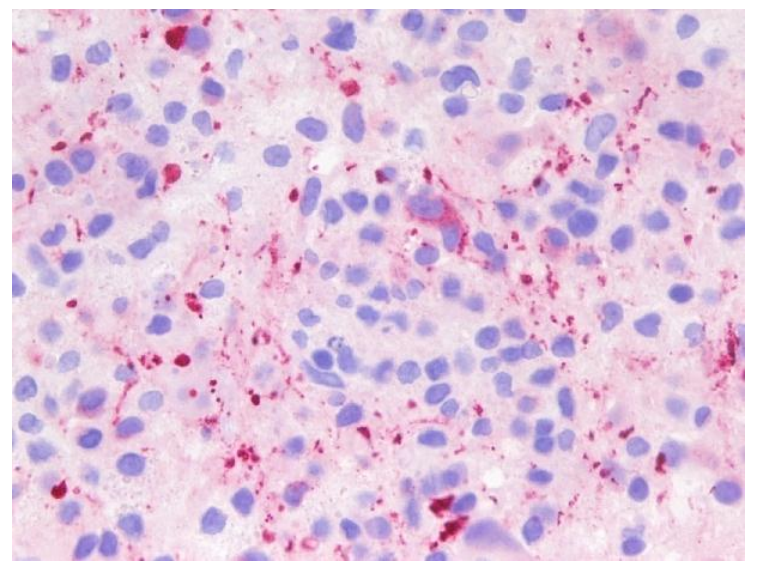

Bild 3.15: Akut geschädigte Axone (rotbraune Strukturen) in früh aktiver Läsion des Subtypen I (APP; x400). 


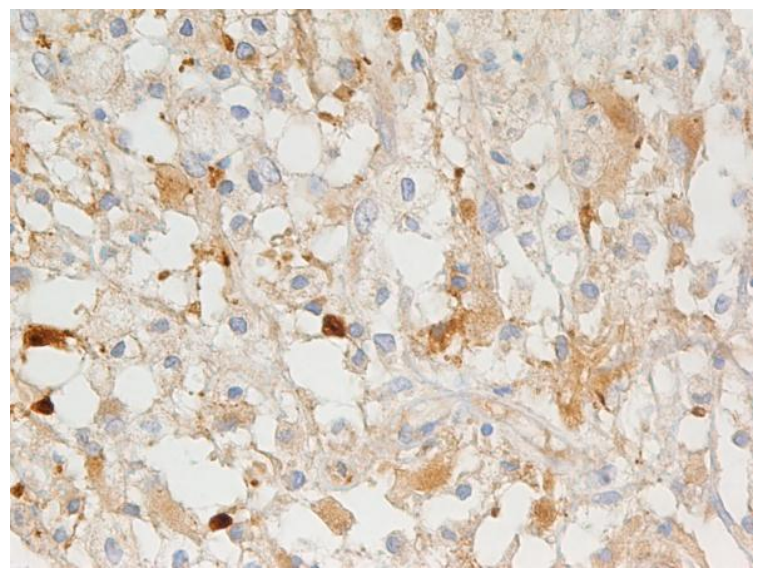

Bild 3.16: Akut geschädigte Axone (braune Strukturen) in früh aktiver Läsion des Subtypen II (APP; x400).

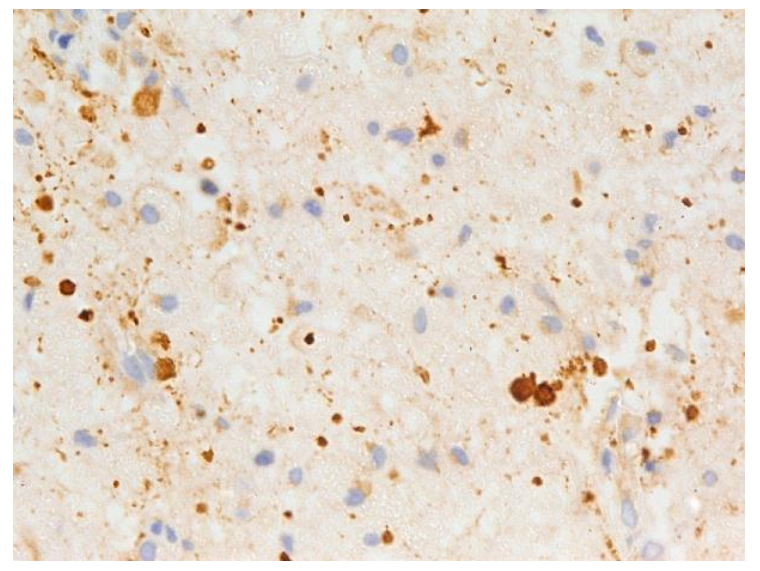

Bild 3.18: Akut geschädigte Axone (braune Strukturen) in früh aktiver Läsion des Subtypen III (APP; x400).

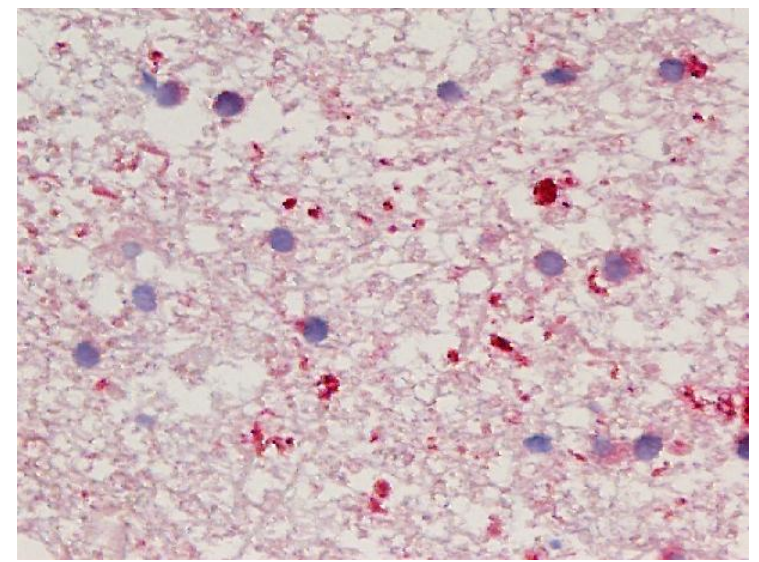

Bild 3.17: Akut geschädigte Axone (rotbraune Strukturen) in früh aktiver Läsion des Subtypen II (APP; x400).

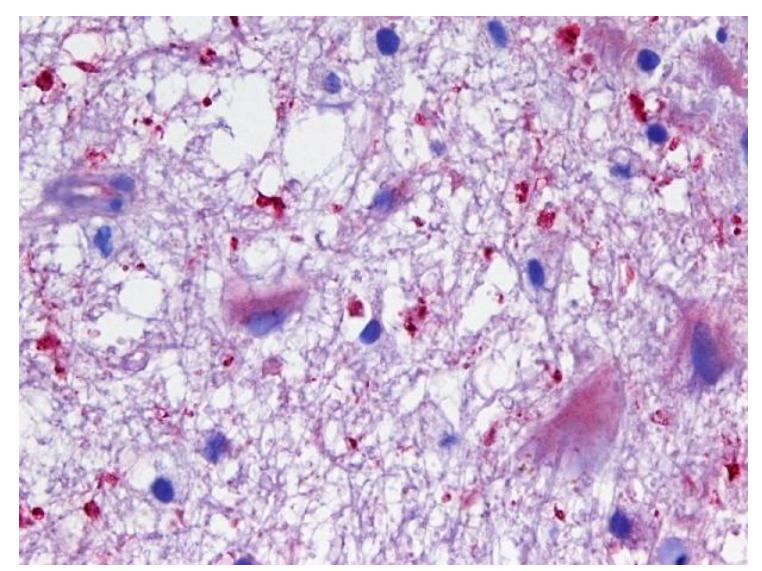

Bild 3.19: Akut geschädigte Axone (rotbraune Strukturen) in früh aktiver Läsion des Subtypen III (APP; x400).

\subsection{Korrelationen von axonaler Dichte und akuter axonaler Schädigung}

Es erfolgte eine Korrelation der Anzahl der APP-positiven Sphäroide und der mittels der Bielschowsky-Versilberung ermittelten relativen axonalen Dichte. Hierbei lässt sich weder in den Läsionen noch in der normal erscheinenden weißen Substanz eine Korrelation nachweisen.

\subsection{Korrelationen der Axonpathologie mit den Entzündungszellen}

Im Folgenden wurden die Daten der hier vorliegenden Studie (APP-positive Sphäroide, relative axonale Dichte) mit denen aus der Arbeit von Fischer (CD3+- und CD8+-T-Zellen sowie KiM1P-positive Makrophagen und KiM1P-MiP-positive 
Makrophagen) verglichen (Fischer 2007). Fischer untersuchte das Entzündungsinfiltrat in den verschiedenen Immunsubtypen der MS. KiM1P ist ein Marker für Makrophagen und Mikrogliazellen. Als KiM1P-MiP-positive Makrophagen wurden KiM1P-positive Makrophagen mit einem Mikroglia Phänotyp bezeichnet.

\subsubsection{Korrelationen der axonalen Dichte mit den Entzündungszellen}

\subsubsection{Gemeinsame Auswertung aller Immunsubtypen sowie}

\section{Läsionsaktivitäten}

Werden die Fälle unabhängig von den Immunsubtypen und der Läsionsaktivität (d.h. einschließlich der weißen Substanz) ausgewertet, zeigt sich zwischen der axonalen Dichte und den CD3 ${ }^{+}-$T-Zellen eine signifikante negative Korrelation $(n=49$; $p<0,0001$; Spearman $r=-0,5318)$. Zwischen den CD8 ${ }^{+}-T$-Zellen und der axonalen Dichte zeigt sich ebenfalls ein signifikanter Zusammenhang $(n=49 ; p=0,0005$; Spearman $r=-0,4760)$. Je mehr $\mathrm{CD}^{+}{ }^{+}$und $\mathrm{CD} 8^{+}-\mathrm{T}-Z$ Zllen vorkommen, desto geringer ist die axonale Dichte. Es liegen jedoch sehr niedrige Korrelationskoeffizienten vor.

Eine negative signifikante Korrelation zeigt sich ferner zwischen der axonalen Dichte aller Subtypen sowie den KiM1P-positiven Makrophagen $(n=50 ; p=0,0005$; Spearman $r=-0,4728$ ); eine positive Korrelation hingegen zwischen der axonalen Dichte und den KiM1P-MiP positiven Zellen ( $n=48 ; p=0,0001$; Spearman $r=0,5252$ ). Es finden sich jeweils ebenfalls sehr niedrige Korrelationkoeffizienten. Da keine Daten der MRP14-positiven Makrophagen in der NAWM vorliegen, musste auf diese Korrelation verzichtet werden.

\subsubsection{Auswertung der früh aktiven Läsionsareale sowie getrennt der} NAWM (unabhängig vom Immunsubtyp)

Werden alle früh aktiven Areale, unabhängig vom Immunsubtyp, mit den Entzündungszellen korreliert, so errechnen sich keine signifikanten Korrelationen. Auch beim Zusammenfassen aller Areale der NAWM und Vergleich mit dem Entzündungsinfiltrat ergeben sich keine signifikanten Korrelationen. 


\subsubsection{Auswertung der früh aktiven Läsionen in Abhängigkeit des Immunsubtyps}

Werden die Immunsubtypen einzeln betrachtet, so findet sich zwischen der axonalen Dichte im Immunsubtyp II und den $\mathrm{CD}^{+}{ }^{+}$T-Zellen eine signifikante negative Korrelation ( $n=16 ; p=0,0237$, Spearman $r=-0,5611)$. Je mehr $C D 3^{+}-T-Z e l l e n$ in der Läsion vorhanden sind, desto geringer ist die axonale Dichte. Es zeigt sich nur beim Subtyp II ebenfalls eine positive Korrelation zwischen der axonalen Dichte und den KiM1P-positiven Makrophagen in Subtyp II ( $n=17 ; p=0,0024$, Spearman $r=0,6843$ ).

Keine Korrelationen zeigen sich zwischen der axonalen Dichte und den KiM1Ppositiven Makrophagen für Subtyp I und III (Subtyp I: 9 Fälle; Subtyp III: 8 Fälle), den MRP14-positiven Zellen (Subtyp I: 9 Fälle; Subtyp: II 16 Fälle; Subtyp: III 8 Fälle) und CD8+-T-Zellen (Subtyp I: 8 Fälle; Subtyp II: 15 Fälle; Subtyp: III 8 Fälle). Bezüglich der KiM1P-MiP-positiven Makrophagen zeigt sich ebenfalls keine signifikante Korrelation (Subtyp I: 8 Fälle; Subtyp II: 12 Fälle; Subtyp: III 7 Fälle). Aufgrund der relativ kleinen Anzahl an übereinstimmenden Fällen sind die Korrelationen jedoch vorsichtig zu interpretieren.

\subsubsection{Auswertung der NAWM in Abhängigkeit des Immunsubtyps}

In der normal erscheinenden weißen Substanz standen nur wenige Fälle mit überschneidenden Daten zur Verfügung, so dass keine Korrelationsberechnung möglich war.

\subsubsection{Korrelationen des akuten axonalen Schadens mit den Entzündungszellen}

\subsubsection{Gemeinsame Auswertung aller Immunsubtypen sowie \\ Läsionsaktivitäten}

Fasst man alle Fälle, unabhängig vom Immunsubtyp und der Läsionsaktivität zusammen, zeigen sich zwischen der akuten axonalen Schädigung und den Entzündungszellen folgende Korrelationen: APP-positive Sphäroide und CD3+-TZellen korrelieren signifikant $(n=42 ; p<0,0001$; Spearman $r=0,6148)$. APP-positive Sphäroide und CD8 ${ }^{+}-$T-Zellen korrelieren signifikant $(n=42 ; p=0,0001$; Spearman $r=$ 0,5552). APP-positive Sphäroide und KiM1P-positive Makrophagen weisen ebenfalls eine signifikante Korrelation auf $(n=44 ; p<0,0001$; Spearman $r=0,6515)$. Ein negative Korrelation ergibt sich für die KiM1P-MiP-positiven Makrophagen und der akuten 
axonalen Schädigung ( $n=42 ; p=0,0004$; Spearman; $r=-0,5180)$. Da auch hier keine Daten für die MRP14-positiven Makrophagen in der normal erscheinenden weißen Substanz vorlagen, musste auf eine gemeinsame Auswertung verzichtet werden.

\subsubsection{Auswertung der früh aktiven Läsionsareale sowie getrennt der NAWM (unabhängig vom Immunsubtyp)}

Werden die APP-Werte der früh aktiven Fälle aller Immunsubtypen mit den einzelnen Entzündungszelltypen korreliert, so ergeben sich keine signifikanten Korrelationen. Bei Auswertung der normal erscheinenden weißen Substanz (Subtyp I-III) zeigt sich eine signifikante Korrelation der APP-Werte mit den CD3 ${ }^{+}$-T-Zellen $(n=16 ; p=0,0183$; Spearman $r=0,5808$ ); die weiteren Korrelationsberechnungen zeigen keine signifikanten Zusammenhänge.

\subsubsection{Auswertung der früh aktiven Läsionen in Abhängigkeit des Immunsubtyps}

In Subtyp I, II und III zeigen sich für die CD3+-T-Zellen (Subtyp I: 8 Fälle, Subtyp II: 11 Fälle; Subtyp III: 7Fälle) keine signifikanten Zusammenhänge mit den APPpositiven Sphäroiden. Die CD8 ${ }^{+}-$T-Zellen (Subtyp I: 7 Fälle; Subtyp II: 12 Fälle; Subtyp III: 7 Fälle), KiM1P-positiven Makrophagen: (Subtyp I: 8 Fälle; Subtyp II: 14 Fälle; Subtyp III: 7 Fälle), KiM1P-MiP-positiven Makrophagen (Subtyp I: 8 Fälle; Subtyp II: 12 Fälle; Subtyp III: 7 Fälle) und MRP14-positiven Zellen (Subtyp I: 8 Fälle; Subtyp II: 13 Fälle; Subtyp III: 7 Fälle) weisen ebenfalls keine signifikanten Korrelationen mit den APP-positiven Sphäroiden in den jeweiligen Subtypen auf.

\subsubsection{Auswertung der NAWM in Abhängigkeit des Immunsubtyps}

In der normal erscheinenden weißen Substanz zeigt sich beim Subtyp III eine signifikante Korrelation zwischen den APP-positiven Sphäroiden und den CD8+-TZellen ( $n=6 ; p=0,0167$, Spearman $r=0,9429$ ). Je mehr CD8+-T-Zellen vorhanden sind, desto größer ist die akute axonale Schädigung. Weitere signifikante Korrelationen zeigen sich nicht. Es sind jedoch die geringen Fallzahlen zu diskutieren. (Subtyp I: CD3- und CD8-Auswertung jeweils 6 Fälle; KiM1P- und KiM1P-MiP-Auswertung je 4 Fälle; Subtyp II: je 5 Fälle; Subtyp III: je 6 Fälle). Von den MRP14-positiven Makrophagen liegen auch hier keine Daten vor. 
Die durchgeführten Korrelationen sind tabellarisch im Anhang zusammengefasst (Tabelle 6.7).

Zusammengefasst zeigt sich eine signifikante Korrelation mit einem Korrelationskoeffizienten > 0,7 zwischen den APP-positiven axonalen Sphäroiden und den CD8 ${ }^{+}$-zytotoxischen T-Zellen in der NAWM des Subtyps III $(r=0,94)$.

\subsection{Korrelation der Axonparameter mit epidemiologischen Daten}

Die epidemiologischen Daten der Patienten sind im Anhang aufgeführt (Tabelle 6.16.5, Seite 59 bis 62). Im Folgenden werden epidemiologische Daten mit der axonalen Schädigung korreliert.

\subsubsection{Mediane Krankheitsdauer vor Biopsieentnahme}

Vergleicht man die mediane Krankheitsdauer (Intervall zwischen Beginn der allerersten klinischen Symptomatik und Biopsieentnahme), so zeigen sich keine signifikanten Unterschiede zwischen den einzelnen Immunsubtypen. Subtyp III zeigt das kürzeste Intervall (Median von 0,9 Monaten). Subtyp II weist mit einer medianen Krankheitsdauer von 5,04 Monaten das längste Intervall auf und Subtyp I liegt mit 1,56 Monaten zwischen diesen Werten. Subtyp II weist zwei Werte mit einem Zeitraum von einigen Jahren auf. So erklärt sich der relativ hohe Medianwert.

Eine Korrelation zwischen der Krankheitsdauer und der axonalen Dichte oder der akuten axonalen Schädigung kann nicht nachgewiesen werden.

Ferner haben wir die Dauer von Beginn der Symptomatik der Läsion, die zur Biopsie führte bis zum Biopsiezeitpunkt mit der axonalen Schädigung korreliert. Bei vorangegangenen Schüben weicht diese Dauer von der zuvor betrachteten medianen Krankheitsdauer ab. Es zeigen sich mediane Zeitintervalle von 0,76 Monaten beim Subtyp I, 1,08 Monaten beim Subtyp II und 0,9 Monaten beim Subtyp III (vgl. Tabelle 6.2, Seite 61). Die Unterschiede zwischen den einzelnen Subtypen sind jedoch nicht signifikant.

Eine Korrelation zwischen der Dauer der ersten Symptome der biopsierten Läsion bis zum Biopsiezeitpunkt und der axonalen Dichte oder der akuten axonalen Schädigung kann nicht nachgewiesen werden (vgl. Tabelle 6.3, Seite 61). 


\subsubsection{Geschlechterverteilung}

Die Geschlechterverteilung der einzelnen MS-Subtypen kann aus Tabelle 6.4 (Seite 62) im Anhang entnommen werden. Ausgewertet wurden zuerst alle Fälle, unabhängig der Läsionsaktivität (NAWM und früh aktive Läsionen zusammengefasst). Die normal erscheinende weiße Substanz sowie die früh aktiven Läsionen wurden anschließend getrennt betrachtet und zuletzt wurden die jeweiligen Immunsubtypen einzeln ausgewertet. Zwischen den Geschlechtern konnten in der vorliegenden Untersuchung keine signifikanten Unterschiede hinsichtlich der axonalen Dichte und des akuten axonalen Schadens nachgewiesen werden.

\subsubsection{Alter zum Zeitpunkt der Biopsie}

Das Alter zum Zeitpunkt der Biopsie kann Tabelle 6.5 (Seite 62) entnommen werden. Subtyp I weist ein medianes Alter von 33 Jahren, Subtyp II von 36 Jahren und Subtyp III von 44 Jahren auf. Obwohl das mediane Alter beim Subtyp III deutlich höher erscheint, findet sich rechnerisch kein signifikanter Unterschied bei Vergleich der Immunsubtypen. Signifikante Korrelationen des Alters mit der axonalen Dichte können nicht nachgewiesen werden. Ein signifikanter Zusammenhang zwischen dem Alter zum Biopsiezeitpunkt und dem akuten axonalen Schaden in früh aktiven Läsionen zeigt sich bei Immunsubtyp III ( $n=8 ; p=0,0218 ; r=-0,8095)$. Das bedeutet: je jünger der Patient zum Biopsiezeitpunkt, desto höher die Anzahl der APP-positiven Sphäroide und somit der akute axonale Schaden. Die geringe Anzahl an Fällen ist jedoch zu beachten. Bei Subtyp I und II sind in der vorliegenden Untersuchung keine signifikanten Unterschiede nachweisbar.

\subsubsection{Klinische Verlaufsformen}

Bei einem Vergleich der klinischen Verlaufsformen „klinisch isoliertes Syndrom (CIS)“, "schubförmig-remittierender Verlauf (RR)" und "sekundär chronisch progredienter Verlauf (SPMS)“ hinsichtlich der axonalen Schädigung zeigt sich ein signifikanter Unterschied zwischen dem CIS und der RRMS: Es finden sich signifikant mehr APP-positive Sphäroide bei Patienten mit einem CIS bei Analyse der früh aktiven Läsionen ( $p=0,015)$.

Die unterschiedliche Häufigkeit der klinischen Verlaufsformen zum Zeitpunkt der Biopsie bei den einzelnen Immunsubtypen ist zu beachten (siehe Tabelle 6.6, Seite 
62): Beim Immunsubtyp I finden sich in $55 \%$, beim Subtyp II in $11 \%$ und beim Subtyp III in 70 \% Patienten mit einem klinisch isolierten Syndrom.

\subsubsection{Vorangehende Hochdosis-Kortison-Therapie}

Hinsichtlich der akuten axonalen Schädigung oder der axonalen Dichte zeigt sich bei den hier untersuchten Präparaten kein signifikanter Unterschied bei Vergleich der Patienten mit und ohne Hochdosis-Kortisontherapie im Vorfeld der Biopsie. 


\section{DISKUSSION}

\subsection{Axonpathologie in MS-Subtypen}

Die Multiple Sklerose zeigt sich hinsichtlich ihres klinischen Verlaufes, der Bildgebung und des Therapieansprechens heterogen. Sie wird daher auch als die „Erkrankung mit tausend Gesichtern“ bezeichnet.

Auch histologisch lassen sich Unterschiede der Läsionen erkennen. Während die Unterschiede hinsichtlich des akuten axonalen Schadens und der axonalen Dichte zwischen früh aktiven Läsionen und der normal erscheinenden weißen Substanz bereits in mehreren Studien beschrieben wurden, werden hier die Unterschiede zwischen den genannten Subtypen beleuchtet.

Lucchinetti et al. beschrieben im Jahr 2000 unterschiedliche Muster der entzündlichen Entmarkung und teilten die früh aktiv entmarkenden MS-Läsionen mittels der in 1.1.5.2 (Seite 7) beschriebenen Methodik in vier unterschiedliche so genannte Immunsubtypen ein, welche auf eine unterschiedliche Immunpathogenese hindeuten (Lucchinetti et al. 2000). Bei den Subtypen I und II stehen hierbei entzündliche und beim Subtyp III und IV degenerative Aspekte im Vordergrund (vgl. 1.1.5.2, Seite 7).

Die interindividelle Heterogenität der MS-Läsionen wirft die Frage auf, ob

a) die axonale Schädigung durch unterschiedliche pathogenetische Mechanismen verursacht wird und somit in den Immunsubtypen ein unterschiedliches Ausmaß aufweist oder

b) die axonale Schädigung als Sekundärfolge einer entzündlichen Entmarkung in allen Subtypen vergleichbar ist.

Bei der histologischen Untersuchung der MS-Biopsien hinsichtlich der axonalen Dichte und des akuten axonalen Schadens zeigen sich folgende Ergebnisse, die im Anschluss diskutiert werden:

a) Axonale Dichte:

In der normal erscheinenden weißen Substanz zeigt sich zwischen den einzelnen Subtypen kein signifikanter Unterschied hinsichtlich der axonalen Dichte. Allerdings findet sich im Median beim Immunsubtyp II eine geringere axonale Dichte gegenüber dem Immunsubtyp I und III, bei jedoch deutlich 
variierenden Werten zwischen einzelnen Patienten auch eines Immunsubtyps (vgl. 3.3, Seite 29).

In den früh aktiven Läsionen zeigt sich hinsichtlich der axonalen Dichte ebenfalls kein signifikanter Unterschied. Eine große Spannweite innerhalb der einzelnen Subtypen ist auch hier zu erkennen.

b) Akuter axonaler Schaden:

In der normal erscheinenden weißen Substanz zeigen sich ebenfalls akut geschädigte Axone. Signifikante Unterschiede finden sich zwischen den einzelnen Immunsubtypen nicht.

In den früh aktiven Läsionen zeigt sich ein signifikanter Unterschied zwischen Subtyp I und II: Subtyp I zeigt signifikant mehr akut geschädigte Axone. Zwischen den anderen Subtypen lässt sich kein signifikanter Unterschied nachweisen.

Die vorliegende Studie diskutiert die axonale Schädigung im Vergleich der Immunsubtypen. Zunächst wird die normal erscheinende weiße Substanz (4.2) abgehandelt. Anschließend wird auf die Läsionsareale eingegangen (4.3).

\subsection{Axonale Schädigung der normal erscheinenden weißen Substanz}

Zeis et al. konnten zeigen, dass in der normal erscheinenden weißen Substanz von an MS erkrankten Patienten eine erhöhte Expression von zellschädigenden Genen stattfindet (Zeis et al. 2008). Laut dieser Studie werden aber ebenfalls neuroprotektive Gene vermehrt exprimiert.

\subsubsection{Axonale Dichte}

Kutzelnigg et al. beschrieben eine axonale Schädigung in der normal erscheinenden weißen Substanz, insbesondere bei Patienten mit einem chronischen Krankheitsverlauf und führten dies auf diffus entzündliche Prozesse zurück (Kutzelnigg et al. 2005). Bildgebend zeigen sich ebenfalls Hinweise auf einen axonalen Schaden in der normal erscheinenden weißen Substanz: Andrade et al. konnten in einer Studie bei MS-Patienten im Vergleich mit einer Kontrollgruppe mittels diffusionsgewichteter Magnetresonanztomografie einen axonalen Schaden 
auch in der normal erscheinenden weißen Substanz nachweisen (Andrade et al. 2007).

Hinsichtlich der axonalen Dichte in der normal erscheinenden weißen Substanz finden sich in dieser Studie zwischen den Immunsubtypen der MS keine signifikanten Unterschiede.

Da bei der Biopsie in der Regel nur kleine Gewebeproben entnommen werden, liegt die ausgewertete normal erscheinende weiße Substanz in der Nähe der entzündlichentmarkenden Läsionen. Unabhängig von den Immunsubtypen könnte somit die Läsionspathologie Einfluss auf die axonale Dichte und axonale Schädigung der normal erscheinenden weißen Substanz haben. Das Ausmaß der Waller'schen Degeneration in der NAWM korreliert mit dem Ausmaß der Schädigung innerhalb von Läsionen (Dziedzic et al. 2010). Ein Unterschied zwischen den Immunsubtypen konnte jedoch nicht nachgewiesen werden (Dziedzic et al. 2010). Vrenken konnte 2006 in einer Studie mittels T1 gewichteter MRT Bilder mit zunehmender Entfernung von der Läsion weniger pathologische Veränderungen in der normal erscheinenden weißen Substanz nachweisen (Vrenken et al. 2006).

Eine weitere Schwierigkeit der standardisierten Auswertung humaner Biopsien ist die unterschiedliche Biopsielokalisation. Unterschiedliche Hirnregionen weisen eine unterschiedliche Dichte der Axone auf. Die axonalen Dichten variieren aufgrund der unterschiedlichen Verläufe der Fasertrakte. In der Studie von Dziedzic et al. konnten jedoch keine signifikant unterschiedlichen Axondichten in unterschiedlichen Hirnregionen nachgewiesen werden (Dziedzic et al. 2010). Die Regionen der normal erscheinenden weißen Substanz konnten aufgrund der humanen und zu diagnostischen Zwecken entnommenen Biopsien nicht standardisiert werden. Die statistische Auswertung zeigt eine ausgeprägte Spannweite der ermittelten Werte, so dass nur sehr ausgeprägte Dichteänderungen zu einem signifikanten Unterschied führen würden.

Möglicherweise kommt es auch zu einer Verfälschung der Ergebnisse, da in den frühen Entmarkungsstadien der hier untersuchten Biopsien ein ausgeprägtes Ödem vorliegen kann. Dieses kann durch eine Distension der Axone eine stärkere axonale Reduktion vortäuschen als tatsächlich vorhanden ist. Da ein Ödem eher in Immunsubtyp I und II zu vermuten ist (Immunsubtyp mit ausgeprägterer Entzündung) und weniger in Immunsubtyp III (eher degenerative Aspekte), könnte ein 
ausgeprägterer axonaler Verlust im Immunsubtyp I und II vorgetäuscht werden. Es handelt sich hierbei allerdings um eine eher hypothetische Annahme, da das Ödem nicht quantitativ untersucht wurde. Subtyp I und II zeigen in der vorliegenden Studie eine geringere axonale Dichte in der NAWM als Subtyp III (vgl. 3.3, Seite 29).

Zusammenfassend finden sich keine signifikanten Unterschiede zwischen den Immunsubtypen hinsichtlich der axonalen Dichte in der NAWM. Es ist jedoch nicht auszuschließen, dass eventuelle Unterschiede durch oben genannte Gründe nicht erfasst wurden.

Bei den dieser Arbeit zugrunde liegenden Biopsien handelt es sich um sehr frühe Stadien der MS. Eventuelle Unterschiede der axonalen Dichte, die einen Verlust der Axone voraussetzen, machen sich möglicherweise erst zu späteren Zeitpunkten nach länger anhaltender Schädigung bemerkbar.

Es wurde daher zusätzlich die akute axonale Schädigung ausgewertet. Mittels des Markers APP wird eine axonale Transportstörung dieses Proteins nachgewiesen (vgl. 1.2.1.2, Seite 9 und 2.4.1, Seite 16). Hierbei handelt es sich um eine frühe axonale Schädigung, welche irreversibel oder auch reversibel sein kann.

\subsubsection{Akuter axonaler Schaden}

In den hier ausgewerteten Biopsien zeigt sich auch in der normal erscheinenden weißen Substanz eine - wenn auch im Vergleich zu den Läsionen geringere - akute axonale Schädigung (vgl. 3.4, Seite 34). Dies entspricht früheren Studien, die ebenfalls einen akuten axonalen Schaden in der normal erscheinenden weißen Substanz beschreiben (Kornek et al. 2000) (vgl. 1.2.2, Seite 9).

APP-positive Sphäroide finden sich in der vorliegenden Studie in allen Immunsubtypen in der NAWM. Im Vergleich zu den akuten Läsionen ist der axonale Schaden in der NAWM ca. 26-mal geringer. Findet jedoch über Jahre hinweg eine geringe akute axonale Schädigung statt, wie es bei einem chronischen MS-Verlauf anzunehmen ist, so ist eine Kumulation des axonalen Schadens zu vermuten, die letztendlich zu einem relevanten Axonverlust führt.

Bjartmar et al. zeigten, dass es auch ohne eine akute Schädigung von Myelin in der normal erscheinenden weißen Substanz zu einem akuten axonalen Schaden kommen kann (Bjartmar et al. 2001). Er führte dies auf eine Waller'sche 
Degeneration zurück und diskutiert, dass eine folgende langsame Demyelinisierung möglicherweise zu einer sekundären Entzündungsreaktion führt.

Unabhängig von der Läsionspathologie und einer Entmarkung könnten zudem Autoantikörper zu einer axonalen Schädigung in der NAWM führen. Mathey et al. konnten Antikörper, welche gegen Neurofascin gerichtet sind, im Serum von MSPatienten nachweisen. Neurofascin ist im Bereich der Ranvier'schen Schnürringe auf Axonen lokalisiert. Die Gabe von diesem Antikörper führte im Tiermodell zu einer axonalen Schädigung und klinischen Verschlechterung (Mathey et al. 2007).

Signifikante Unterschiede zwischen den einzelnen Immunsubtypen hinsichtlich der akuten axonalen Schädigung in der normal erscheinenden weißen Substanz konnten in dieser Studie nicht nachgewiesen werden. Immunsubtyp III weist hier tendenziell mehr akut geschädigte Axone auf. Eine signifikante Korrelation zeigt sich zwischen den CD8+-T-Zellen und den APP-positiven Sphäroiden in der normal erscheinenden weißen Substanz beim Subtyp III. Zytotoxische, CD8+-T-Zellen können in der Zellkultur zu einer Transsektion von Axonen führen (Neumann et al. 2002). Beim Immunsubtyp III kommt es zudem zu einer Oligodendrozytenapoptose in der normal erscheinenden weißen Substanz angrenzend zu der entmarkten Läsion. Hypothetisch könnte es hierdurch zu einer axonalen Störung durch fehlende trophische Unterstützung durch Oligodendrozyten kommen. Lassmann untersuchte die Immunpathogenese des Immunsubyps III (Lassmann 2003a). Es wurden ähnliche Gewebsveränderungen nachgewiesen, wie sie bei hypoxischen Schäden zu finden sind. Eine vermehrte Expression von HIF-1alpha (hypoxia inducible factor), einem Antigen, das als Marker für hypoxische Zellschäden angesehen werden kann, wurde nachgewiesen. Hypoxische Schäden können einerseits vaskulär bedingt und andererseits durch toxische Stoffwechselprodukte verursacht sein. Toxische Produkte führen vermutlich bei der MS zu einer hypoxischen Gewebeschädigung und auch axonalem Schaden (Lassmann 2003a).

Zusammenfassend lassen sich auch bei der Auswertung des akuten axonalen Schadens keine signifikanten Unterschiede zwischen den Immunsubtypen in der NAWM feststellen. 


\subsection{Axonale Schädigung innerhalb der Läsionen}

\subsubsection{Axonale Dichte}

In der vorliegenden Studie konnte eine signifikant reduzierte axonale Dichte in den Läsionen im Vergleich zu der umgebenden normal erscheinenden weißen Substanz gezeigt werden. Dies unterstreicht schon bekannte MRT- und histologische Studien, die eine Reduktion von Axonen in frühen Stadien der MS zeigen (u.a.: Andrade et al. 2007, De Stefano et al. 2001, Kuhlmann et al. 2002). Ein Teil der ermittelten Reduktion der axonalen Dichte in den Läsionen ist möglicherweise auf ein durch die Entzündung bedingtes Ödem zurück zu führen (vgl. 4.2.1, Seite 46).

In früh aktiv entmarkenden Läsionen führen in erster Linie entzündliche Prozesse zu einer Demyelinisierung und zu einer axonalen Schädigung. In späteren Stadien finden möglicherweise unabhängige neurodegenerative Prozesse statt (Zamvil und Steinman 2003). Jedoch lassen sich - trotz unterschiedlicher Zusammensetzung des Entzündungsinfiltrates, die im Folgenden dargestellt werden - zwischen den einzelnen Immunsubtypen in dieser Studie keine signifikanten Unterschiede in der axonalen Dichte nachweisen. Subtyp II weist lediglich mit einer axonalen Dichte von 49\% tendenziell geringere Axonwerte auf als die Subtypen I und III (je 54\%) (vgl. 3.3, Seite 29). Bei Korrelation der axonalen Dichte allgemein mit den Entzündungszellen von Fischer (Fischer 2007) konnte eine negative Korrelation der axonalen Dichte und der Makrophageninfiltration festgestellt werden. Interessanterweise zeigte sich nur im Subtyp II eine signifikante positive Korrelation bezüglich der KiM1P-positiven Makrophagen und der axonalen Dichte, so dass man hier für die Makrophagen eine axonprotektive oder ödemreduzierende Wirkung postulieren könnte. Die mögliche Rolle der Makrophagen wird im nächsten Kapitel erörtert. Ferner zeigte sich eine signifikante negative Korrelation zwischen der axonalen Dichte im Subtyp II und den $\mathrm{CD}^{+}-\mathrm{T}-Z e l l e n$. Je mehr CD3 ${ }^{+}$-T-Zellen vorhanden sind, desto geringer ist die axonale Dichte (vgl. 3.6.1.3, Seite 40). Bei Subtyp I und III konnten keine Signifikanzen zwischen der axonalen Dichte und den Entzündungszellen gefunden werden. Die relativ geringen Fallzahlen sind hier jedoch zu beachten.

Eine axonale Schädigung kann sich durch Transportstörungen äußern, die durch die APP-Färbung dargestellt werden können. Diese Schädigung ist potentiell reversibel. Ferner können dephosphorylierte, geschädigte Axone in MS-Läsionen nachgewiesen 
werden (Charles et al. 2002, Dziedzic et al. 2010). Eine irreversible Schädigung tritt mit der Durchtrennung von Axonen ein - es lassen sich in der Folge axonale Sphäroide anfärben. Die Durchtrennung von Axonen hat eine Waller'sche Degeneration zur Folge. Dies ist die Degeneration des distalen Nervenanteils. Dieser Prozess kann Monate bis Jahre dauern (Vargas und Barres 2007). Das „Endstadium“ der axonalen Schädigung ist letztendlich der axonale Verlust.

Dieser zeitliche Verlauf könnte begründen, warum in frühen MS-Stadien noch keine Unterschiede bezüglich der axonalen Dichte nachweisbar sind (vgl. 3.3, Seite 29). Ferner lässt sich so die fehlende Korrelation der akuten axonalen Schädigung und der axonalen Dichte in der vorliegenden Studie erklären. Es wäre daher sinnvoll, inaktive, ältere Läsionen hinsichtlich der axonalen Dichte zu untersuchen und hier die verschiedenen Immunsubtypen zu vergleichen. Allerdings stehen uns nur wenige Fälle mit sowohl früh aktiv entmarkenden als auch inaktiv entmarkenden Läsionen zur Verfügung, so dass diese Untersuchung derzeit nicht durchführbar ist.

\subsubsection{Akuter axonaler Schaden}

Ein akuter axonaler Schaden tritt bereits in frühen Stadien der MS-Erkrankung auf. Bei MS-Patienten mit einem schubförmigen Verlauf und einem sekundär chronisch progredientem Verlauf ist die akute axonale Schädigung zu Beginn der Erkrankung stärker ausgeprägt als im weiteren Verlauf (Kuhlmann et al. 2002).

In der vorliegenden Studie weist der Immunsubtyp I in den früh aktiven Läsionen signifikant mehr akut geschädigte Axone auf als Subtyp II (Median: 9060 Sphäroide pro $\mathrm{mm}^{2}$ versus: 4500 Sphäroide pro $\mathrm{mm}^{2}$ ). Die Anzahl der akut geschädigten Axone beim Immunsubtyp III liegt zwischen diesen Werten (Median: 7000 Sphäroide pro $\mathrm{mm}^{2}$ ) (vgl. 3.4, Seite 34).

Ob die akute axonale Schädigung jedoch letztendlich zu einer irreversiblen Axonschädigung führt, bleibt offen, da die mittels APP nachgewiesene Transportstörung theoretisch auch reversibel sein kann.

In Subtyp II lassen sich immunhistochemisch C9neo-positive Komplementablagerungen und lgG-Antikörper nachweisen. Dies legt eine Antikörper/Komplementvermittelte Entmarkung dar. Verschiedene Studien zeigten Ablagerungen von Komplement und Antikörpern in MS-Läsionen unabhängig von 
Immunsubtypen (Gay et al. 1997 und Storch et al. 1998) und postulierten eine Rolle für die Entmarkung. Vogt et al. wiesen mittels einer MRT Studie nach, dass antiMyelin Antikörper im Liquor mit der Läsionslast im MRT korrelieren (Vogt et al. 2008). Antikörper können auch gegen axonale Strukturen gerichtet sein. Bei MS-Patienten konnten im Liquor mehr IgG Antikörper gegen Neurofilamente nachgewiesen werden als in der Kontrollgruppe (Bartos et al. 2007). Weiterhin konnten bei MS-Patienten Antikörper gegen Neurofascin (NF186), einem neuronalem Protein, welches im Bereich der Ranvier'schen Schnürringe lokalisiert ist, nachgewiesen werden, die zu einer axonalen Schädigung führen können (Mathey et al. 2007). Antikörper könnten auch in den hier untersuchten Biopsien zu einer Schädigung der Axone beitragen.

Ferner zeigen sich In Subtyp I und II zahlreiche T-Zellen und Makrophagen, deren toxische Produkte, wie beispielsweise Tumornekrosefaktor-alpha, zu einer Gewebeschädigung führen können (Hofman et al. 1989 und Selmaj et al. 1991). Weiterhin könnte eine axonale Schädigung durch CD8+-T-Zellen bedingt sein (Neumann et al. 2002).

Fischer hat bei den hier untersuchten Fällen eine Charakterisierung des entzündlichen Infiltrates durchgeführt. Dazu hat sie die T-Zellen (CD3), die Subpopulation der zytotoxischen T-Zellen (CD8) sowie die Makrophagen/Mikrogliazellen (Ki-M1P) und früh aktivierten Makrophagen (MRP14) in den einzelnen Immunsubtypen ausgewertet. Signifikante Korrelationen zwischen der akuten axonalen Schädigung und den Entzündungszellen waren bei Betrachtung allein der früh aktiven Läsionen nicht nachweisbar. Allerdings sind es möglicherweise neben den schädigenden Einflüssen eines Entzündungsinfiltrates bei den hier untersuchten Fällen auch neuroprotektive Faktoren, die eine Rolle spielen.

Es ist daher bei einer geringeren akuten axonalen Schädigung beim Immunsubtyp II gegenüber Subtyp I auch eine neuroprotektive Wirkung des Entzündungsinfiltrates zu diskutieren (Lassmann et al. 2001). Einige Studien legen nahe, dass die Entzündung in den Läsionen auch schützende Faktoren enthält, die die Gewebeschädigung verhindern oder eine Reparation des zerstörten Gewebes begünstigen. Makrophagen können in Zellkulturen die Remyelinisierung fördern (Diemel et al. 1998) und somit zu einer Axonprotektion beitragen. Makrophagen 
fördern die Remyelinisierung z. B. durch Phagozytose (Clearence) von residuellen Myelinresten (Chen et al. 2000, McKerracher et al. 1994, Mukhopadhyay et al. 1994). Fischer (Fischer 2007) konnte signifikant mehr Makrophagen in Subtyp II gegenüber Subtyp I nachweisen. Möglicherweise übernehmen die Makrophagen in den hier vorliegenden Fällen eine protektive Rolle bezüglich der Axone.

Subtyp III unterscheidet sich neuropathologisch weitreichend von Subtyp I und II. Ein wichtiger Unterschied hinsichtlich der Entstehung der Demyelinisierung von Axonen ist beim Immunsubtyp III der Oligodendrozytenuntergang durch Apoptose (Lucchinetti et al. 2000). Im Immunsubtyp III zeigen sich in Fischers Doktorarbeit signifikant weniger MRP14-positive Makrophagen als in Immunsubtyp I und II. MRP14 ist ein Marker, der bei Entzündungen in frühen Stadien anzutreffen ist. MRP14-positive Makrophagen sind mit einem möglichen hämatogenen Ursprung assoziiert. Daher könnten die Ergebnisse von Fischer für eine vermehrte Makrophagenaktivierung hirneigener Makrophagen beim Immunsubtyp III sprechen (Fischer 2007).

Die akute axonale Schädigung ist beim Immunsubtyp I höher als bei den Immunsubtypen II und III. Möglicherweise spielen beim Immunsubtyp I CD4+-TZellen eine wichtige Rolle. Eine signifikante Korrelation des akuten axonalen Schadens, d.h. der APP-positiven Sphäroide, mit der Gesamtpopulation der T-Zellen bei Betrachtung der früh aktiven Läsionen (vgl. 3.6.2.3, Seite 41) ließ sich jedoch nicht nachweisen. CD4+-T-Zellen wurden nicht getrennt ausgewertet, da die immunhistochemische Färbung am Paraffinmaterial nicht zuverlässig gelingt. Es sind die geringen Fallzahlen zu beachten, die eine mögliche Korrelation nicht darlegen.

CD4+-T-Zellen werden seit Anfang der 1990er Jahre als Haupteffektorzellen bei der MS angesehen (Zamvil und Steinman 1990). Die experimentelle autoimmune Enzephalomyelitis (EAE) ist ein Tiermodell der MS. Hierbei werden durch die Injektion unterschiedlicher Proteine in Labortiere MS-ähnliche Autoimmunprozesse ausgelöst. Durch einen Transfer von myelinspezifischen CD4+-T-Zellen kann jedoch ebenfalls eine EAE ausgelöst werden, wodurch die pathogene Rolle der CD4+-TZellen deutlich wird (Zamvil und Steinman 1990). Sonobe et al. wiesen in einer Studie am EAE-Modell bei Mäusen nach, dass CD4+-T-Zellen IFN- $\gamma$, TNF- $\alpha$ und 
auch Interleukin-17 produzieren (Sonobe et al. 2007). Interleukin-17 ist ein bedeutender Faktor in der Entstehung der EAE (Sonobe et al. 2007). Lassmann et al. wiesen histopathologische Ähnlichkeiten der mittels CD4+-T-Zellen ausgelösten EAE und den Subtypen I und II nach (Lassmann et al. 2001). In Untersuchungen von MS-Autopsien konnte ein Zusammenhang zwischen CD4+-T-Zellen sowie einer axonalen Schädigung gezeigt werden (Skundric et al. 2006). Das entzündliche Milieu mit der Expression von Zytokinen und Chemokinen durch CD4+-T-Zellen mit Aktivierung von Makrophagen bedingt möglicherweise die axonale Schädigung in Patienten mit einem Subtyp I.

Bei Korrelation der epidemiologischen Daten über mediane Krankheitsdauer vor Biopsie, Geschlecht, Alter zum Zeitpunkt der Biopsie oder eine der Biopsie vorangehende Hochdosis-Kortisontherapie mit der axonalen Schädigung oder axonalen Dichte lassen sich keine Zusammenhänge nachweisen (Ausnahme: Ein signifikanter Zusammenhang zwischen dem Alter zum Biopsiezeitpunkt und dem akuten axonalen Schaden in früh aktiven Läsionen zeigt sich bei Immunsubtyp III, wobei jüngere Patienten eine ausgeprägtere akute axonale Schädigung aufweisen). Vergleicht man jedoch die akute axonale Schädigung bei den verschiedenen Verlaufsformen der MS, so zeigt sich eine signifikant erhöhte Anzahl an APPpositiven Sphäroiden bei Patienten mit einem klinisch isolierten Syndrom (CIS) gegenüber Patienten mit einem schubförmigen Krankheitsverlauf (RRMS) (vgl. 3.7.4, Seite 43). Zudem finden sich beim Subtyp I der hier untersuchten Fälle mehr CISVerläufe als beim Subtyp II. Es besteht somit die Möglichkeit, dass die ausgeprägtere akute axonale Schädigung beim Immunsubtyp I durch eine höhere Patientenanzahl mit CIS-Verläufen (mit)bedingt ist. Für einen Vergleich der einzelnen Verlaufsformen bei einzelnen Subtypen sind die vorhandenen Fallzahlen zu gering. In vorangehenden Studien wurde übereinstimmend gezeigt, dass der mittels APP bestimmte akute axonale Schaden in den frühen Krankheitsphasen am ausgeprägtesten ist (Kuhlmann et al. 2002). Die mittlere Krankheitsdauer vor der Biopsie zeigte in hiesiger Studie jedoch keine signifikanten Unterschiede.

\subsection{Fazit}

Die vorliegende Arbeit gibt Hinweise auf eine interindividuelle Heterogenität (vgl. 4.1, Seite 45) der axonalen Schädigung bei der MS in Abhängigkeit von den 
Immunsubtypen. Es zeigen sich signifikante Unterschiede hinsichtlich der akuten axonalen Schädigung zwischen Subtyp I und II. Möglicherweise spielt beim Immunsubtyp I eine T-Zell-vermittelte Axonschädigung eine Rolle. Beim Subtyp II sind vermehrt Makrophagen nachzuweisen (Fischer 2007), die in vorliegender Studie mit der axonalen Dichte korrelieren und die eine axonprotektive Rolle spielen könnten.

Jedoch ist eine Beeinflussung der Ergebnisse durch eine höhere Anzahl von Patienten mit einem klinisch isolierten Syndrom (CIS) beim Immunsubtyp I möglich. Patienten mit einem CIS, welches frühe Krankheitsstadien darstellt, zeigen eine ausgeprägtere axonale Schädigung. Eine gemeinsame Endstrecke der axonalen Schädigung, welche bei den Immunsubtypen gleich verläuft, ist somit nicht auszuschließen. 


\section{ZUSAMMENFASSUNG}

Die Multiple Sklerose ist eine entzündlich-entmarkende Erkrankung des zentralen Nervensystems, bei der es auch zu einer axonalen Schädigung kommt. Die Bedeutung der axonalen Schädigung liegt in der Korrelation mit der klinischen Behinderung der MS-Patienten (vgl. 1.2, Seite 8 und 1.2.3, Seite 11).

Sowohl klinisch als auch histologisch zeigt sich die Multiple Sklerose heterogen. Lucchinetti et al. teilten die MS-Läsionen aufgrund histopathologischer Unterschiede in vier unterschiedliche, so genannte Immunsubtypen ein, welche auf eine unterschiedliche Immunpathogenese hindeuten (Lucchinetti et al. 2000).

Aufgrund dieser Erkenntnisse widmet sich die vorliegende Arbeit dem akuten axonalen Schaden und der axonalen Dichte in MS-Läsionen und in der umgebenden weißen Substanz unter Berücksichtigung unterschiedlicher MS-Subtypen. 55 Biopsien von MS-Patienten wurden untersucht. Die Biopsien wurden zu diagnostischen Zwecken (z.B. Ausschluss eines Tumors) entnommen und repräsentieren ein frühes Krankheitsstadium. Es erfolgt eine Korrelation mit dem Entzündungsinfiltrat und den epidemiologischen Daten.

Ziel der vorliegenden Arbeit ist es, zu untersuchen, ob die axonale Schädigung durch unterschiedliche pathogenetische Mechanismen verursacht wird und in den Immunsubtypen ein unterschiedliches Ausmaß aufweist oder ob die axonale Schädigung als Sekundärfolge der entzündlichen Entmarkung in allen Subtypen vergleichbar ist.

Bei der Untersuchung der normal erscheinenden weißen Substanz lassen sich keine signifikanten Unterschiede hinsichtlich der akuten axonalen Schädigung oder der axonalen Dichte bei Vergleich der Immunsubtypen nachweisen. Die Analyse der relativen axonalen Dichte der früh aktiv entmarkenden Läsionen lässt ebenfalls keine Unterschiede zwischen den Immunsubtypen erkennen. Es zeigt sich jedoch eine signifikant höhere akute axonale Schädigung beim Immunsubtyp I gegenüber Subtyp II. Möglicherweise spielt beim Immunsubtyp I eine T-Zell-vermittelte Axonschädigung ein Rolle, jedoch ließen sich keine signifikanten Korrelationen mit dem T-Zellinfiltrat bei den relativ kleinen Fallzahlen nachweisen. Möglicherweise sind ebenfalls 
neuroprotektive Entzündungszellen für das Ausmaß der axonalen Schädigung von Relevanz.

Die vorliegende Arbeit gibt somit Hinweise auf eine interindividuelle Heterogenität der axonalen Schädigung in Abhängigkeit von den Immunsubtypen der MS. Jedoch ist eine Beeinflussung der Ergebnisse durch eine höhere Anzahl von Patienten mit einem klinisch isolierten Syndrom (CIS) beim Immunsubtyp I möglich. Patienten mit einem CIS, welches frühe Krankheitsstadien darstellt, lassen eine ausgeprägtere akute axonale Schädigung erkennen. Eine gemeinsame Endstrecke der axonalen Schädigung, welche bei den Immunsubtypen gleich verläuft, ist somit nicht auszuschließen.

Es bedarf weiterer Analysen a) zur Untermauerung der vermehrten Axonschädigung im Immunsubtyp I gegenüber II und b) der Pathogenese der Axonschädigung. Eine möglicherweise subtypenspezifische - Therapie zur Verminderung des axonalen Schadens sollte das Ziel therapeutischer Bemühungen sein. 


\section{ANHANG}

\subsection{Abkürzungsverzeichnis}

APP: Amyloid-Precursor-Protein

CIS: clinically isolated syndrome

CNP: Zyklische Nukleotid-Phosphodiesterase

CT: Computertomographie

DM: Demyelinisierung

EA: early active (früh aktiv)

EBV: Epstein-Barr-Virus

EDSS: Expanded Disability Status Scale

HE: Hämatoxilin-Eosin

HLA: Humanes Leukozyten Antigen

IgG: Immunglobulin G

KiM1P: pan macrophage stain

KiM1P-MiP: pan macrophage stain microglial phenotype

LA: late active (spät aktiv)

LFB-PAS: Luxol-Fast-Blue-Period-Schiffsäure

MAG: Myelin-assoziiertes Glykoprotein

MBP: Myelin-basisches Protein

MOG: Myelin-Oligodendrozyten-Glykoprotein

MRP14: myeloid-related protein 14

MRT: Magnetresonanztomographie

MS: Multiple Sklerose

NAA: N-Acetyl-Aspartat

NAWM: normal appearing white matter (normal erscheinende weiße Substanz)

NO: Stickstoffmonoxid

PBS: phosphat buffered saline

PLP: Proteolipoprotein

PPMS: primary progressive multiple sclerosis

RRMS: relapsing remitting multiple sclerosis

SMI-32: neurofilament $\mathrm{h}$ non-phosphorylated monoclonal antibody

SPMS: secondary progressiv multiple sclerosis

VEP: visuell evozierte Potentiale 


\subsection{Tabellen $6.1-6.7$}

Tabelle 6.1: Epidemiologische Daten der Immunsubtypen I-III

\begin{tabular}{|c|c|c|c|c|c|c|}
\hline Subtyp & FallNr. & Geschlecht & $\begin{array}{c}\text { Alter bei } \\
\text { Bx } \\
\text { (Jahre) }\end{array}$ & $\begin{array}{c}\text { Krankheits- } \\
\text { dauer vor } \\
\text { Bx }\end{array}$ & $\begin{array}{c}\text { Klinischer } \\
\text { Verlauf } \\
\text { bei Bx } \\
\text { (FU) }\end{array}$ & $\begin{array}{l}\text { Hochdosis- } \\
\text { Kortisonthe } \\
\text { rapie prä- } \\
\text { OP }\end{array}$ \\
\hline I & 1 & männlich & 20 & $\begin{array}{c}11 / 2 \\
\text { Monate }\end{array}$ & CIS & k. A. \\
\hline I & 2 & männlich & 30 & 30 Tage & CIS & nein \\
\hline I & 3 & weiblich & 22 & 3 Monate & $\mathrm{RR}(\mathrm{SP})$ & k. A. \\
\hline I & 4 & weiblich & 33 & $\begin{array}{c}\text { wenige } \\
\text { Tage }\end{array}$ & CIS & k. A. \\
\hline I & 5 & weiblich & 30 & ca. 30 Tage & $\mathrm{RR}$ & ja \\
\hline I & 6 & männlich & 33 & 9 Tage & CIS & ja \\
\hline I & 8 & männlich & 40 & 3 Monate & CIS & nein \\
\hline I & 9 & weiblich & 44 & 10-14 Tage & $\mathrm{RR}$ & ja \\
\hline I & 10 & weiblich & 42 & 6 Wochen & $\mathrm{RR}$ & ja \\
\hline I & 11 & männlich & 33 & 3 Wochen & CIS & k. A. \\
\hline II & 1 & weiblich & 36 & 2 Wochen & $\mathrm{RR}(\mathrm{SP})$ & k. A. \\
\hline II & 2 & weiblich & 35 & k. A. & $\mathrm{RR}$ & k. A. \\
\hline II & 3 & weiblich & 42 & k. A. & SP & k. A. \\
\hline II & 4 & weiblich & 48 & 6 Tage & $\mathrm{RR}$ & ja \\
\hline II & 5 & weiblich & 43 & k. A. & $\mathrm{RR}$ & k. A. \\
\hline
\end{tabular}




\begin{tabular}{|c|c|c|c|c|c|c|}
\hline II & 6 & weiblich & 44 & 12 Jahre & k.A. & ja \\
\hline II & 7 & weiblich & 26 & k. A. & $\mathrm{RR}$ & k. A. \\
\hline II & 8 & weiblich & 25 & k. A. & $\mathrm{RR}$ & k. A. \\
\hline II & 9 & männlich & 24 & k. A. & $\mathrm{RR}(\mathrm{SP})$ & nein \\
\hline II & 10 & weiblich & 31 & 3 Monate & $\mathrm{RR}(\mathrm{SP})$ & nein \\
\hline II & 11 & weiblich & 22 & 18 Tage & $\mathrm{RR}$ & ja \\
\hline II & 12 & weiblich & 50 & $\begin{array}{c}2 \text { Jahre } 7 \\
\text { Monate }\end{array}$ & $\mathrm{RR}(\mathrm{SP})$ & ja \\
\hline II & 13 & männlich & 37 & 1 Jahr & $\mathrm{RR}(\mathrm{SP})$ & ja \\
\hline II & 14 & weiblich & 29 & k. A. & SP & k. A. \\
\hline II & 15 & weiblich & 54 & 8 Monate & $\mathrm{RR}$ & ja \\
\hline II & 16 & männlich & 36 & k. A. & CIS & k. A. \\
\hline II & 17 & weiblich & 27 & k. A. & $\mathrm{RR}(\mathrm{SP})$ & k. A. \\
\hline II & 18 & männlich & 34 & k. A. & CIS & k. A. \\
\hline III & 1 & weiblich & 41 & $\begin{array}{c}11 / 2 \\
\text { Monate }\end{array}$ & SP & ja \\
\hline III & 2 & weiblich & 31 & 2 Wochen & CIS & ja \\
\hline III & 3 & weiblich & 61 & 7 Tage & CIS & ja \\
\hline III & 4 & weiblich & 58 & 2 Wochen & $\mathrm{RR}$ & ja \\
\hline III & 5 & weiblich & 65 & 3 Monate & CIS & ja \\
\hline
\end{tabular}




\begin{tabular}{|c|c|c|c|c|c|c|}
\hline III & 6 & männlich & 51 & $\begin{array}{c}\text { wenige } \\
\text { Wochen }\end{array}$ & RR & k. A. \\
\hline III & 7 & männlich & 36 & 3 Wochen & CIS & nein \\
\hline III & 8 & männlich & 26 & 2 Wochen & CIS & k. A. \\
\hline III & 9 & weiblich & 47 & $\begin{array}{c}21 / 2 \\
\text { Monate }\end{array}$ & CIS & k. A. \\
\hline III & 10 & männlich & 39 & 13 Tage & CIS & ja \\
\hline
\end{tabular}

$B x=$ Biopsie-Zeitpunkt, $F U=$ Follow-up, $k . A .=$ keine Angaben $; C I S=$ Klinisch isoliertes Syndrom, $R R=$ Schubförmiger Krankheitsverlauf; $S P=$ Sekundär chronisch progredienter Krankheitsverlauf

Tabelle 6.2 Dauer der ersten Symptome der biopsierten Läsion bis zum Biopsiezeitpunkt

\begin{tabular}{|l|l|l|l|}
\hline \multicolumn{1}{|c|}{ Subtyp I } & \multicolumn{1}{|c|}{ Subtyp II } & \multicolumn{1}{c|}{ Subtyp III } \\
\hline $\begin{array}{l}\text { Dauer der ersten } \\
\text { Symptome bis }\end{array}$ & 0,76 Monate & 1,08 Monate & 0,90 Monate \\
zum & & & \\
Biopsiezeitpunkt & & & \\
\hline
\end{tabular}

Tabelle 6.3 Korrelationen zwischen Dauer der ersten Symptome bis zum Biopsiezeitpunkt und der axonalen Dichte (Biel) sowie des akuten axonalen Schadens (APP) in den Läsionen (EA) und in der normal erscheinenden weißen Substanz (NAWM)

\begin{tabular}{|c|c|c|c|}
\hline & Subtyp I & Subtyp II & Subtyp III \\
\hline Biel/EA & $\mathrm{n}=9$ & $n=16$ & $\mathrm{n}=9$ \\
\hline APP/EA & $\mathrm{n}=11$ & $\mathrm{n}=11$ & $\mathrm{n}=8$ \\
\hline Biel/NAWM & $n=6$ & $n=7$ & $n=8$ \\
\hline APP/NAWM & $n=5$ & $n=6$ & $n=7$ \\
\hline
\end{tabular}

Sind keine signifikanten Korrelationen vorhanden, wird nur die Fallzahl genannt. $r=$ Spearman Korrelationskoeffizient 
Tabelle 6.4 Geschlechterverteilung der MS-Subtypen

\begin{tabular}{|c|c|c|c|c|}
\hline Geschlecht & Subtyp I & Subtyp II & Subtyp III & gesamt \\
\hline weiblich & $6(55 \%)$ & $14(78 \%)$ & $6(60 \%)$ & $26(67 \%)$ \\
\hline männlich & $5(45 \%)$ & $4(22 \%)$ & $4(40 \%)$ & $13(33 \%)$ \\
\hline
\end{tabular}

Angegeben sind die Anzahl der Patienten sowie deren Prozentanteil.

Tabelle 6.5 Medianes Alter (in Jahren) zum Zeitpunkt der Biopsie unter Berücksichtigung der einzelnen Subtypen und des Geschlechtes

\begin{tabular}{|c|c|c|c|c|}
\hline $\begin{array}{c}\text { Altern in } \\
\text { Jahren }\end{array}$ & Subtyp I & Subtyp II & Subtyp III & gesamt \\
\hline weiblich & 31,5 & 36 & 52,5 & 41 \\
\hline männlich & 33 & 36 & 37,5 & 34 \\
\hline gesamt & 33 & 36 & 44 & 36 \\
\hline
\end{tabular}

Tabelle 6.6: Anzahl der MS-Biopsien unterteilt nach klinischer Verlaufsformen zum Zeitpunkt der Biopsie unter Berücksichtigung der Subtypen I-III

\begin{tabular}{|c|c|c|c|c|}
\hline MS-Verlauf & Subtyp I & Subtyp II & Subtyp III & gesamt \\
\hline CIS & $6(55 \%)$ & $2(11 \%)$ & $7(70 \%)$ & 15 \\
\hline RRMS & $3(27 \%)$ & $13(72 \%)$ & $2(20 \%)$ & 18 \\
\hline SPMS & 0 & $3(17 \%)$ & $1(10 \%)$ & 4 \\
\hline k. A. & $2(18 \%)$ & 0 & 0 & 2 \\
\hline
\end{tabular}

Angabe: Anzahl der Patienten(Prozent) bezogen auf den jeweiligen Subtyp. $C I S=$ clinical isolated syndrome (klinisch isoliertes Syndrom); RRMS = schubförmigremittierende Multiple Sklerose, SPMS = sekundär progrediente Multiple Sklerose. 
Tabelle 6.7: Korrelationen zwischen axonalem Schaden und Entzündungszellen

\begin{tabular}{|c|c|c|c|c|c|}
\hline & CD3 & CD8 & MRP14 & KiM1P & $\begin{array}{c}\text { KiM1P- } \\
\text { MiP }\end{array}$ \\
\hline \multicolumn{6}{|l|}{ Subtyp I-III } \\
\hline $\begin{array}{c}\text { APP } \\
\text { EA+NAWM }\end{array}$ & $\begin{array}{c}n=42 \\
p<0,0001 \\
r=0,6148\end{array}$ & $\begin{array}{c}n=42 \\
p=0,0001 \\
r=0,5552\end{array}$ & $n=28$ & $\begin{array}{c}n=44 \\
p<0,0001 \\
r=0,6515\end{array}$ & $\begin{array}{c}n=42 \\
p=0,0004 \\
r=-0,5180\end{array}$ \\
\hline $\begin{array}{c}\text { Biel } \\
\text { EA+NAWM }\end{array}$ & $\begin{array}{c}n=49 ; \\
p<0,0001 ; \\
r=-0,5318\end{array}$ & $\begin{array}{c}n=49 \\
p=0,0005 \\
r=-0,4760\end{array}$ & $n=34$ & $\begin{array}{c}n=50 ; \\
p=0,0005 ; \\
r=-0,4728\end{array}$ & $\begin{array}{c}n=48 ; \\
p=0,0001 ; \\
r=0,5252\end{array}$ \\
\hline APP/EA & $n=26$ & $n=26$ & $n=28$ & $n=29$ & $\mathrm{n}=27$ \\
\hline $\begin{array}{c}\text { APP } \\
\text { /NAWM }\end{array}$ & $\begin{array}{c}n=16 \\
p=0,0183 ; \\
\text { Spearman } \\
r=0,5808\end{array}$ & $n=16$ & $n=0$ & $n=15$ & $n=15$ \\
\hline Biel/EA & $n=32$ & $n=32$ & $n=34$ & $n=35$ & $n=33$ \\
\hline Biel/NAWM & $n=17$ & $n=17$ & $n=0$ & $\mathrm{n}=15$ & $n=15$ \\
\hline \multicolumn{6}{|l|}{ Subtyp I } \\
\hline APP/EA & $\mathrm{n}=8$ & $\mathrm{n}=8$ & $n=8$ & $n=8$ & $n=8$ \\
\hline $\begin{array}{c}\text { APP } \\
\text { /NAWM }\end{array}$ & $n=5$ & $\mathrm{n}=5$ & $\mathrm{n}=0$; & $n=4$ & $n=4$ \\
\hline $\mathrm{Biel} / \mathrm{EA}$ & $\mathrm{n}=8$ & $n=8$ & $n=9$ & $n=9$; & $n=9$ \\
\hline Biel/NAWM & $n=5$ & $\mathrm{n}=5$ & $n=0$; & $n=4$ & $n=4$ \\
\hline & & & & & \\
\hline
\end{tabular}




\begin{tabular}{|c|c|c|c|c|c|}
\hline & CD3 & CD8 & MRP14 & KiM1P & $\begin{array}{c}\text { KiM1P- } \\
\text { MiP }\end{array}$ \\
\hline \multicolumn{6}{|l|}{ Subtyp II } \\
\hline APP/EA & $\mathrm{n}=11$ & $\mathrm{n}=11$ & $n=13$ & $n=14$ & $n=12$ \\
\hline $\begin{array}{c}\text { APP } \\
\text { /NAWM }\end{array}$ & $n=5$ & $n=5$ & $\mathrm{n}=0$ & $n=5$ & $n=5$ \\
\hline Biel/EA & $\begin{array}{c}n=16 ; \\
p=0,0237 \\
r=-0,5611\end{array}$ & $n=16$ & $n=16$ & $\begin{array}{c}n=17 \\
p=0,0024 \\
r=0,6843\end{array}$ & $n=15$ \\
\hline Biel/NAWM & $n=5$ & $n=5$ & $\mathrm{n}=0$ & $\mathrm{n}=5$ & $\mathrm{n}=5$ \\
\hline \multicolumn{6}{|l|}{ Subtyp III } \\
\hline APP/EA & $n=7$ & $\mathrm{n}=7$ & $\mathrm{n}=7$ & $n=7$ & $\mathrm{n}=7$ \\
\hline $\begin{array}{c}\text { APP } \\
\text { /NAWM }\end{array}$ & $n=6$ & $\begin{array}{c}n=6 ; \\
p=0,0167, \\
r=0,9429\end{array}$ & $\mathrm{n}=0$ & $n=6$ & $n=6$ \\
\hline Biel/EA & $n=8$ & $\mathrm{n}=8$ & $\mathrm{n}=8$ & $n=8$ & $n=8$ \\
\hline Biel/NAWM & $\mathrm{n}=6$; & $\mathrm{n}=6$ & $\mathrm{n}=0$ & $\mathrm{n}=6$ & $\mathrm{n}=6$ \\
\hline
\end{tabular}

Sind keine signifikanten Korrelationen vorhanden, wird nur die Fallzahl genannt. $r=$ Spearman Korrelationskoeffizient 


\section{LITERATURVERZEICHNIS}

Aboul-Enein F, Weiser P, Höftberger R, Lassmann H, Bradl M (2006): Transient axonal injury in the absence of demyelination: a correlate of clinical disease in acute experimental autoimmune encephalomyelitis. Acta Neuropathol 111, 539547

Andrade RE, Gasparetto EL, Cruz LCJr, Ferreira FB, Domingues RC, Marchiori E, Domingues RC (2007): Evaluation of white matter in patients with multiple sclerosis through diffusion tensor magnetic resonance imaging. Arq Neuropsiquiatr $\underline{65(3 A)}, 561-564$

Anthony DC, Miller KM, Fearn S, Townsend MJ, Opdenakker G, Wells GM, Clements JM, Chandler S, Gearing AJ, Perry VH (1998): Matrix metalloproteinase expression in an experimentally-induced DTH model of multiple sclerosis in the rat CNS. J Neuroimmunol $\underline{\text { 87(1-2), }}$ 62-72

Archelos JJ, Hartung HP (2000): Pathogenetic role of autoantibodies in neurological diseases. Trends Neurosci 23(7), 317-327

Barnett MH, Prineas JW (2004): Relapsing and remitting multiple sclerosis: Pathology of the newly forming lesion. Ann Neurol $\underline{55}, 458-468$

Bartos A. Fialova L, Soukupova J, Kukal J, Malbohan I, Pit'ha J (2007): Elevated intrathecal antibodies against the medium neurofilament subunit in multiple sclerosis. J Neurol 254(1), 20-25

Bielschowsky M (1903): Die Silberimprägnation der Neurofibrillen. Neurol Centralbl 21, 997-1006

Bitsch A, Brück W (2002): Differentiation of multiple sclerosis subtypes: implications for treatment. CNS Drugs 16(6), 405-418 
Bitsch A, Schuchardt J, Bunkowski S, Kuhlmann T, Brück W (2000): Acute axonal injury in multiple sclerosis. Correlation with demyelination and inflammation. Brain $\underline{123}, 1174-1183$

Bjartmar C, Kidd G, Mork S, Rudick R, Trapp BD (2000): Neurological disability correlates with spinal cord axonal loss and reduced $\mathrm{N}$-acetyl aspartate in chronic multiple sclerosis patients. Ann Neurol 48(6), 893-901

Bjartmar C, Kinkel RP, Kidd G, Rudick RA, Trapp BD (2001): Axonal loss in normal-appearing white matter in a patient with acute MS. Neurology $\underline{57(7)}$, 124852

Bjartmar C, Wujek JR, Trapp BD (2003): Axonal loss in the pathology of MS: consequences for understanding the progressive phase of the disease. J Neurol Sci 206(2), 165-171

Boenisch T: Handbuch immunchemische Färbemethoden. Dako Deutschland GmbH, Hamburg 2003

Bolanos JP, Almeida A, Stewart V, Peuchen S, Land JM, Clark JB, Heales SJ (1997): Nitric oxide-mediated mitochondrial damage in the brain: mechanisms and implications for neurodegenerative diseases. J Neurochem $\underline{68(6)}$, 2227-2240

Bramlett HM, Kraydieh S, Green EJ, Dietrich WD (1997): Temporal and regional patterns of axonal damage following traumatic brain injury: a beta-amyloid precursor protein immunocytochemical study in rats. J Neuropathol Exp Neurol $\underline{56}$, 1132-1141

Breij EC, Brink BP, VeerhuisR, van den Berg C, Vloet R, Yan R, Dijkstra CD, van der V Bo L (2008): Homogeneity of active demyelinating lesions in established multiple sclerosis. Ann Neurol $\underline{63(1)}, 16-25$

Brück W (1997): The role of macrophages in Wallerian degeneration. Brain Pathol $\underline{7}, 741-52$ 
Brück W, Stadelmann C (2003): Inflammation and degeneration in multiple sclerosis. Neurol Sci 24 Suppl 5, 265-267

Brück W, Porada P, Poser S, Rieckmann P, Hanefeld F, Kretzschmar HA, Lassmann H (1995): Monocyte/macrophage differentation in early multiple sclerosis lesions. Ann Neurol $\underline{38}, 788-96$

Buddeberg BS, Kerschensteiner M, Schwab M (2003): Die Bedeutung der axonalen Schädigung bei Multipler Sklerose. Schweiz Med Forum 38, 904-908

Charcot JM (1868): Histologie de la sclérose en plaques. Gazette des Hôpitaux Paris $\underline{141}, 554-8$

Charles P, Reynolds R, Seilhean D, Rougon G, Aigrot MS, Niezgoda A, Zalc B, Lubetzki C (2002): Re-expression of PSA-NCAM by demyelinated axons: an inhibitor of remyelination in multiple sclerosis? Brain 125(Pt9), 1972-1979

Chen MS, Huber AB, van der Haar ME, Frank M, Schnell L, Spillmann AA, Christ F, Schwab ME (2000): Nogo-A is a myelin-associated neurite outgrowth inhibitor and an antigen for monoclonal antibody IN-1. Nature $\underline{403(6768)}$, 434-9

Compston A (2004): Mechanisms of axon-glial injury of the optic nerve. Eye 19(11), 1182-1187

Delank HW, Gehlen W: Neurologie. 9. Auflage; Georg Thieme Verlag, Stuttgart 2001

De Stefano N, Matthews PM, Fu L, Narayanan S, Stanley J, Francis GS, Antel JP, Arnold DL (1998): Axonal damage correlates with disability in patients with relapsing-remitting multiple sclerosis. Results of a longitudinal magnetic resonance

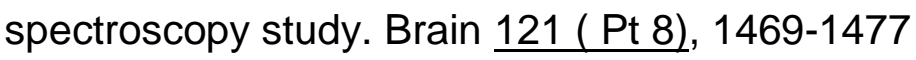


De Stefano N, Narayanan S, Francis GS, Arnaoutelis R, Tartaglia MC, Antel JP, Matthwes PM, Arnold DL (2001): Evidence of axonal damage in the early stages of multiple sclerosis and its relevance to disability. Arch Neurol $\underline{58}, 65-70$

Diemel LT, Copelman CA, Cuzner ML (1998): Macrophages in CNS remyelination: friend or foe?. Neurochem Res 23(3), 341-347

Dziedzic T, Metz I, Dallenga T, König FB, Müller S, Stadelmann C, Brück W (2010): Wallerian degeneration: a major component of early axonal pathology in multiple sclerosis. Brain Pathol 20(5), 976-85

Ferguson B, Matyszak MK, Esiri MM, Perry VH (1997): Axonal damage in acute multiple sclerosis lesions. Brain 120, 393-399

Firth D (1941): The case of Augustus d'Este` (1794-1848): the first account of disseminated sclerosis. Proc R Soc Med 34, 381-384

Fischer I: Immunhistochemische Analyse des Entzündungsinfiltrates in MultipleSklerose-Läsionen unter Berücksichtigung der immunpathogenetischen Subtypen. Med. Diss. Göttingen 2007

Ganter P, Prince C, Esiri MM (1999): Spinal cord axonal loss in multiple sclerosis: a post-mortem study. Neuropathol Appl Neurobiol 25(6), 459-467

Gay FW, Drye TJ, Dick GWA, Esiri MM (1997): The application of multifactoral cluster analysis in the staging of plaques in early multiple sclerosis. Identification and characterization of the primary demyelinating lesion. Brain $\underline{120}, 1461-1483$

Gleixner C, Müller M, Wirth S: Neurologie und Psychiatrie. Medizinische Verlags und Informationsdienste, Breisach am Rhein 2004

Hafler DA (2004): Multiple sclerosis. J Clin Invest 113(6), 788-794 
Hafler DA, Compston A, Sawcer S, Lander ES, Daly MJ, De Jager PL, de Bakker PI, Gabriel SB, Mirel DB, Ivinson AJ, Pericak-Vance MA, Gregory SG, Rioux JD McCauley JL, Haines JL, Barcellos LF, Cree B, Oksenberg JR, Hauser SL (2007): Risk alleles for multiple sclerosis identified by a genomewide study. N Engl J Med 357(9), 851-862

Halliday AM, McDonald WI, Mushin J: Visual evoked response in diagnosis of multiple sclerosis. Br Med J 1973,4(5893), 661-4

Hein T, Hopfenmüller W (2000): Projection of the number of multiple sclerosis patients in germany. Nervenarzt $\underline{71(4)}, 288-94$

Hofman FM, Hinton DR, Johnson K, Merrill JE (1989): Tumor necrosis factor identified in multiple sclerosis brain. J Exp Med 170(2), 607-612

Hsu SM, Raine L, Fanger H (1982): The use of avidin-biotin complex (ABC) in immunoperoxidase technique. J Histochem Cytochem 29, 577-580

Kapoor R, Davies M, Smith KJ (1999): Temporary axonal conduction block and axonal loss in inflammatory neurological disease. A potential role for nitric oxide? Ann N Y Acad Sci 893, 304-308

Keegan M, König F, McClelland R, Brück W, Morales $Y$, Bitsch A, Panitch $H$, Lassmann H, Weinshenker B, Rodriguez M, Parisi J, Lucchinetti CF (2005) Relation between humoral pathological changes in multiple sclerosis and response to therapeutic plasma exchange. Lancet $\underline{366,579-582}$

König FB, Wildemann B, Nessler S, Zhou D, Hemmer B, Metz I, Hartung HP, Kieseier BC, Brück W (2008): Persistence of immunopathological and radiological traits in multiple sclerosis. Arch Neurol 65(11), 1527-1532 
Kornek B, Storch MK, Weissert R, Wallstroem E, Stefferl A, Olsson T, Linington C, Schmidbauer M, Lassmann H (2000): Multiple sclerosis and chronic autoimmune encephalomyelitis. A comparative quantitative study of axonal injury in active, inactive, and remyelinated lesions. Am J Pathol 157, 267-276

Kuhlmann T, Lingfeld G, Bitsch A, Schuchardt J, Brück W (2002): Acute axonal damage in multiple sclerosis is most extensive in early disease stages and decreases over time. Brain 125, 2202-2212

Kurtzke JF, Hyllested K, Heltberg A, Olsen A (1993): Multiple sclerosis in the Faroe Islands. 5. The occurrence of the fourth epidemic as validation of transmission. Acta Neurol Scand $\underline{88(3)}, 161-173$

Kutzelnigg A, Lucchinetti CF, Stadelmann C, Brück W, Rauschka H, Bergmann M, Schmidbauer M, Parisi JE, Lassmann H (2005): Cortical demyelination and diffuse white matter injury in multiple sclerosis. Brain $\underline{128}, 2705-2712$

Landtblom A, Fazio P, Fredrikson S, Granieri E (2010): The first case history of multiple sclerosis: Augustus d'Este' (1794-1848). Neurol Sci 31, 29-33

Lassmann H (2003a): Hypoxia-like tissue injury as a component of multiple sclerosis lesions. J Neurol Sci $\underline{206}$, 187-191

Lassmann H (2003b): Axonal injury in multiple sclerosis. J Neurol Neurosurg Psychiatry 74(6), 695-697

Lassmann H, Brück W, Lucchinetti CF (2001): Heterogeneity of multiple sclerosis pathogenesis: implications for diagnosis and therapy. Trends Mol Med $\underline{7(3)}$, 115121

Li GL, Farooque M, Holtz A, Olsson Y (1995): Changes of beta amyloid precursor protein after compression trauma to the spinal cord: an experimental study in the rat using immunohistochemistry. J Neurotrauma 12, 269-277 
Lim ET, Sellebjerg F, Jensen CV, Altmann DR, Grant D, KeirG, Thompson EJ, Giovannoni G (2005): Acute axonal damage predicts clinical outcome in patients with multiple sclerosis. Mult Scler 11(5), 532-536

Lopachin RM, Lehning EJ (1997): Mechanism of calcium entry during axon injury and degeneration. Toxicol Appl Pharmacol 143(2), 233-244

Losseff NA, Webb SL, O'Riordan Jl, Page R, Wang L, Barker GJ, Tofts PS, McDonald WI, Miller DH, Thompson AJ (1996): Spinal cord atrophy and disability in multiple sclerosis. A new reproducible and sensitive MRI method with potential to monitor disease progression. Brain 119 (Pt 3), 701-708

Lovas G, Szilagyi N, Majtenyi K, Palkovits M, Komoly S (2000): Axonal changes in chronic demyelinated cervical spinal cord plaques. Brain 123 (Pt 2), 308-317

Lucchinetti CF, Brück W, Rodriguez M, Lassmann H (1996): Distinct patterns of multiple sclerosis indicates heterogeneity on pathogenesis. Brain Pathol $\underline{6(3)}, 259-$ 274

Lucchinetti CF, Brück W, Parisi J, Scheithauer B, Rodriguez M, Lassmann H (2000): Heterogeneity of multiple sclerosis lesions: implications for the pathogenesis of demyelination. Ann Neurol $\underline{47}, 707-717$

Lundmark F, Duvelfelt K, Lacobaeus E, Kockum I, Wallstrom E, Khademi M, Oturai A, Ryder LP, Saarela J, Harbo HF, Celius EG, Salter H, Olsson T, Hillert J (2007): Variation in interleukin 7 receptor alpha chain (IL7R) influences risk of multiple sclerosis. Nat Genet $\underline{39}, 1108-1113$

Mahad DJ, Ziabreva I, Campbell G, Lax N, White K, Hanson PS, Lassmann H, Turnbull DM (2009): Mitochondrial changes within axons in multiple sclerosis. Brain $\underline{132 \text { Pt } 5}, 1161-1174$

Marburg O (1906): Die sogenannte akute multiple Sklerose. Jahrb Psychiatr Neurol 27, 213-312 
Martyn CN, Gale CR (1997): The epidemiology of multiple sclerosis. Acta Neurol Scand $\underline{169}, 3-7$

Mathey EK, Derfuss T, Storch MK, Williams KR, Hales K, Woolley DR, Al Hayani A, Davies SN, Rasband MN, Olsson T, Moldenhauer A, Velhin S, Hohlfeld R, Meinl E, Linington C (2007): Neurofascin as a novel target for autoantibodymediated axonal injury. J Exp Med 204(10),_2363-2372

Mattson MP, Cheng B, Culwell AR, Esch FS, Lieberburg I, Rydel RE (1993): Evidence for excitoprotective ans intraneuronal calcium-regulating roles for secret forms of the beta-amyloid precorsuor protein. Neuron 10(2), 243-254

McDonald WI, Compston A, Edan G, Goodkin D, Hartung HP, Lublin FD, McFarland HF, Paty DW, Polman CH, Reingold SC et al. (2001): Recommended diagnostic criteria for multiple sclerosis: Guidelines from the international panel on the diagnosis of multiple sclerosis. Ann Neurol $\underline{50}, 121-127$

McKerracher L, David S, Jackson DL, Kottis V, Dunn RJ, Braun PE (1994): Identification of myelin-associated glycoprotein as a major myelin-derived inhibitor of neurite growth. Neuron $\underline{13(4)}$, 805-11

Medana IM, Martinic MA, Wekerle H, Neumann H (2001): Transection of major histocompatibility complex class I-induced neurites by cytotoxic T lymphocytes. Am J Pathol 159(3), 809-815

Mews I, Bergmann M, Bunkowski S, Gulotta F, Brück W (1998): Oligodendrocyte and axon pathology in clinically silent multiple sclerosis lesions. Mult Scler $\underline{4(2)}$, $55-62$

Mukhopadhyay G, Doherty P, Walsh FS, Crocker PR, Filbin MT (1994): A novel role for myelin-associated glycoprotein as an inhibitor of axonal regeneration. Neuron 13(3), 757-67 
Neumann H, Medana IM, Bauer J, Lassmann H (2002): Cytotoxic T lymphocytes in autoimmune and degenerative CNS diseases. Trends Neurosci 25(6), 313-319

Pesini P, Kopp J, Wong H, Walsh JH, Grant G, Hökfelt T (1999): An immunohistochemical marker for Wallerian degeneration of fibers in the central and peripheral nervous system. Brain Res $\underline{828}$, 41-59

Peterson JW, Bo L, Mork S, Chang A, Trapp BD (2001): Transected neurites, apoptotic neurons, and reduced inflammation in cortical multiple sclerosis. Ann Neurol $\underline{50(3)}, 389-400$

Poser CM (1995): Viking voyages: the origin of multiple sclerosis? An essay in medical history. Acta Neurol Scand Suppl 161, 11-22

Poser CM, Brinar VV (2001): Diagnostic criteria for multiple sclerosis. Clin Neurol Neurosurg $\underline{103}, 1-11$

Poser S, Stickel B, Krtsch U, Burckhardt D, Nordman B (1989): Increasing incidence of multiple sclerosis in South Lower Saxony, Germany. Neuroepidemiology $\underline{8}, 207-13$

Prineas JW, Barnard RO, Revesz T, Kwon EE, Sharer L, Cho ES (1993): Multiple sclerosis. Pathology of the recurrent lesion. Brain 116(3), 681-93

Redford EJ, Kapoor R, Smith KJ (1997): Nitric oxide donors reversibly block axonal conduction: demyelinated axons are especially susceptible. Brain $\underline{120(\mathrm{Pt}}$ 12), 2149-2157

Schmidt RM: Geschichte der Medizin; in: Multiple Sklerose; hrsg. von Schmidt RM, Hoffmann FA, 4 Auflage; Elsevier Urban \& Fischer Verlag, München Jena S 2006 3-10

Selmaj K, Raine CS, Cannella B, Brosnan CF (1991): Identification of lymphotoxin and tumor necrosis factor in multiple sclerosis lesions. J Clin Invest 87(3), 949-954 
Serafini B, Rosicarelli B, Franciotta D, Magliozzi R, Reynolds R, Cinque P, Andreoni L, Trivedi P, Salvetti M, Faggioni A, Aloisi F (2007): Dysregulated Epstein-Barr virus infection in the multiple sclerosis brain. J Exp Med 204(12), 2899-2912

Skundric DS, Cai J, Cruikshank WW, Gveric D (2006): Production of IL-16 correlates with CD4+ Th1 inflammation and phosphorylation of axonal cytoskeleton in multiple sclerosis lesions. J Neuroinflamm $\underline{3}, 13$

Smith KJ, Lassmann H (2002): The role of nitric oxide in multiple sclerosis. Lancet Neurol 1(4), 232-41

Sonobe Y, Jin S, Wang J, Kawanokuchi J, Takeuchi H, Mizuno T, Suzumura A (2007): Chronological changes of CD4(+) and CD8(+) T cell subsets in the experimental autoimmune encephalomyelitis, a mouse model of multiple sclerosis. Tohoku J Exp Med 213(4), 329-339

Storch MK, Piddlesden S, Haltia M, livanainen M, Morgan P, Lassmann H (1998): Multiple sclerosis: in situ evidence for antibody- and complement-mediated demyelination. Ann Neurol 43(4), 465-471

Trapp BD, Peterson J, Ransohoff RM, Rudick R, Mörk S, Bö L (1998): Axonal transection in the lesions of multiple sclerosis. N Engl J Med $\underline{338}, 278-85$

Vargas ME, Barres BA (2007): Why is Wallerian degeneration in the CNS so slow? Annu Rev Neurosci $\underline{30}$, 153-79

Vogt M, Teunissen CE, lacobaeus E, Heijnen P, Breij E, Olsson T, Brundin L, Killestein J, Dijkstra CD (2008): CSF anti-myelin antibodies are related to MR measures of disease activity in multiple sclerosis. J Neurol Neurosurg Psychiatry 80(10), 1110-5 
Vrenken H, Geurts JJ, Knol DL, Polman CH, Castelijns JA, Pouwels PJ, Barkhof $F$ (2006): Normal-appearing white matter changes vary with distance to lesions in multiple sclerosis. AJNR Am J Neuroradiol 29(9), 2005-2011

Yam PS, Takasago T, Dewar D, Graham DI, McCulloch J (1997): Amyloid precursor protein accumulates in white matter at the margin of a focal ischaemic lesion. Brain Res $\underline{760}, 150-157$

Young IR, Hall AS, Pallis CA, Legg NJ, Bydder GM, Steiner RE (1981): Nuclear magnetic resonance imaging of the brain in multiple sclerosis. Lancet 1981, II, 1063-6

Zamvil SS, Steinman L (1990): The T lymphocyte in experimental allergic encephalomyelitis. Annu Rev Immunol $\underline{8}, 579-621$

Zamvil SS, Steinman L (2003): Diverse targets for intervention during inflammatory and neurodegenerative phases of multiple sclerosis. Neuron $\underline{38(5)}, 685-688$

Zeis T, Graumann U, Reynolds R, Schaeren-Wiemers N (2008): Normalappearing white matter in multiple sclerosis is in a subtle balance between inflammation and neuroprotection. Brain $131 \mathrm{Pt1}, 288-303$

Zhou D, Srivastava R, Nessler S, Grummel V, Sommer N, Brück W, Hartung HP, Stadelmann C, Hemmer B (2006): Identification of a pathogenic antibody response to native myelin oligodendrocyte glycoprotein in multiple sclerosis. Proc Natl Acad Sci U S A 103(50), 19057-19062 
Danksagung

Zunächst bedanke ich mich bei Herrn Prof. Dr. W. Brück für die Überlassung des Themas, die sehr gute Zusammenarbeit und die stets hervorragende Betreuung.

Für die Bereitstellung von Biopsie-Material und für die gute Kooperation, bedanke ich mich bei Frau Prof. Dr. C. F. Lucchinetti (Mayo Clinic Rochester, Minnesota, USA). Allen technischen Mitarbeiterinnen des Labors der Abteilung Neuropathologie sowie Frau Dr. Fatima König danke ich ebenfalls herzlich für ihre Unterstützung.

Diese Arbeit wäre nie zu Ende geführt worden ohne die beharrlichen Ermutigungen und die konstruktive Kritik meiner Betreuerin Dr. Imke Metz, der ich dafür von Herzen danke. 